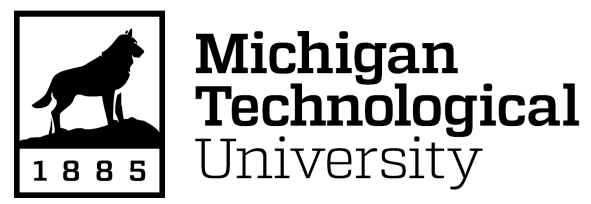

Michigan Technological University Digital Commons @ Michigan Tech

\title{
LENSES OF INDUSTRY: THE RISE OF INDUSTRIAL PHOTOGRAPHY IN THE UNITED STATES AND THE LAKE SUPERIOR MINING DISTRICT, 1880-1933
}

Robert Anthony

Michigan Technological University, rdanthon@mtu.edu

Copyright 2015 Robert Anthony

Recommended Citation

Anthony, Robert, "LENSES OF INDUSTRY: THE RISE OF INDUSTRIAL PHOTOGRAPHY IN THE UNITED STATES AND THE LAKE SUPERIOR MINING DISTRICT, 1880-1933", Open Access Master's Thesis, Michigan Technological University, 2015.

https://doi.org/10.37099/mtu.dc.etdr/4

Follow this and additional works at: https://digitalcommons.mtu.edu/etdr

Part of the Archaeological Anthropology Commons, Cultural History Commons, History of Science, Technology, and Medicine Commons, Other History Commons, Photography Commons, and the United States History $\underline{\text { Commons }}$ 


\title{
LENSES OF INDUSTRY:
}

THE RISE OF INDUSTRIAL PHOTOGRAPHY IN THE UNITED STATES AND THE LAKE SUPERIOR MINING DISTRICT, 1880-1933

\author{
By \\ Robert D. Anthony
}

\begin{abstract}
A THESIS
Submitted in partial fulfillment of the requirements for the degree of MASTER OF SCIENCE

In Industrial Archaeology
\end{abstract}

MICHIGAN TECHNOLOGICAL UNIVERSITY

2015

(C) 2015 Robert D. Anthony 

This thesis has been approved in partial fulfillment of the requirements for the Degree of MASTER OF SCIENCE in Industrial Archaeology.

Department of Social Sciences

\author{
Thesis Advisor: $\quad$ Steven A. Walton \\ Committee Member: Sarah F. Scarlett \\ Committee Member: Beth A. Zinsli \\ Department Chair: Hugh S. Gorman
}





\section{Contents}

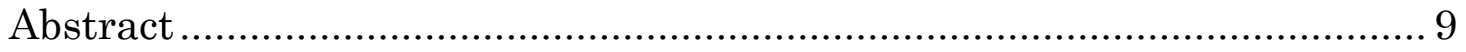

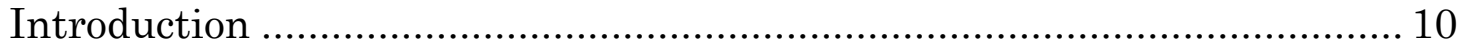

Chapter One: The Professional Man's Mute but Valuable Assistants:

Industrial Workers and Avocational Photography, 1880-1930

Chapter Two: Focusing on Detail: Instruction for Industrial

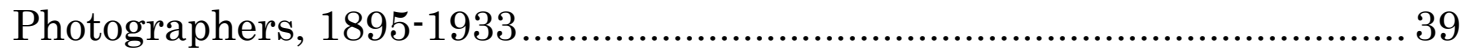

Chapter Three: Changing Views: Halftone Photographs in Engineering and Mining Journal, 1886-1930 ................................................ 73

Chapter Four: Industrial Photography and the Lake Superior Mining

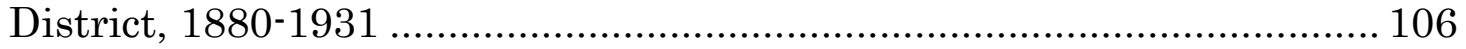

Chapter Five: Conclusion ........................................................ 141

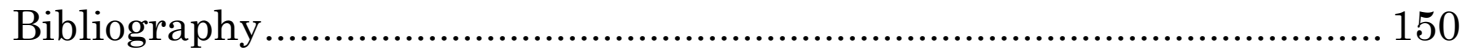

Appendix of Permissions ........................................................ 153 
List of Figures and Tables

Figure 1.1: Advertisement for E. \& H. T. Anthony \& Company photographic instruments. Engineering and Mining Journal 47 (March 16, 1889): xix. 36

Figure 1.2: Advertisement for The Scovill \& Adams Company showing a lady photographer with camera and dry plates. Engineering and Mining Journal 47 (April 20, 1889): xi.

Figure 1.3: The professional man's mute but valuable assistants. Engineering and Mining Journal 52 (August 8, 1891): ii. 38

Figure 2.1: "New Open-Hearth Steel Plant of the Youngstown Sheet \& Tube Company." "The Use of the Camera in Industrial Plants," Iron Age 90, no. 8 (1912): 393.

Figure 2.2: A View Camera and tilted plate holder for correcting perspective, as described by Hand. S. Ashton Hand, "Industrial Photography," The Iron Trade Review 44 (1909): 198. 68

Figure 2.3: Building exterior photographed with the camera tilted upward (top). Perspective corrected view (bottom). S. Ashton Hand, "Industrial Photography," The Iron Trade Review 44 (1909): 198.

Figure 2.4: Shop Interior. S. Ashton Hand, "Industrial Photography," The Iron Trade Review 44 (1909): 199......................................................... 70

Figure 2.5: "Details brought out and shadows avoided by preparation of machine parts before photographing. S. Ashton Hand, "Industrial Photography," The Iron Trade Review (1909): 199. 71

Figure 2.6: Advertisement for the Photostat. Engineering News 69, no. 25 (June 19, 1913): 6. 72

Figure 3.1: Close up illustrating how halftone dots of varying size represent continuous tones of photographs. By R.D. Anthony. 99

Figure 3.2: Line Engravings versus Halftones in Frank Leslie's Illustrated Newspaper, March 1880 through March 1900. 99

Figure 3.3: Line Engravings versus Halftones in Harper's Monthly Magazine, March 1895 and March 1900. 100

Figure 3.4: Line Engravings versus Halftones in Engineering and Mining Journal, 1867-1930. 100

Figure 3.5: Comparison of old and new furnaces at South Chicago Iron works. Engineering and Mining Journal 44 (1887): 41. 101 Figure 3.6: Advertisement for Gates Rock and Ore Breaker. Engineering and Mining Journal 48 (August 10, 1889): xx. 101 
Figure 3.7: General exterior view of excavation for Croton Aqueduct in New York State (top). Halftone of Rand mining drills from retouched print (bottom). Engineering and Mining Journal 41 (1886): 319. 102

Figure 3.9: Line engraving of Osgood boom dredge. Engineering and Mining Journal 48 (1889): vii. 103

Figure 3.8: Poor quality halftone of Osgood boom dredge. Engineering and Mining Journal 47 (1889): 411. 103

Figure 3.10: General Exterior View of South Chicago Irons Works Rolling Mill. Engineering and Mining Journal 44 (1887): 43. 104

Figure 3.11: Roman mining tools. Engineering and Mining Journal 45 (1888): 125. 104

Figure 3.12: Transverse Section of Steel Ingot. One of the first photomicrographs printed in E\&MJ. Engineering and Mining Journal 46 (1888): 375 .

Figure 4.1: General exterior view of the Quincy Mine looking southeast, 1875. MS015-MI-2-8, Quincy Mining Company Survey, Michigan Technological University Archives Copper Country Historical Collections.

Figure 4.3: Exterior view of the Calumet \& Hecla library looking northwest. MS003-009-010-04, Calumet \& Hecla Photograph Collection, Michigan Technological University Archives and Copper Country Historical Collections. 132

Figure 4.2: General exterior view of the Calumet \& Hecla Mine showing line of shaft houses on the company's large land holdings. Acc-03-095D001-010, Quincy and Huron Photographic Collection, Michigan Technological University Archives and Copper Country Historical Collections.

Figure 4.5: Interior of Calumet \& Hecla hoist house with Nordberg hoist that was connected to the rock skips and man cars in a neighboring building via the cable on the drum. MS003-25A-40, Calumet \& Hecla Photograph Collection, Michigan Technological University Archives and Copper Country Historical Collections.

Figure 4.4: Calumet \& Hecla Bath House. MS003-012-GN132.4, Calumet \& Hecla Photograph Collection, Michigan Technological University Archives and Copper Country Historical Collections. 133

Figure 4.7: Interior View of the Quincy machine shop. Acc-03-095D-001023, Quincy and Huron Photographic Collection, Michigan Technological University Archives and Copper Country Historical Collections. 
Figure 4.6: Dumping a car into a skip at the 70th level in the Calumet \& Hecla Mine, 1915-1916. MS003-25A-002, Calumet \& Hecla Photograph Collection, Michigan Technological University Archives and Copper Country Historical Collections. 134

Figure 4.8: Steam stamp in a Quincy Mill. Acc-03-095D-001-013, Quincy and Huron Photographic Collection Michigan Technological University Archives and Copper Country Historical Collections.

Figure 4.9: Advertisement from the Keweenaw Miner, featuring a Nordberg hoist owned by Calumet \& Hecla, 1916. From: The Keweenaw Miner: Calumet \& Hecla Mining Company Semi-Centennial, 1866-1916 (Calumet, Michigan: Keweenaw Printing Company, 1916): 52.

Figure 4.11: Calumet \& Hecla library reading room. MS003-014-GN-154-3, Calumet \& Hecla Photograph Collection, Michigan Technological University Archives and Copper Country Historical Collections.

Figure 4.10: Statue of Alexander Agassiz in Agassiz Park, Calumet, Michigan, 1923. MS003-007-004-01, Calumet and Hecla Photograph Collection, Michigan Technological University Archives and Copper Country Historical Collections.

Figure 4.12: Quincy number 2 shaft-rockhouse during construction. Acc541-01-01-1991-001-001, Quincy Mining Company Glass Plate Negative Collection, Acc. \#54, Michigan Technological University Archives and Copper Country Historical Collections.

Figure 4.13: Man Engine inside the Quincy Mine, by Frederick Fraley Sharpless. ACC 239-5-6-1985-02-90, Frederick Fraley Sharpless

Photograph Collection, Michigan Technological University Archives and Copper Country Historical Collections.

Figure 4.15: Soldiers protecting Quincy Mine property during the Great Strike of 1913-14. Acc-400-12-13-1988-01-08-34, Quincy Mining Company, Michigan Technological University Archives and Copper Country Historical Collections,.

Figure 4.14: Photograph of blind miners working at the C\&H broom factory. MS003-004-017-01, Calumet and Hecla Photograph Collection, Michigan Technological University Archives and Copper Country Historical Collections.

Figure 4.16: A large Prescott water pump in the 1060' level of CCI's Franklin Mine, 1918. MS86-100, Plate no. 167: Courtesy of the Central Upper Peninsula and Northern Michigan University Archives. 
Abstract

This thesis, Lenses of Industry, examines how industrial companies and engineers adapted photography to their needs in the late nineteenth and early twentieth centuries. Innovations in camera and plate technologies marketed to a broad range of people contributed to a steep rise in the number of photographers in the United States. Recognizing the potential that photography held for industrial companies and engineers, a handful of experts advocated the idea that photography had the potential to make many aspects of business faster, and easier, as well as to make visual records more truthful and accurate. Likewise, innovations in halftone printing technology allowed trade journals like Engineering and Mining Journal to print photographic illustrations, which engineers perceived as being more objective representations of machines and heavy equipment than handmade engravings. The photo collections of three Lake Superior mining companies show that approaches to industrial photography varied according to company and industry. Lake Superior mines did not use photography as regularly or as systematically as large national corporations because mines did not have large public interfaces that sold consumer goods to the public. 
Introduction

This thesis examines the ways industrial companies and engineers, specifically the mining industry, adapted photography to corporate and technical uses during the late nineteenth and early twentieth centuries. Covering the period from 1880 to 1933 , it takes into account innovations in photographic technology that opened the doors for the medium to be applied to a host of new applications from publicity to research. Moreover, it analyzes the ideological changes that led to the development of the concept of industrial photography, or photographs taken by company photographers and engineers in accordance with their professional needs.

Drawing from articles that were published in several prominent trade journals, it tracks the evolution of the concept of industrial photography as articulated by leaders in the field, including S. Ashton Hand and John Graff. Industrial photography was in its infancy in the $1890 \mathrm{~s}$, but by the time of the Great Depression, most companies used photography for advertising and publicity. Similarly, various forms of technical photography used by engineers, from photo-surveying to photo-microscopy, had attained a high level of sophistication and importance for industrial applications. It also explores the use of photography within the mining industry through a chronological study of photographs published in the Engineering \& Mining Journal, as well as through the photo collections of three producers of copper 
and iron, the Calumet \& Hecla Mining Company, the Quincy Mining Company, and the Cleveland-Cliffs Iron Company.

In Image Worlds: Corporate Identities at General Electric, 1890-1930, David Nye argues that industrial photography arrived at the close of the nineteenth century and matured rapidly during the early decades of the twentieth. Prior to the 1890 s, there was little in the way of commercial photography as most photographers operated independent of corporate structures. However, this changed rapidly during the next forty years. As new companies like General Electric and Westinghouse grew larger, they needed an increasingly large assortment of human and material resources as they vied for monopolistic control over entire markets. Thus, they developed complex communication networks to influence the way they were seen by investors, management, engineers, employees, and consumers. ${ }^{1}$

Photographs were an important aspect of this communication network as they were used in conjunction with text to show technologies, products, and people in a way that augmented descriptions and reinforced what the companies wanted people to think, in a transparent way. Therefore, Nye argues industrial photography was born as companies created photographic departments charged with producing pictures that catered to specific audiences. Consequently, they developed a form of photography that differed

1 David E. Nye, Image Worlds, Corporate Identities at General Electric, 1890-1930 (Cambridge, Massachusetts: MIT Press, 1985), 1-31, 148-160. 
from that of independent commercial photographers in that it pertained to industrial subjects, particularly machinery, and was dictated by corporate ideology. ${ }^{2}$

Nye argues that there was no articulated theory of industrial photography at the time. However, this thesis differs from Image Worlds by using period articles to demonstrate that concepts which differentiated industrial from other forms photography were consciously recognized in the early twentieth century. This thesis also focuses on mining companies and how their photographs catered to engineers. Mining photographs showed heavy machinery, industrial plants, and underground operations. All of these would have been of no use in advertising to the general public, which is the primary concentration of Nye's work.

Rather than publishing photos in popular magazines, mining companies published in trade journals intended for engineers. Nye's book succinctly addresses photos in GE's trade journal as a way of influencing engineers, but his argument does not include analysis of the transition from line engraved illustrations to halftone photographs in periodicals that began in the 1880s. This thesis tracks the numbers and subject categories of halftone photographs in Engineering \& Mining Journal from the first 3 printed in 1886, until they began appearing on almost every page of the journal in the early 1930s. Thus, Lenses of Industry supplies historians of

\footnotetext{
2 Ibid., 31-58.
} 
photography and historians of industry with a detailed look at the emergence of the concept of industrial photography, as well as how it was utilized by the mining industry.

Throughout much of the industrial revolution, artists commonly produced drawings and paintings of the landscape that showed railroads, bridges, steamships and factories in a way that painted industry in a positive light. ${ }^{3}$ Many were the work of independent artists who were not controlled or directly influenced by industrial corporations, and thus do not reflect how companies wanted to portray themselves. Though stereographic photo cards of industrial subjects became popular during the second half of the nineteenth century, most cannot be defined as industrial photographs because they were made and sold by photographic enterprises rather than being used for the business-related communications of industrial companies and engineers. Even images of independent photographers that were commissioned by industrial companies are not industrial photographs in the strictest sense because the photographers were not engineers or members of corporate structures.

Despite the differences between commercial and industrial photography, industrial photographers often adapted the conventions of

\footnotetext{
${ }^{3}$ Helena E Wright, "The Image Makers: The Role of the Graphic Arts in Industrialization," IA: The Journal of the Society for Industrial Archeology 12 , no. 2 (1986): 5-18.
} 
traditional forms of art to their needs, which varied according to the audience they were producing for. For example, when shooting portraits,

managers and engineers were taken at an intimate distance against a neutral background, in imitation of practices first developed in painting. In contrast, inventors appeared in a recognizable context, at work, usually holding a new apparatus. ${ }^{4}$

Using established practices industrial photographers were able to produce pictures that fulfilled the needs of the company while also allowing them to work faster because they did not have to develop a new technique for every photo. Both approaches were common for mass marketing things like light bulbs. However, the needs of the mining industry differed from some of the largest corporations like General Electric and Westinghouse because mining companies did not have large publicity departments that marketed domestic appliances to the general public.

Rather than appealing to the domestic market on a human basis, mines relied on selling to other companies, which resulted in a much different approach to photography. Their primary audiences were readers of industrial trade journals, not popular magazines. Therefore, the pictures taken by their photographers usually showed heavy machinery, large construction projects, mining operations, and other things pertaining to a technically oriented audience. Unlike advertisements for household goods intended for the public, heavy machines were shown in isolation and, except for biographical entries

\footnotetext{
${ }^{4}$ Nye, Image Worlds, 151.
} 
about prominent engineers and innovators, people were absent in pictures because trade journals were geared specifically toward engineers, whose jobs dealt with technology, not labor or public relations. Because of its focus on the mining industry, Lenses of Industry primarily examines photography of heavy equipment and machinery that epitomized images in mining journals and the company collections of C\&H, Quincy, and CCI.

Chapter one sets the stage using histories written between the 1880s and the 2010s, ${ }^{5}$ as well as historic journals like Anthony's Photographic Bulletin and The Photographic Times. It explains technologies like commercial dry plates that made taking pictures faster and easier, as well as marketing of photographic equipment to engineers through advertisements in the engineering press. Manufacture and sale of an assortment of new photographic technologies allowed more people, including engineers and other professionals, to take up photography. This gave them the opportunity to apply it to their own professional pursuits. The study begins with technological changes, but technology is only one half of the story as ideas

5 John Alvord, "Photography for Engineers," Annual Report of the Illinois Society of Engineers and Surveyors 10 (1895): 115-119; S. Ashton Hand, "Industrial Photography," The Iron trade Review 44 (1909): 195-200; "The Use of the Camera in Industrial Plants," The Iron Age 90, no. 8 (1912): 393-397; John H. Graff, "Technical Photography and it use in Industrial and Commercial Organizations." The Journal of Industrial and Engineering Chemistry 9, no. 11 (1917): 1052-1054; "Value of Photography to Engineering," Engineering Journal 16, no. 11 (1933): 474-480. Despite defining industrial photography as being distinct from artistic photography, Hand and Graff both refer to advertising photographs as a form of art that contributed to the aesthetic appeal of popular periodicals. 
about photography's role within industry and engineering changed significantly between 1890 and $1930 .^{6}$

Published on a weekly or monthly basis, the engineering press was a vital form of communication as it allowed professionals to keep up to date on myriad technological developments, progress on major construction projects, stock quotations, current prices of materials and products, as well as the production levels of major companies. It also acted as a medium for professional networking as biographies of prominent capitalists and engineers, as well as obituaries for the same were printed regularly. Because illustrations were a major component of such journals they offer insight into the roles that visual materials, including line engravings and photographs, played in industrial communication.

The potential that photography held as a business tool for companies was not expressly recognized until the last decade of the nineteenth century. The usefulness of technical applications, like photo-microscopy and photosurveying were documented relatively early as books on these subjects were published during the 1880s. However, trade journal articles about technical

\footnotetext{
${ }^{6}$ In The Social Construction of Technological Systems: New Directions in the Sociology and History of Technology (Cambridge, Massachusetts: M.I.T. Press, 1987) historians Wiebe E. Bijker, Thomas P. Hughes, and Trevor Pinch argued that human decision-making determines the course of technological development. They also argued that technology cannot be fully understood without analyzing the social conditions under which it was developed. Social construction of technology (SCOT) refutes technological determinism, the idea that technology steers the course of human history.
} 
photography and company photography did not appear in the engineering press until the 1890s. Chapter two explains the evolution of the concept of industrial photography from its appearance in the late nineteenth century to its full arrival in the 1930s.

Published intermittently throughout the period, the arguments of industrial photography articles differ considerably. The earliest, published in 1895 , is an announcement of the fact that the camera had been proven as a useful engineering tool, and that learning to use a camera and process pictures was within the reach of any engineer or surveyor who possessed patience and determination. It was largely an encouragement for engineers who were new to photography. Articles published between 1906 and 1917 served as instruction for industrial photographers and managers who organized company photographic departments. In contrast, that engineers could and should be photographers was a given by 1933, when the final article listed many recent innovations in technical photography, but offered no instruction or encouragement for beginners. It simply acknowledged how thoroughly photography had been integrated into advertising, record keeping, surveying, metallurgy and electrical engineering. The time frame covered by Lenses of Industry thus concludes with the 1933 article, which marked the end of industrial photography's developmental phase.

Chapter three then looks at halftone printing methods that allowed photographs to become a regular feature in trade journals, and it examines 
how and why photographs came to dominate the pages of the engineering press. Using a similar format as chapter two, it begins by explaining the technology that made printing photographs feasible. It then follows up with a statistical analysis that compares the number and content of line engravings and photographs printed in one of the nation's leading industrial publications, Engineering and Mining Journal.

Halftone photographs appeared in $E \& M J$ in 1886 , shortly after the first commercially viable halftone equipment was patented. At that time, hand engraved plates were the standard method of printing illustrations. However, over the course of the next four decades, halftone photographs in the journal steadily increased in number until 1930 when they had all but replaced line engravings. Though the subjects shown in most of the photos, machinery, industrial structures, and prominent individuals were similar to those in line engravings, the subject matter did broaden out as photomicrographs, $\mathrm{x}^{-r a y s}$, underground shots, and human interest pictures began to appear.

The change in numbers is partly due to the fact that halftone plates were much faster to make than hand engraved plates. Also, being produced by the action of light upon chemicals, halftones were often accepted as being more accurate representations of the original image, a trait that was favorable to engineers. This was in spite of the fact that halftones were subject to decisions on part of the technicians that made them, as were 
regular photos. Much like the way dry plates and hand cameras allowed many professionals and engineers to take up photography, halftoning allowed photographs to be printed in large number. However, in both cases the users of the technology were the drivers of change as they recognized technologies' potential to increase the scale on which visual materials were employed in a host of applications.

Chapter two argues that the concept of industrial photography emerged during the final decade of the nineteenth century, and by the time of the Great Depression had become commonplace. Chapter three tracks this process in the mining industry by analyzing the number of halftone photographs printed in $E \& M J$, and it shows that photography became an essential part of professional communication for mining engineers. Chapter four tests these conclusions using case studies of the three largest companies that operated in the Lake Superior mining district. Examining the photos in the collections of C\&H, Quincy, and CCI according to their content, the chapter shows that the concepts of industrial photography, as laid down in Image Worlds and trade journal articles, were examples of highly successful photographic departments at some the largest, best organized, and wealthiest companies like General Electric and Westinghouse. The mining company collections have few photographs that would have been used for marketing to the general public. This indicates that large systematic photo departments, 
like those described by John H. Graff and discussed in chapter two, were not necessary for mining companies.

$\mathrm{C} \& \mathrm{H}$ and Quincy began taking photographs shortly after they opened in the 1860s, and over time their use of photography increased. Both of their collections have hundreds of photographs of machinery, equipment, and underground operations, some of which were published in the Keweenaw Miner and the Mining Congress Journal. However, neither company ran a photo department that documented operations as thoroughly or as methodically as the examples presented by Graff. In most cases the companies' photos do not have information that identifies the photographer, the date, or for what purpose the company intended them, leaving one to determine these things through analysis of the images' content. In contrast, CCI's collection has very few photos predating 1910, meaning the company didn't use photography as extensively as C\&H and Quincy, but all of their photos were used to illustrate annual reports, which allows the pictures to be accurately dated and offers direct insight into why they were taken.

Thus, chapter four shows that different companies had different approaches to photography. These approaches were based on the companies' own needs, rather than what leaders in their fields recommended. The needs of the mining industry differed from those of other industries as mining companies required less public promotion than manufacturers of consumer goods. There is no single corporate ideology of industrial photography, but 
rather an assortment of ideas and practices that varied depending on what the company needed to do.

Lenses of Industry examines industrial photography through four lenses. It surveys technological innovations that made industrial photography possible, and the ideas of photographers who formally introduced the concept of applying new photographic technology toward industrial functions. It also focuses on the mining industry by analyzing the numbers and types photographs published in Engineering and Mining Journal throughout the formative years of industrial photography. Lastly, it compares and contrasts three mining companies' approaches to photography with ideas put forth in articles that articulated the concept of industrial photography. 
Chapter One:

The Professional Man's Mute but Valuable Assistants: Industrial Workers and Avocational Photography, 1880-1930

The rise of American industrial photography during the late nineteenth century paralleled the developments of a contemporaneous explosion of popular photography. New products produced by an array of manufacturers and marketed to a wide range of people across social and economic strata opened the door for photography to become commonplace. In the 1870s and '80s taking a picture transitioned from a science reliant upon an individual's skill in manipulating touchy chemicals and equipment, to one that was encouraged by a growing market of ready-to-use plates, chemicals, and apparatus. Despite wide discrepancies in skill levels and motivations for taking pictures, by 1900 photographers were found in just about every demographic of American society. According to the United States Census, in 1880 there were approximately 9,990 people in the U.S. who made their livings as photographers, by 1900 there were more than $27,000{ }^{1}$

Photography was a well-established technology by 1850, but taking photographs was an arduous task. Mixing noxious, unstable chemicals and manipulating complicated equipment required time and patience. Most photographers utilized wet processes in which the plate was sensitized

${ }^{1}$ David E. Nye, Image Worlds, Corporate Identities at General Electric, 1890-1930 (Cambridge, Massachusetts: MIT Press, 1985), 33. 
immediately before exposure and developed directly afterward. Allowing the chemicals on the plate to dry before the negative was finalized meant that the image would be ruined or its quality greatly diminished. Though a handful of photographers created dry processes in which the plates could be stored for a short time before and after exposure, they did not gain wide popularity because the images were not as sharp as those of wet plates and because the exposure times were often unworkably long. Thus, the camera was wedded to a travelling darkroom that usually consisted of a lightproof wagon or tent accompanied by dozens of pounds of equipment, water, and chemicals. Transporting such a load restricted where a photographer could go to take a picture, and the slow speed of photo plates meant long exposures were usually necessary. In short, the limitations imposed by photographic chemistry presented challenges to even the most adept photographers. ${ }^{2}$

Of all the innovations in cameras, lenses and chemical technologies that took place during the late nineteenth century, the creation of gelatine bromide emulsions in the 1870 s was the most significant in breaking down barriers to photography and giving rise to a new class of hobbyists and amateurs, as well as a more serious group of avocationals who were not photographers by trade, but took the art very seriously. The primary

2 W. Jerome Harrison, A History of Photography: Written As A Practical Guide And An Introduction To Its Latest Developments (New York: Scovill Manufacturing Company, 1887), 45-63; Erich Stenger, The History of Photography: Its Relation To Civilization and Practice, trans. Edward Epstean (Easton, Pennsylvania: Mack Printing Company, 1939), 26-30. 
advantage of gelatine emulsions was that they preserved the light-sensitive silver compounds within them, allowing the plates to be sensitized long before exposure and developed sometime afterward. Early dry plates were relatively slow in terms of their exposure time, but during the 1870 s several photographers successfully experimented with various chemicals and processes in attempts to increase the sensitivity of gelatine emulsions. By the end of the 1870s, dry plates that could capture sharp images in as little as $\frac{1}{25}$ of a second were commercially available. Manufacturers of photographic equipment wasted little time in capitalizing on the new technology. The reduced perishability and complex chemistry of dry plates made them ideal for industrializing the production of photo-sensitive materials. For the first time, a photographer need not be an avid chemist or have a travelling darkroom, as the craft of preparing his or her own plates, papers, and developers was becoming obsolete in the face of large-scale production and marketing of photographic materials. ${ }^{3}$

One well known entrepreneur, George Eastman, was among the first to successfully manufacture and market commercial dry plates, but it was

\footnotetext{
3 Harrison, A History of Photography, 58-77; J.C. Worthington \& J.C. Millen, The Photographic Primer: A Complete Manual of Practice (Riverton, New Jersey: The Riverton Press, 1896), 35-50; Beaumont Newhall, The History of Photography: From 1839 to the Present (New York: The Museum of Modern Art),103-118;

4 Reese V. Jenkins, "Technology and the Market; George Eastman and the Origins of Mass Amateur Photography," Technology and Culture 16, no. 1 (1975): 1-19.
} 
another innovation that secured his legacy. In 1889, The Eastman Dry plate and Film Company began selling the Kodak no. 1 camera, which was the first of its kind. It was designed to be used by people who had no experience taking pictures. Later that year, Eastman began selling Kodak cameras preloaded with enough transparent celluloid roll film (another Eastman innovation) for one-hundred exposures. After the exposures were made, the entire camera could be shipped back to the factory where the film was processed and the camera reloaded, or one could bring the camera to a local photographer for film processing. In 1889, a Kodak was priced at the substantial sum of $\$ 25.00$, placing it out of the financial reach of most. However, in 1900 the first Kodak Brownie model was introduced at the modest price of $\$ 1.00$, including film. It quickly became popular because of its low price and ease of use. ${ }^{4}$

During the first three decades of the twentieth century, an array of manufacturers saturated the market with hundreds of roll film cameras. Perhaps the most important of these was the Leica I Model A, introduced in the United States in 1925. The significance of the Leica was that unlike other cameras it used $35 \mathrm{~mm}$ film, which was small enough to allow the camera to be very compact, yet produce as many as 36 sharp images on a single roll of film, almost twice as many as the leading format, Kodak's 120. Additionally, because $35 \mathrm{~mm}$ film was manufactured for the motion picture industry on a 
large scale, it was inexpensive. $35 \mathrm{~mm}$ cameras became very popular during the 1930 s, and by the 1960 s they had become standard for amateurs. ${ }^{5}$ With popular photography on the rise in the early 1900s, many industrial companies had employees and engineers who were also competent photographers. Subsequently, these companies began using photographs more than was previously thought necessary, or even possible, and they recognized new ways in which the medium could be applied to a host of applications, including advertising, blueprinting, photo-microscopy, photosurveying, and duplicating documents. ${ }^{6}$

Throughout the first two decades of the twentieth century, the role of photographs in industry expanded from being little more than a means of replacing older visual technologies like sketching and line engraving, to serving as an important tool that no company could do without, or so John Graff claimed in his 1917 article, "Technical Photography and Its Use in Industrial and Commercial Organizations." In Michigan, the Calumet \& Hecla Mining Company and The Quincy Mining Company began taking photographs for their records in the late 1860s, a practice which increased during the next seventy years. By the time of World War One, photographing property, machinery, and underground operations had become standard

\footnotetext{
5 Todd Gustavson, Camera: A History of Photography from Daguerreotype to Digital (New York: Fall River Press, 2009), 133-141, 212-218. 6 Newhall, The History of Photography, 103-118; "The Use of the Camera in Industrial Plants," The Iron Age 90, no. 8 (1912), 393-397.
} 
practice with both companies. On the other hand, Cleveland-Cliffs Iron does not appear to have used photography as extensively, since there are no photos predating the turn of the twentieth century in their records. Thus, use of photography was not consistent throughout the mining industry. ${ }^{7}$

As the photographic community grew in the 1880s and '90s across all industries, engineers and employees of industrial companies were among the many to invest in an assortment of new photographic products and services from handheld snapshot cameras and photo finishing, to gelatine dry-plates and patent developers. Throughout the second half of the century, E. \& H. T. Anthony \& Company was one of the nation's leading photographic enterprises and the company was well renowned for the quality of their products. Their advertisement (Figure 1.1) was like many ads for other photographic companies at the time, showing a box of dry plates beneath a view camera on a tripod. A photographer using this setup could go anywhere he or she could carry the camera, tripod and box, make multiple exposures, and then develop the plates later. The Scovill and Adams Company was another one of the largest manufacturers of photographic equipment in the United States. Their ad (Figure 1.2) is similar to that of Anthony's as it shows a dry plate box beneath the tripod, and it lists many of the engineering-related photographic products offered by the company. The ad also shows a female photographer. The intent of the advertisement may have

7 “The Use of the Camera in Industrial Plants," 393-397. 
been to sell cameras to women, despite the ad's claim that it was a glimpse of a woman intended for engineers in mine locations with predominantly male populations. Though engineering trade journals were geared toward men, women were among the growing ranks of photographers during the dry plate era.

The page of advertisements for engineering products from an 1891 volume of Engineering and Mining Journal (Figure 1.3) demonstrates that photo equipment was being marketed to engineers along with their more traditional tools. It displays an assortment of “The professional man's mute but valuable assistants," including field books, sketch books, surveying instruments, and Scovill \& Adams photo equipment. By the late 1880s, the camera had become part of common engineering equipment just like sketchbooks and transits, and it was advertised accordingly in the engineering press.

A rise in the number of engineer photographers paved the way for companies to use photography as a business tool a greater extent. At midcentury, only the largest and most well-funded industrial ventures warranted thorough photo-documentation. For example, more than 17,000 photographic prints were made to illustrate the jury's reports on the most significant products of industry displayed at the Great Exhibition of London in 1851, while mundane industrial photographs from that time are very rare. Similarly, major projects in large cities, such as the building of the Paris 
Opera House in the 1860s warranted series of photographs to document construction processes. At the time, most companies did not use photography extensively because limitations imposed by optical printing, photogravure, and photo-lithography (the available printing methods of the time) prevented photos from being printed in the trade journals and pamphlets. In most cases, there was no desire to take photographs that could not be disseminated among professionals or consumers. ${ }^{8}$

Commenting on his visit to the 1893 World's Fair in Chicago, prominent photographic innovator and renowned author Herman Vogel pointed out that despite unwavering nationwide homogeneity in subject matter and style, American photographs had reached a level of technical proficiency surpassed nowhere else in the world. This was due, at least in part, to the American photographic industry, "with its efforts toward introducing something new every day or offering the best in quality of the old." 9 With the arrival of these new products came a proliferation of photographers from a wide range of backgrounds, who were equally diverse

8 The Use of the Camera in Industrial Plants," Iron Age 90, no. 8 (1912): 393-397; A History of Photography: Social and Cultural Perspectives, trans. Janet Lloyd, ed. Jean-Claude Lemagny and Andre Rouille (Cambridge: Cambridge University Press, 1987), 45-47; David A. Hansen, "The Beginnings of Photographic Reproduction in the USA," History of Photography 12, no. 14 (1988): 357-376.

9 H.W. Vogel, "Letter From Germany: The Chicago World's FairPhotography in Different Countries," Anthony's Photographic Bulletin 24, (1893): 666; Newhall, The History of Photography, 103-118; W. Jerome Harrison, A History of Photography, 21-57. 
in regard to their photographic skills. On one end of the spectrum were avocationals who made a serious study of optics and chemistry, gaining a high level of technical proficiency in order to master the arts of composition, exposure, development, and printing, which helped them to produce high quality images. Industrial and engineer photographers typically used largeformat plates in conjunction with versatile view cameras that allowed them to control exposure, focus, and perspective. In most industrial applications, such as taking pictures of machines, highly skilled photographers were employed since technical quality was of the utmost importance. Obtaining sharp, evenly exposed images of machines inside workshops was difficult, requiring long exposures and flashlight produced by burning magnesium. Careful exposure made it possible for photographers to take photos that revealed an apparatus's fine details and did not require retouching before being made into halftones prints in trade journals and magazines.

On the other end of the spectrum were true amateurs who remained satisfied with push-button pictures and commercial photo-finishing services. These photographers were usually most interested in taking snapshots in broad daylight, of family, friends, and special occasions to be pasted into scrapbooks. Therefore, they did not require advanced knowledge of photography that would help them take pictures of complicated subject matter in tricky lighting situations. Though most industrial photographs 
were taken using large-format view cameras, engineers were known to carry hand cameras to make quick and easy records in the field. ${ }^{10}$

At the time there was a divide in photography between the medium's abilities as a means of mechanically reproducing sights as they were shown by nature, and the idea that the photographer could also be an artist.

Pictorialism was the dominant artistic photographic movement of the second half of the nineteenth century. It was based on the idea that the camera should be more than an objective recording instrument and was best placed in the hands of a photographer who appreciated "beauty, transcendence, and moral value," and wished to compete with painters and engravers in regards to such. ${ }^{11}$ Essentially, pictorialism was the photographic descendent of the eighteenth-century Romantic Movement.

Some believed that pictorialists did nothing more than create deficiencies in their own photographs, such as purposely making the image out of focus, to mimic true art. ${ }^{12}$ To them, photography was, "a medium almost mathematical in its truthfulness," 13 that was best used as a form of encyclopedic documentation in scientific pursuits from mapping the known

10 John W. Alvord, "Photography for Engineers," Annual Report of the Illinois Society of Engineers and Surveyors 10 (1895): 117.

11 Elizabeth Edwards, "Unblushing Realism and the Threat of the Pictorial: Photographic Survey and the Production of Evidence, 18851918," History of Photography 33, no. 1 (2009): 3-17. 12 Elizabeth Eastlake, "Photography," The Quarterly Review 101 (April 1857): 442-468. Elizabeth Eastlake is also known by her married name, Elizabeth Rigby.

13 Edwards, "Unblushing Realism," 6. 
universe to creating a visual record of the various human races. Because photos captured fine detail more quickly and easily than drawing, and because the image was formed by the direct action of light upon the plate rather than the interpretation of the human hand, many considered photographs to be truthful representations of nature. This was despite the facts that photographers made subjective decisions about composition, lighting, and exposure. Photographs also reduced three dimensions to two, did not reproduce color, and often showed various defects and distortions created by the lens and plate.

Industrial photographers tried to make machines, equipment, and factories appear like they did to the unaided eye by correcting the perspective of buildings, and sometimes painting the surfaces of machines to ensure even exposure. However, in so doing they simultaneously altered the image to suit their own preferences. Thus, industrial photographs were often thought of as objective and truthful, but in reality it was up to the individual photographer to decide what looked good in a picture, and what did not.

By the 1890s engineers who took up photography as a hobby often found it to be an excellent addition to their professional skill sets. In 1912, an anonymous author writing about industrial photography claimed, "the enormous growth and facilities of the companies manufacturing cameras and photographic supplies were not built up as a consequence for the demand from the professional, but of that from the great army of amateurs, of whom 
at least a few are to be found among the employees of almost every plant, large or small." ${ }^{14}$ Aside from taking general exterior views of factories and works sites, as well as shots of machinery to be printed in trade journals, engineers also developed new technical applications for photographs. The camera recorded and reproduced sights faster than the human hand. Its ability to quickly capture the fine details of machines, work sites, mineral samples, and terrain became essential in chemical, mechanical, and electrical research, as well as in surveying and formal education. ${ }^{15}$

New photographic products made taking pictures more practical, but the success of industrial and engineering photography also relied on the ability to publish photographs. Until the 1880 s, illustrations in periodicals were mostly printed using handmade line-engravings. Though many faithfully represented the photographs they were based on, engraving was a slow process and some level of abstraction was unavoidable. However, the arrival of halftone technology opened another door for industrial photography by allowing photos to be mechanically reproduced and printed in the engineering press, significantly decreasing the creative adjustments between the original photos and their printed versions. Developed in the 1880s,

\footnotetext{
14 "The Use of the Camera in Industrial Plants," 394.

15 "Value of Photography to Engineering," The Engineering Journal 16, no. 11 (1933): 474-480; Lieut. Henry A Reed, Photography Applied to Surveying New York: Wiley \& Sons, 1888): 1-4; Louis Derr, Photography: For Students of Physics and Chemistry (London: The Macmillan Company, 1906), 1-3, 190.
} 
halftoning optically transfers images directly to metal printing plates, allowing photographs to be quickly reproduced with ordinary printing presses alongside blocks of raised type. This meant that for the first time, photographs could be printed in trade journals with large circulations, and that the number of illustrations was no longer limited by the speed of engravers. ${ }^{16}$

In 1886, Engineering and Mining Journal began printing halftone photographs in addition to the line engravings that had been a regular feature of the journal since the 1860s. In the years following the arrival of halftones, the number of images in the pages of $E \& M J$ increased steadily as the ratio of photographs to line engravings grew. By the early 1930s, photographs had all but replaced engravings and they showed a much wider range of subjects. Though views of machinery and heavy equipment remained a constant in the age of photography, other traditional subject matter like general exterior views of factories and portraits of prominent businessmen began appearing in greater numbers. The relative ease of illustrating with halftone photographs provided an opportunity to bring more images of distant people, places, and things to the reader.

${ }^{16}$ Christopher R. Harris, "The Halftone and American Magazine Reproduction 1880-1900," History of Photography 17, no. 1 (1993): 77-80; T.C. Hepworth, "Journalistic Photography," Photographic Times 36, no. 8 (1904): 355-358. 
During the final quarter of the nineteenth century, the camera transitioned from a luxury reserved for the largest industrial ventures and the most salient feats of engineering, to a tool that was readily available to engineers and companies of all sizes. Additionally, during the first quarter of the twentieth century, photographs published in E\&MJ increased in number. They also broadened out in regard to their subject matter, which was no longer limited to the technical details of equipment and machinery that characterized line engravings. The result of these developments was the full arrival of photography as a communication medium for industrial companies and engineers. 


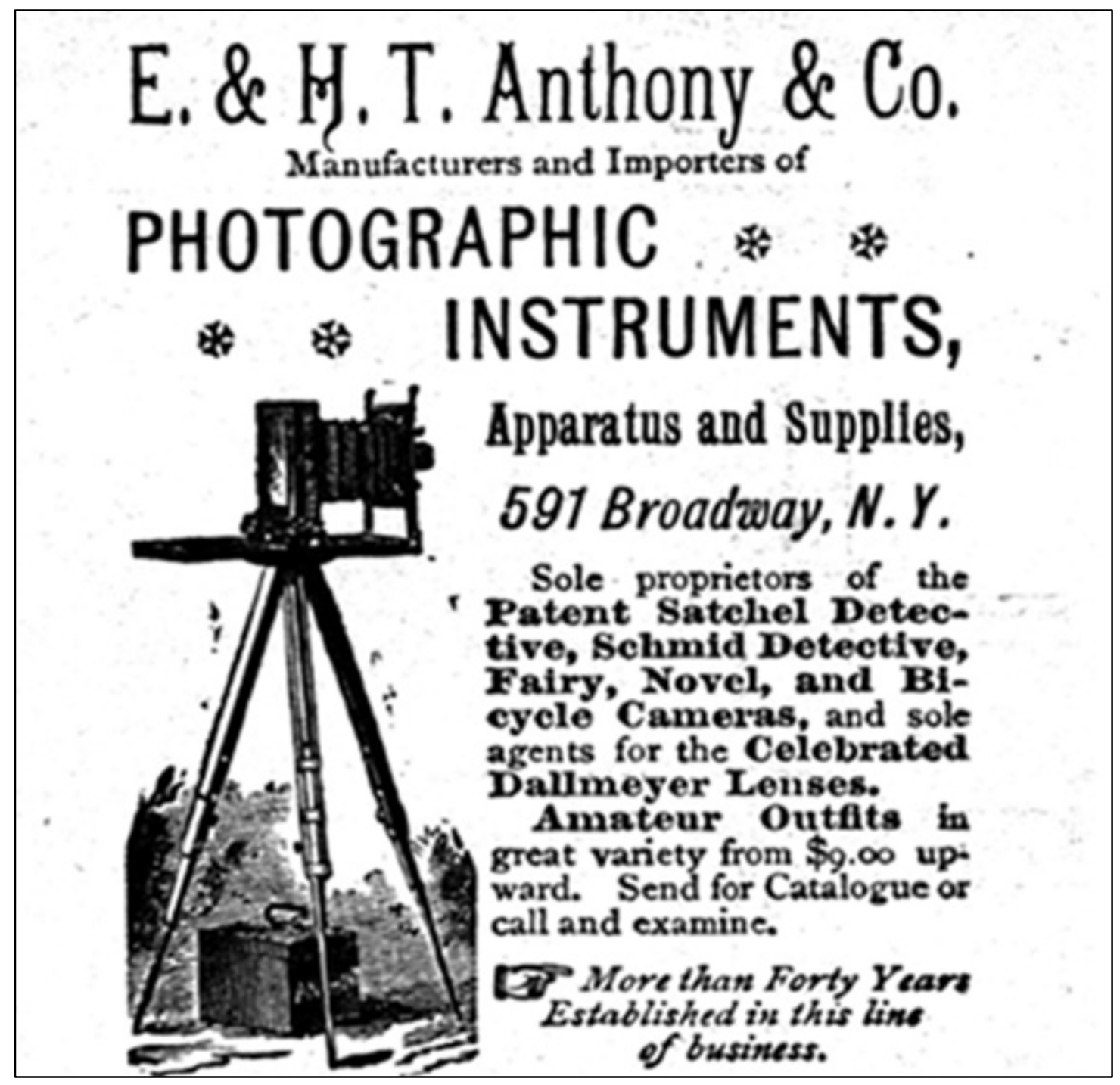

Figure 1.1: Advertisement for E. \& H. T. Anthony \& Company photographic instruments. Engineering and Mining Journal 47 (March 16, 1889): xix. 


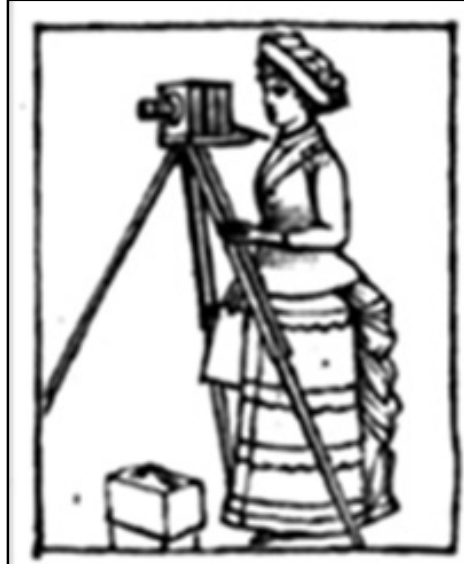

\section{A LADY}

is so seldom seen at the mines and in the camp that we thought that the very picture of one would be welcome. Photographic cameras, lenses and apparatus for mining, engineering and surveying. Outfits for exploring expeditions, surveys, prospecting parties, etc. American Optical Company's cameras, Morrison wide-angle lenses, Steinheil and Ross lenses of all styles, Eastman roll holder8, dryplates of all the leading brands, "ivory" flims, chemicals, flash light cartridges, etc., etc. Every possible photographic requisite. Send for specimen copy of the "Photographic Times." Catalogues, estimates and information cheerfully supplied on application.

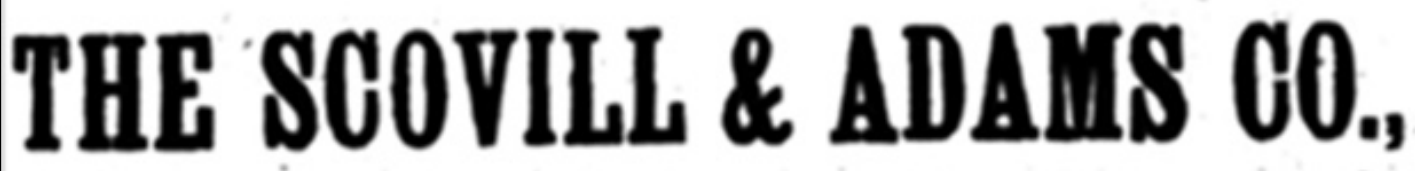

\section{Froome Street, New York.}

Figure 1.2: Advertisement for The Scovill \& Adams Company showing a lady photographer with camera and dry plates. Engineering and Mining Journal 47 (April 20, 1889): xi. 


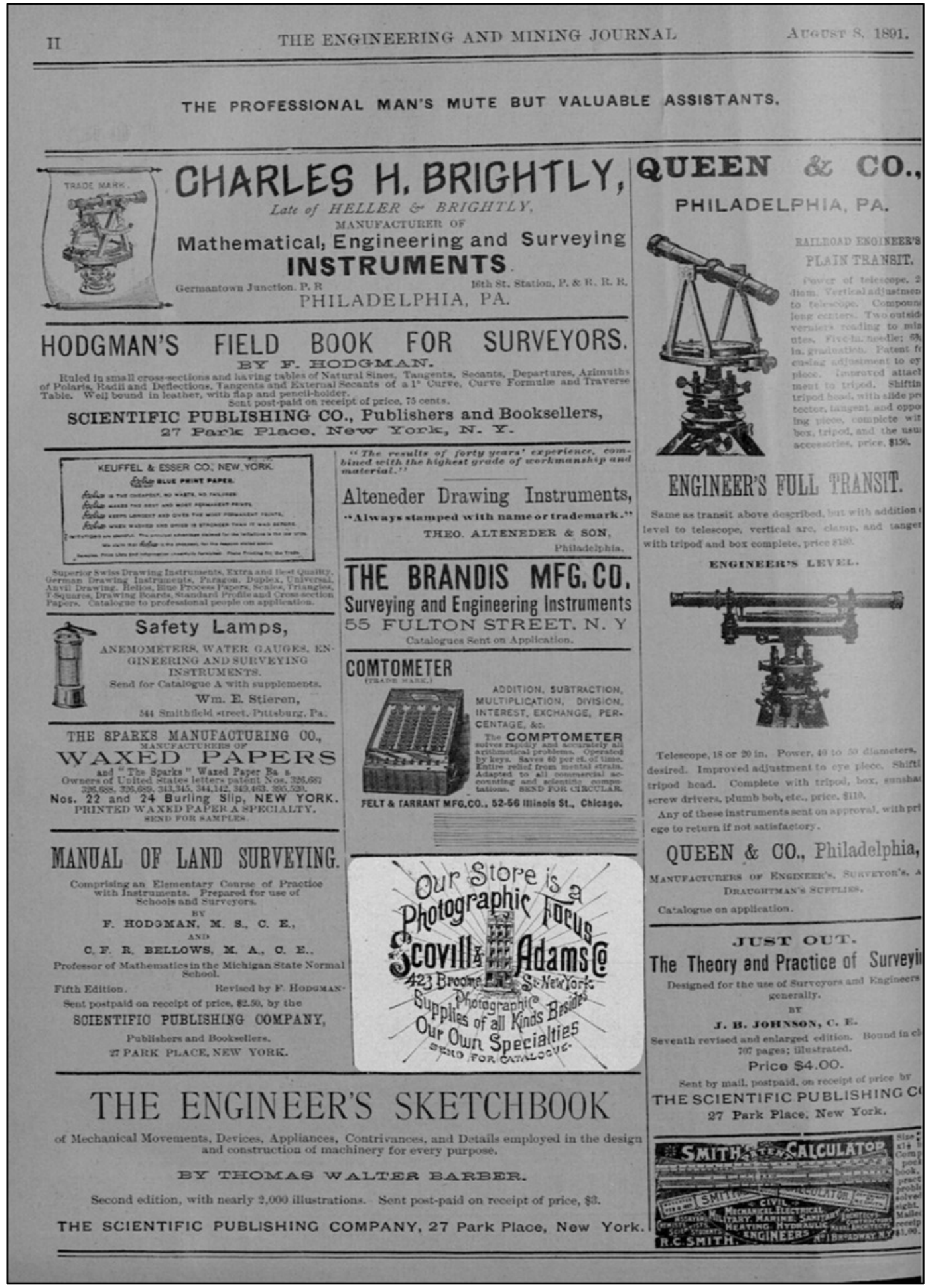

Figure 1.3: The professional man's mute but valuable assistants. Engineering and Mining Journal 52 (August 8, 1891): ii. 
Chapter Two:

\section{Focusing on Detail: Instruction for Industrial Photographers, 1895-1933}

From 1880 to 1930, photography within industry became recognized as an integral tool of business as new uses for photographs were found by industrial photographers. Early on, learning to take pictures for use in advertising, company records, technical writing, land surveys, and a host of other purposes was mostly up to the individual engineer. Manuals on technical photography like George M. Sternberg's, Photomicrographs and How to Make Them (1884), and Henry A Reed's, Photography Applied to Surveying (1888) were part of a growth in how-to literature on scientific photography. These were available to engineers, but little if any formal instruction was available, especially outside of major cities. In the $1890 \mathrm{~s}$, trade journals began printing articles that discussed technical uses for photography in engineering, as well as techniques for taking pictures of machines, factory interiors, and other subjects. Such literature coincided with a proliferation of photographers of all skill levels, who comprised an increasingly large segment of industrialized society, and it helped solidify photography's place in industry. By the 1920s, the idea that a company should have a special department dedicated to producing photographs for the firm took a strong hold in the minds of engineers, as well as in the practices of many industrial enterprises. By World War One, John Graff advocated for 
the implementation of photographic curricula in engineering schools as even the smallest concerns of engineers utilized photography to some end. In response to these developments, engineer photographers began voicing their thoughts and opinions on the subject in articles published occasionally in several trade journals from the 1890s onward.

In 1895, an Illinois surveyor, John Alvord published an article entitled "Photography for Engineers," in which he argued that photography had great potential to make the engineer's work faster, and that just about anyone could master the art with diligent practice. Though he mentioned that engineers had already developed quite a few technical applications for photography, including surveying and keeping records of construction processes, most of his argument is devoted to establishing that engineers should not be afraid of the camera. This suggests that although technical photography had found its way into industry, it was not yet commonplace. However, that changed substantially over the next three decades. In 1933, the anonymous authors of "The Value of Photography to Engineering" made no mention of the skills that technical photographers had to learn to become proficient in their art, nor did they introduce the basics concepts of what industrial and engineering photography were. Instead they assumed that 
engineers knew how to take pictures, and that photography had become firmly established within various fields of engineering. ${ }^{1}$

By the dawn of the twentieth century, photographs were becoming a necessity in industrial advertising and their

uses [were] multiplying almost daily as one ingenious mind after another [found] in photography another way in which time and effort [could] be economized or made more effective, as, for instance, by using the art to... dispense with lengthy and sometimes involved written descriptions. ${ }^{2}$

Many large companies like Westinghouse and General Electric instituted photographic departments, whose job it was to make prints for all other departments. Aside from the production of marketing materials, these departments also made copies of tracings, blueprints, contracts and many other documents without the need for a draftsman or typist. They were also responsible for documenting the stages of large construction projects so that company executives, who often resided in locations distant from where the work was being done could monitor the work. Photography was already an established tool of industry, but its significance had yet to be fully acknowledged. ${ }^{3}$

1 John W. Alvord, "Photography for Engineers," The Annual Report of the Illinois Society of Engineers and Surveyors 10 (1895): 115-119; "The Value of Photography to Engineering," Engineering Journal 16, no. 11 (1933): 474-480.

2 "The Use of the Camera in Industrial Plants," Iron Age 90, no. 8 (1912): 393.

${ }^{3}$ Ibid., 393-397. 
"Photography for Engineers," published in the Annual Report of the Illinois Society of Engineers and Surveyors in 1895, addressed rudimentary skills and encouraged engineers to strive for quality beyond that which the amateur could achieve. When snapshot cameras entered the market in the late 1880s, George Eastman's advertisement, “you push the button and we do the rest," sold thousands of Kodaks, but it glossed over the fact that a camera, no matter how simple, was only as good as the photographer. True amateurs were often hard-pressed to produce good pictures with the simplest of cameras and the assistance of professional photo-finishing. In the words of John Alvord,

The camera came into fashion and hundreds of amateurs invested their money in a mysterious looking black box with cabalistic screws protruding from it in various places, only to find after various vicissitudes of hope, joy, fear, vexation and despair, that pressing the button did not make a picture even if the rest was done by experts. ${ }^{4}$

Convinced by advertising that over simplified the art and science of taking pictures, many frustrated novices probably gave up photography before they gave themselves a chance to become proficient.

At first, Alvord was similarly vexed by his own camera. Upon showing his first snapshots to his friends, they "shrieked with laughter," and only after months of diligent practice did his pictures improve. In order to avoid some of the mistakes he made early on Alvord encouraged engineers to seek the assistance of professional photographers when it came to selecting a

\footnotetext{
${ }^{4}$ Alvord, "Photography for Engineers," 115.
} 
suitable camera, as well as learning to judge exposure, develop plates, make prints, and mix chemicals. He also pointed out that a view camera and tripod was a much better setup for engineers than a snapshot camera. It allowed for greater control over exposure, focus, and perspective, which were especially important when taking pictures in less than ideal conditions, such as inside of a factory. Clearly, the expectation of instant success was ill-suited to the needs of engineer photographers, who had to exercise a great deal of control in taking photos, an ability that came only with time and practice. ${ }^{5}$

In addition to outlining the process of learning photography, Alvord also offered a brief synopsis of the various applications for which he and other engineers were already using the camera. To him, it was particularly useful in field work. He acknowledged that mastering photography made snapshot cameras less mysterious. This was beneficial since snapshots were very useful for making fast and accurate field records of construction projects, machinery, and structures without having to take time to draw them.

Nevertheless, he acknowledged that the camera's uses extended far beyond acting as substitute for drawing. Several times throughout the article he likened the instrument to his transit, assuring the reader that any engineer who had mastered the established tools of their field could become equally proficient at taking pictures. By the time of his article's publication, photography was used by engineers in so many ways that Alvord claimed, if

5 Alvord, "Photography for Engineers," 116. 
he were to list them, "[he] might extend the list indefinitely."6 By the final decade of the nineteenth century, engineers and surveyors had already demonstrated the camera's potential value to their respective fields. However, that Alvord had to learn how to take pictures with some help from vocational photographers, but not from others in his line of work, indicates photography was not part of an engineer's professional training in the decades leading up to the turn of the twentieth century. ${ }^{7}$

Despite lack of formal instruction, the fact that the camera's ability to record fine detail made it superior to the human eye in many ways was recognized by engineers. Accordingly, they took technical photography to a new level that reached beyond using the camera as a means to create illustrative records of machines and construction processes. One of the earliest technical applications was the photo-micrograph, which became essential to metallurgy and chemical engineering in the 1880 s and ' 90 s. Combining the camera and microscope allowed metallurgists and chemists to, depict the various changes resulting from different workings or treatments within certain limits. With this control [came] commercial satisfaction and regularity in repetition... The crystalline structures of metals and alloys as well as the chemical compositions of a host of products were made readily visible by the photo-micrograph and greatly improved quality and reliability by, [showing] the cause of failure in metal structures and [eliminating] disasters by showing the tendencies of certain metals and alloys to crystalize under stress and fatigue. ${ }^{8}$

\footnotetext{
${ }^{6}$ Ibid., 118.

7 Ibid., 115-118.

8 "The Value of Photography to Engineering," 478.
} 
Biologists and doctors used photo-micrographs first, and later many engineers adapted it to their own needs.

By the nineteenth century, scientists had already developed a methodological approach for investigating the natural world. It utilized tools that enhanced visual perception, allowing scientists to see objects and phenomena that were invisible to the naked eye. The photo-micrograph, used extensively by biologists and doctors, was one of them. Engineers' adoption of photo-micrography parallels changes in the development of new technologies, which shifted from reliance on empirical testing to methodological approaches borrowed from the science community. "Technological knowledge was uprooted from its matrix in centuries-old craft traditions and grafted onto science." ${ }^{9}$ Instead of artisans passing down knowledge of their crafts through apprenticeships, technical schools trained engineers to approach technological problems scientifically. Accordingly, they adapted scientific tools to their own needs.

In 1884, George M. Sternberg, a surgeon in the United States Army, published a book titled, Photomicrographs and How to Make Them. Approaching the subject from the point-of-view of a biologist he did not discuss photographing metals, alloys, or minerals, but instead focused on the cellular structures of plants and animals, as well as fungi, bacteria, and

9 Edwin Layton, "Mirror-Image Twins: The Communities of Science and Technology in 19th-Century America," Technology \& Culture 12, no. 4 (1971): 562-580. 
viruses. However, he covered the needed equipment, as well as the process of making photo-micrographs in depth and at times his argument echoes that of Alvord. In particular, Sternberg stressed the fact that because one is a good microscopist does not mean one can make good photo-micrographs. A photomicrographer must also be a good photographer, which only comes with a lot of practice as,

even with [the use of dry plates], and with explicit printed directions with reference to their use, the beginner is pretty sure to expend a considerable amount of time and material, if he trusts to his unaided efforts, in experiments relating to time of exposure, development, etc. ${ }^{10}$

In this sense, instructional literature on scientific photography was similar to that of engineering photography; many scientists and engineers did not know how to take pictures, even if they understood the gist of how to apply photography to their work.

Writing in the era when amateur photography was taking off, Sternberg recommended dry plates because they could be purchased in large quantities, stored for long periods of time, and were more sensitive than wetplates. Despite these bits of advice, he did not discuss photo processing in depth, but devoted most of his book to the side of making photo-micrographs that was the work of the microscopist. Though the book does not include any photo-micrographs of industrial products, it is of note that instructional literature regarding technical photography was available as early as 1888 ,

${ }^{10}$ George M. Sternberg, Photo-Micrographs and How to Make Them (Boston: James R. Osgood and Company, 1884), 18. 
even if it was not intended for engineers. Of equal importance is Sternberg's claim, "These pictures from life have always a greater interest for those who are being introduced to the wonders of nature as revealed by the microscope, than have hand-made drawings." 11 Clearly, he believed that photographs were more truthful to nature than drawing.

Photographs were faster and arguably easier to make than drawings. However, part of the reason engineers, surveyors, and scientists favored photos was that they were understood as being more objective than drawings because they were produced by the direct action of light upon a photosensitive plate; whereas drawings were more heavily subject to human interpretation and the skill of the artist. Though a quality drawing produced by a skilled artist often sufficed in representing nature as it was seen to the eye, it took longer to produce. By the 1900s, it also indicated that the company or engineer was not keeping up with the times. Photographs engaged the viewer, showed fine details accurately without the need for lengthy written descriptions, and offered an impression of authenticity that drawings did not. Photographs showed things realistically. They appeared to be free from the values and ideals that were inherent in the work of traditional artists, despite the subjective decisions made by photographers, who determined what to show and how to show it.

11 Ibid., 23. 
By comparison, photography had been applied to topographical surveying since the 1850 s, but little in the way of formal instruction was available, and only a handful of books on the subject had been published. At the beginning of the nineteenth century the French army developed a process for surveying, in which two drawings of the same terrain were made at different locations that were a known distance from one another. The sketches could then be used to triangulate the locations of major details of the terrain and produce a topographical map. However, such representations of the Earth's surface were plagued with inaccuracies because the results were highly dependent upon the skill of the artists, and even when the best artists were employed, "the results were only approximately exact." 12 Thus, the process was eventually abandoned in favor of photographic methods.

Photogrammetry, or the use of photographs to measure angles and distances was a principle pioneered by Colonel Aime Laussedat of the French army. In 1864, Laussedat was director of the National Conservatory for the Arts and Trades (Conservatoire National des Arts et Metiers) in Paris. That year he published an exhaustive treatise on photographic surveying that explained the use of photographs as substitutes for perspective drawings made in the field. ${ }^{13}$ The book was so thorough and well thought-out that more

${ }^{12}$ Lieut. Henry Albert Reed, Photography Applied to Surveying (New York: J. Wiley \& Sons, 1888): 1. ${ }^{13}$ Col. Aime Laussedat, Ouverture du Cours de Géométrie Appliquée aux Arts au Conservatoire (Paris: E. Lacroix, 1864). 
than twenty years later Lieutenant Henry A. Reed of the U.S. Army, claimed that every subsequent publication on the subject of photographic surveying used the principles laid down by Laussedat. ${ }^{14}$

Photo-surveys made the work of surveyors easier by allowing them to produce detailed maps by taking pictures at two triangulation points and then returning to the workshop, where the views were geometrically reduced into topographic representations of the terrain. The method was particularly popular in wilderness areas and mountainous regions, such as the Northwest Territory of Canada, where difficult terrain made traditional surveying methods labor intensive. By the late 1890s thousands of square miles were mapped in detail. Over the next three decades the use of photo-surveying increased and was made even more effective by the airplane in the 1920s. This was complemented by the introduction of high speed films that allowed photos to be taken instantly from high altitudes. The Canadian Department of the Interior in Ottawa commenced aerial surveys in 1921, and by 1932 had mapped more than 402,500 square miles from the air. ${ }^{15}$ Thus, photography often made the work of surveyors less laborious by allowing them to make maps from pictures of terrain, rather than having to walk the terrain and measure distances using chains and tape measures.

14 Reed, Photography Applied to Surveying, 2.

15 "Value of Photography to Engineering," 475. 
In "Industrial Photography," published in The Iron Trade Review in 1909, S. Ashton Hand, like John Alvord, introduced photography as a tool that held great potential for industry. Hand emphasized the fact that diligent practice and proficiency with one's equipment were fundamental skills required by any serious photographer. Both authors also recommended $6 \frac{1}{2} \mathrm{x}$ $8 \frac{1}{2}$ inch view cameras because they were small enough to carry on one's back, yet large enough to produce sharp images. However, unlike Alvord, Hand described specific techniques for taking pictures that were aesthetically pleasing, as well as functional in regard to their intended uses. Almost all of Hand's article discusses proper procedures for taking pictures of machines and factories for use in advertising, which was one of the most common industrial uses for photography. He explained preparation of the subject, lighting, exposure, and composition in detail, rather than mentioning their importance in general terms as Alvord did. In this sense "Industrial Photography" was a brief instruction manual for advanced amateurs whereas "Photography for Engineers" was a word of encouragement for beginners, and a call to arms for engineers in general. ${ }^{16}$

At the turn of the twentieth century American periodicals commonly printed illustrated advertisements for industrial products, and had become "veritable works of art, and their preparation [called] for photographic work

16 S. Ashton Hand, "Industrial Photography," The Iron Trade Review 44 (1909): 195-200. 
of the highest order." 17 Similarly, from the 1880 s onward, the industrial and engineering press printed an increasing number of photos that became central to technical communication. Halftone photographs had become vital to the producing engineer as distribution of products relied increasingly on illustrated advertisements since pictures of machines and heavy equipment offered potential buyers a preliminary look at a product. ${ }^{18}$ In the words of Hand,

Photographs of machinery, interiors of shops, products of machines, processes of manufacture, etc. are generally made to aid the selling department of an establishment in disposing of its product. Sometimes the photographs themselves are used as an advertising medium, but in the majority of cases half-tones are made from them for use in catalogs, or for illustrations in trade journals... To this end should be the aim of the photographer to produce prints that will require the least retouching when used for making halftones, and this for two reasons: The retouching of prints for halftone work is expensive; and the print that requires the least retouching gives the best results in the finished halftone. ${ }^{19}$

Therefore, being able to take photos that could be transformed into quality halftones was an important skill for the industrial photographer to master. A negative that yielded a good print did not necessarily make a good halftone because halftone prints had a narrower latitude than optical prints. In other words, the subject had to be evenly lit and the negative had to be evenly exposed, or else the resulting halftone would be unacceptable. If the negative was slightly over-or under-exposed, the halftone print would not show details
17 Ibid., 195.
18 Ibid., 195-200.
19 Ibid., 195. 
in highlight or in shadow, that is, the brightest areas and the darkest areas, respectively. Similarly, if the difference in the amount of light reflected by the brightest and darkest areas of the subject was too great, details in both would be lost in the final print due to the narrow latitude. ${ }^{20}$

From a technical point of view, the collage image of the Youngstown Plant from Hand's article (Figure 2.1) is very well done. All six of the individual photographs were evenly exposed and incorporated into a halftone print that shows excellent tonal rendition. If any retouching was involved in preparing the individual prints for halftoning, it is not immediately apparent. Though the industrial photography article that the halftone was taken from ${ }^{21}$ does not specify the image's original purpose, it looks as though it was intended to be printed in a magazine advertisement or a company-sponsored publication intended for the general public. The collage format reduced the size of the photos making details less visible, which would not have been an issue for an audience unconcerned with technical detail. Moreover, the overall appearance of the collage catches the eye and draws attention to the center image of the smoke stacks (the quintessential symbol of industry) with its placement in the center of a symmetrical arrangement. Thus, the halftone has a strong artistic element that trade journal photos usually did not exhibit.

20 Ibid., 195-200.

21 "The Use of the Camera in Industrial Plants," 393. 
Trade journal photos were meant to convey apparently straightforward representations of engineering related subjects. The halftones in Engineering \& Mining Journal usually showed exterior views of factories and work sites or machinery, (similar to Figure 2.1), but they were rarely elaborate. In the Youngstown image, the print in the center was cropped into a shape that is not seen in $E \& M J$ among the invariably rectangular photos. Moreover, the prints in the collage were given borders, and laid out in a symmetrical fashion on a cloud-like background, two things not seen in $E \& M J$, whose photos were centered and usually limited to two per page. Most trade journals stuck to a similar format laid down in the mid nineteenth century that was intended to conform to standards of professional communication. ${ }^{22}$ Consequently, their illustrations were meant to convey information through their content, more than to attract attention through aesthetic appeal.

One common solution to the difficulty of making quality halftones was to correct flaws and emphasize important details by making an optical print of the original negative and then retouching it before making a halftone print via another negative. In Hand's opinion this was unacceptable because retouching was expensive, but also because he believed a print that required no retouching resulted in the best halftones. Nearly thirty years later this

22 David E. Nye, Image Worlds: Corporate Identities at General Electric, 1890-1930 (Cambridge Massachusetts, MIT Press, 1985), 61. 
opinion was still accepted as valid, but apparently little had been done to remedy the problem. In "The Value of Photography to Engineering," the anonymous authors claimed,

most photographs used to illustrate and sell engineering products are retouched, and so long as such work is confined to making good the deficiencies of the camera in order to represent the product as it appears to the eye, it is legitimate, but too often the retoucher is made to show things in an impossibly idealistic way, with results that are false and ridiculous to a thoughtful observer. ${ }^{23}$

Like Hand, they believed that the least altered photographs were the best photographs because alterations made by the human hand reduced their truthfulness.

Hand stressed that good photographers went to great lengths to ensure exposure and perspective were just right and offered ways to avoid retouching photographs. For example, when capturing landscapes of mining sites or exteriors of factories, photographers employed the rise, tilt, swing, and shift movements of view cameras to alter perspective and thus avoid distorting the image. The view camera's movements allowed photographers to move the lens in relation to the plate instead of tilting or turning the entire camera. The movements were particularly helpful when photographing large buildings and structures. The rise movement, which allows the lens to be raised or lowered in relation to the plate is useful when photographing tall subjects like buildings. Rather than pointing the camera upward to include

23 "Value of Photography to Engineering," 480. 
all of the building and simultaneously making it appear as though vertical lines are converging, the photographer could place the camera level and raise the lens to include the top of the building in the frame without creating distortion (Figure 2.3). Undoubtedly, adjusting the camera lens before the exposure would be much easier and faster than altering its perspective afterward. According to Hand, taking these steps was better than correcting the perspective afterward not only because doing so created extra work and resulted in loss of image quality, but also because it disrupted the truth claim on which industrial photography relied. However, if a subject could not be photographed without distortion or be re-photographed to correct distortion, a negative that showed a distorted perspective of a building or a machine could be adjusted. First the negative was placed in a frame and tilted (Figure 2.2). Then, a second exposure was taken of the tilted negative with the rear objective of the view camera tilted in the opposite direction. Last, the resulting positive plate was photographed to produce a perspective corrected negative that could be used to make positive prints. ${ }^{24}$

Taking a pictures of a factory's interior presented challenges of its own as it required the photographer to ensure that the difference in the brightness of light being reflected from various objects or parts of machines was as even as possible. In order to produce vivid if somewhat deceptive views and avoid the artificial look caused by retouching, windows had to be

24 Hand, "Industrial Photography," 198. 
masked with thin cloth to diffuse light, evenly illuminate the subject and cast no sharp shadows. Though this reduced shadows and highlights making more details visible, it changed the appearance of the room by showing it in a different light than it was normally seen. However, the action of controlled light upon the plate produced a seemingly more natural image that was preferable over one that was retouched. In the photo shown in figure 2.4, no special precaution was taken to ensure even lighting. Thus, the machines in the background are more heavily exposed than those in the foreground. However, since the photographer achieved relatively even exposure, no retouching was required before making a halftone from this negative.

In some situations photographers had more intrusive procedures that were required to take photographs that required no retouching. Painting an entire machine a single color that would reflect light evenly, including parts that were not normally painted at all, was common. In order to prevent walls, floors, and other objects distracting from or blending in with a machine, matching floor cloths and backdrops were used to improve contrast, idealizing the machine and giving it the impression of existing in isolation, much like a drawing (Figure 2.5).

The photographers that took such pictures were often in the employ of the company that was selling the machine. Though usually not photographers by trade, they held themselves to high standards and learned the nuances of cameras, plates, and developers, as well as methods of 
composition and lighting that favored industrial subjects. As industrial companies integrated photography into various aspects of production and marketing, they often recruited such individuals from the ranks of their employees for several of reasons. John H. Graff, head of the photographic department at the Berlin Mills Company in New Hampshire claimed there was no shortage of photographers among engineers, whose scientific backgrounds allowed them to master the complexities of optics and chemistry more easily than those with no prior knowledge of such subjects. Similarly, in addition to proficiency with a camera, technical photographers required an understanding of, "drawing, engineering in its different branches, elementary chemistry and physics, microscopy, business management, buying, selling and advertising." 25 Lastly, an employee who was "intimately familiar with a product and its manufacture [knew] the parts which should be photographed, especially if one [was] depicting a machine or part of one." ${ }^{26}$ These traits are part of what set industrial photographers apart from other photographers.

The anonymous author of "The Use of the Camera in Industrial Plants," offered a sampling of case studies that described ways in which employees of various industrial companies utilized photography. The Westinghouse Electric Manufacturing Company had a number of

\footnotetext{
25.John H. Graff, "Technical Photography and its use in Industrial and Commercial Organizations," The Journal of Industrial and Engineering Chemistry 9, no. 11 (1917): 1052. 26 "The Use of the Camera in Industrial Plants," 394.
} 
photographers who worked in conjunction with Westinghouse's publicity department. Some of them were field men who went out and took pictures while others were technicians who were responsible for printing and copying. These men annually produced thousands of large format negatives and prints that included relatively common subjects such as portraiture and general exterior views. However, they were also tasked with trickier things like interior views and night work that required long exposures and flashes. The pictures they made were numbered, categorized, and filed to be used when the company received an order for illustrations of their products or facilities. Scores of enlargements, sometimes as big as $24 \times 30$ inches were done up by the photo department for use in conjunction with sales proposals. The intent of the images was so that, "the purchaser may be more clearly advised as to the appearance of the Westinghouse apparatus, and it is conceded that a better idea of the apparatus can be given by means of a photograph than with a drawing." 27

According to Graff, the Berlin Mills Company of Berlin, was among the first to create a department headed by a technical photographer. Graff oversaw this department, who assisted more than fifty of the corporation's other departments in the production of visual material. Having planned and

27 "The Use of the Camera in Industrial Plants," 396; Graff, "Technical Photography," 1053. 
installed the department, Graff believed himself to be the first person ever to do so by 1917, and also claimed to have coined the phrase "technical photography." As an engineer and photographer himself, Graff possessed the necessary background to instruct others on the details of technical photography, as well as to organize a department that was responsible for keeping detailed records for most aspects of production and sales. The bulk of the work undertaken by the department under his direction consisted of photo-copying documents to, "save the original drawings... standardize the filing system... and to have exact copies of deeds, contracts, and other documents and specifications free from all possible human errors or misunderstandings." 28 Photo-copying not only saved time, it probably saved money by reducing the number of clerks and secretaries the company needed.

To these ends, several methods were employed depending on the nature of the work. When contact printing, a bright light was shined through a document to make a negative image on a piece of photosensitive paper that was in contact with the side opposite the light. Contact printing was a relatively simple process that was popular because it had been the standard method of printing used by photographers for decades. It allowed high quality copies to be made in a fraction of the time that it took to reproduce documents by hand. However, replacing individual sheets of photo paper after each exposure and developing one at-a-time limited the number of

${ }^{28}$ Ibid., 1053. 
copies that could be made. It also meant enlargements and reductions were impossible because contact prints are limited to a 1:1 ratio. Therefore, the method was best used when only limited quantities of large format reproductions were needed. ${ }^{29}$

The "Photostat," developed by the Commercial Camera Company of Rochester, New York in the early 1900s made copying small things like typewritten letters and pencil sketches much faster and easier than contact printing. Made up of a camera fixed to a copying board, it made a series of exposures along a roll of flexible paper. The Photostat expedited the copying process as there was no need to exchange paper after every exposure, and it eliminated the need for a darkroom as the machine had a developing device attached to it. Thus, if reproducing large numbers of documents to be filed for later use, the operator would make hundreds of copies one after another and then process the entire roll at once without removing it from the machine. If a few copies were needed immediately he or she would cut the paper after the required number of exposures and put it into a light-tight box to be transported to a separate darkroom. The Photostat was ideal for small documents as it was economic and easy to use in comparison to a view camera. It was also useful for making replicas of blueprints and line drawings, although the size of the copying board and the paper roll prevented the Photostat from doing very large work. Large detailed documents were

${ }^{29}$ Graff, "Technical Photography,” 1053. 
best copied by photographing them on ordinary plates and making optical enlargements, a more involved method than contact printing or using the Photostat, but one that produced superior results in regard to clarity and contrast, and was unrestricted in the size of the prints that could be made. ${ }^{30}$ An advertisement for the Photostat (Figure 2.6) sells it as a means of improving efficiency by increasing the number of copies that one person can make in a given time, while simultaneously reducing cost by eliminating the need for draftsmen and stenographers. Additionally, the advertisement highlights the fact that those who operated photographic equipment no longer needed much in the way of technical skill. Copying with the Photostat was automated to the point where the operator did not even need to adjust the focus. Thus, it reduced companies' reliance on skilled labor. It also improved the accuracy of copied documents, and allowed more visual materials to be produced, two key components of Graff's argument.

From the nascent days of technical photography, progress on construction projects was often recorded by engineers tasked with taking pictures so that the company would have a visual record of the various stages of construction. According to Alvord and Graff, these pictures were often taken with the intention of gathering evidence to be used in court should a legal dispute arise. Much of what set photographs apart from other, more traditional forms of visual media, was that they recorded detail in a way that

${ }^{30}$ Graff, "Technical Photography,” 1053. 
was incontrovertible. Though photos could be altered, it was nearly impossible to create one that showed non-existent progress at construction sites. In the words of Alvord, "Court cases are most useful places to use a photograph... Dilatory contractors confronted with a series of dated negatives of their work will find their suit for extras damaged in court or out." ${ }^{11}$ For example, E.L. Smith \& Company, a large cement manufacturing operation, did not employ any full-time photographers, but the company relied on employees skilled in the use of a camera to take pictures in addition to their primary duties. During construction of a large cement works in Bellingham, Washington in 1912, select members of the field crew were responsible for photographing their own progress. Once a week or more panoramic negatives of the work site measuring 6 inches tall by 45 inches wide were forwarded to New York so that, "executives in that city [could] post themselves at a glance as to the more noticeable features of progress made at a point on the other side of the continent." 32

Until World War One, an argument made by industrial photographers was that instead of self-education, engineering schools should integrate formal instruction on photographic engineering into their curricula. In 1917, Graff pointed out a multitude of reasons why engineering schools should begin training "photographical engineers." Among them was the fact that

31 Alvord, "Photography for Engineers," 118.

32 "The Use of the Camera in Industrial Plants," 396-397. 
technical photography was becoming much more complex, and it would benefit from standardization. An article written by anonymous authors 16 years later showed that in the years following Graff's publication, technical photography did reach new levels of complexity. However, instead of addressing photographic engineering as a field in itself, the authors' described photography as a tool that had been adapted to existing fields of engineering. Basically, there was an explosion of uses for technical photography in engineering during the 1920s and '30s. Consequently, training "photographical engineers" to understand the breadth of technical photography in depth would have been difficult, if not impossible. Therefore, rather than developing photographical engineering as a subject in itself, engineers customized photography to the needs of existing fields of engineering. ${ }^{33}$

"The Value of Photography to Engineering," a paper that appeared in Engineering Journal in 1933 boasted of progress that had been made in engineering photography since the 1880 s by enumerating its many uses, and yet only explaining them in moderate detail. Consequently, the article would have been of limited use as instructional material for students. Instead, the authors listed many new technical applications for the camera from photogrammetry to oscillography. This confirmed that technical photography

33 Graff, "Technical Photography," 1053-1054; "Value of Photography to Engineering," Engineering Journal 16, no. 11 (1933): 474-480. 
had become well-established within many fields of engineering, but not as a field in itself as Graff had suggested it would 16 years earlier. Advertising, surveying, and photo-micrography were still among the most widely used industrial applications for photography in the early 1930s, but now highspeed emulsions used in conjunction with motion picture cameras were capable of capturing moving subjects, change over periods of time, and very fast electrical phenomena at rates as high as three-thousand frames per second. Additionally, engineers exploited to a much greater extent film's ability to perceive wavelengths of the electromagnetic spectrum that were shorter and longer than visible light and therefore invisible to the naked eye. ${ }^{34}$

Metallurgists and chemists both used various forms of photography to study the effects that different treatments had on materials and to inspect their final products before selling them. Discovered in 1886, X-rays proved useful in examining the insides of castings and forgings to find slag, blowholes, and other flaws in metal that would have otherwise gone undetected. Gamma rays produced by radium were discovered in 1900 . They worked their way into the engineers' toolkit and were used in a similar manner as $\mathrm{x}$-rays, though unlike $\mathrm{x}$-rays they were able to penetrate steel more than ten inches thick. Infrared emulsions also extended the limits of visual perception. Because they are naturally occurring, can pass through fog 
and haze, and do not need to be generated like higher intensity waves, aerial surveyors used them to capture long-range photographs that showed geographic details more than three-hundred miles from the camera and were limited only by the curvature of the Earth. ${ }^{35}$

Two innovations in the realm of electrical engineering were the oscillograph, a high-speed multi-exposure camera with sixteen lenses focused on a photo plate underneath a revolving disc, and the Klydonograph, a device that creates a graphic record of electrical surges. Both relied on high speed exposures that captured electricity in action in order to show characteristics of electrical surges such as their magnitude, time of day, polarity, steepness of wave front, direction of travel, and oscillations. The nature of these properties were mysterious to engineers before the development of photographic instruments capable of recording them; the design and use of such instrumentation illustrates the high level of complexity that engineering photography obtained in half a century of development. ${ }^{36}$

Between the appearance of instructional literature in the late nineteenth century and the highly sophisticated applications developed in the decades following World War One, photography became an essential tool of corporate communication and engineering. By the 1930s, the photograph became firmly established as a necessity for advertising and technical

35 Ibid., 478-480.

36 Ibid., 475-478. 
communication. Additionally, engineers of the 1930s no longer struggled with mastering the basic skills needed to take pictures as did engineers of the 1890s. As early as 1912 it was assumed that engineers understood the basics of photography. Accordingly, instead of advocating for the adoption of photography as a technical tool, and instructing engineers on rudimentary skills, literature on industrial photography focused on applying those skills to increasingly sophisticated uses. 


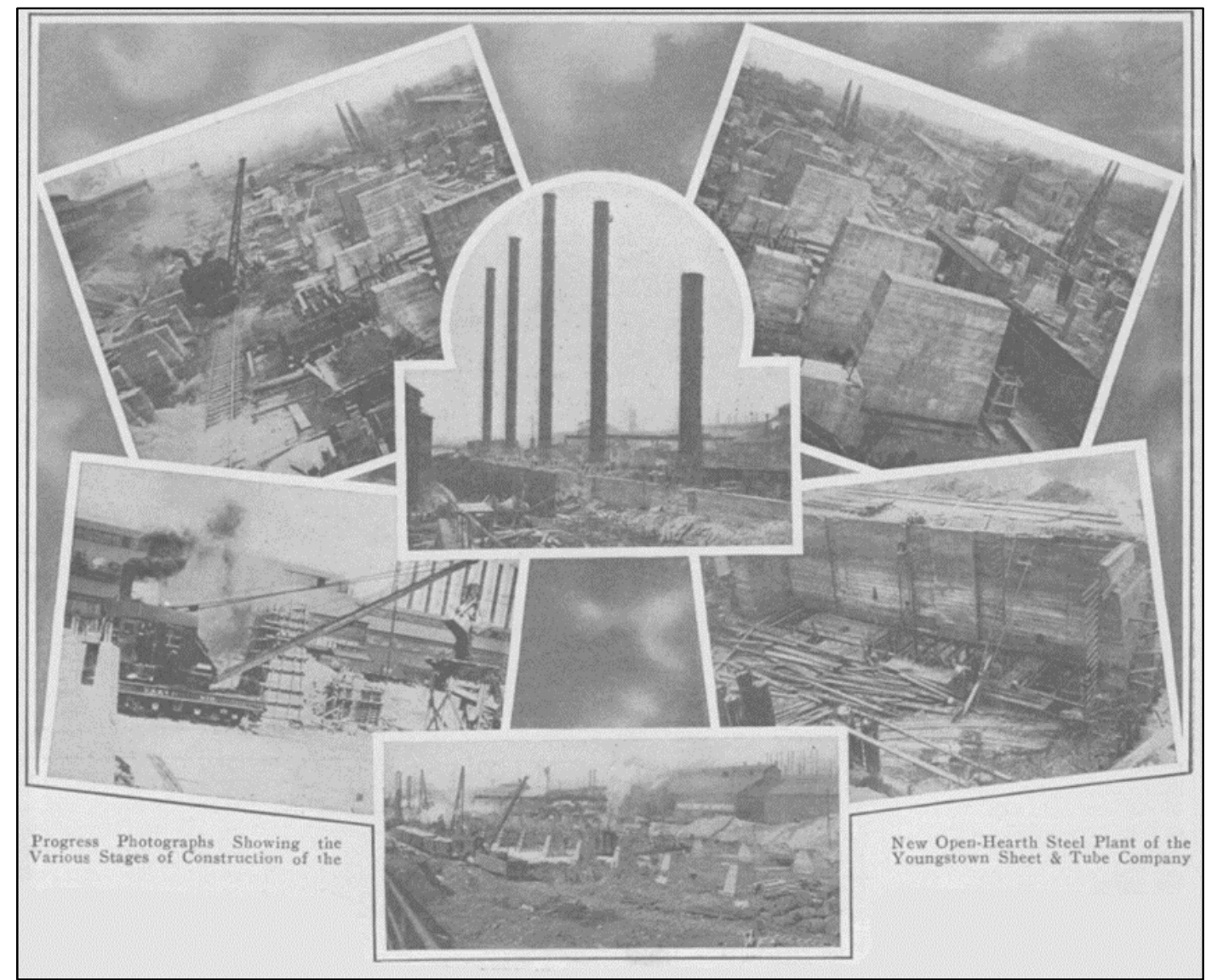

Figure 2.1: "New Open-Hearth Steel Plant of the Youngstown Sheet \& Tube Company." "The Use of the Camera in Industrial Plants,"Iron Age 90, no. 8 (1912): 393. 


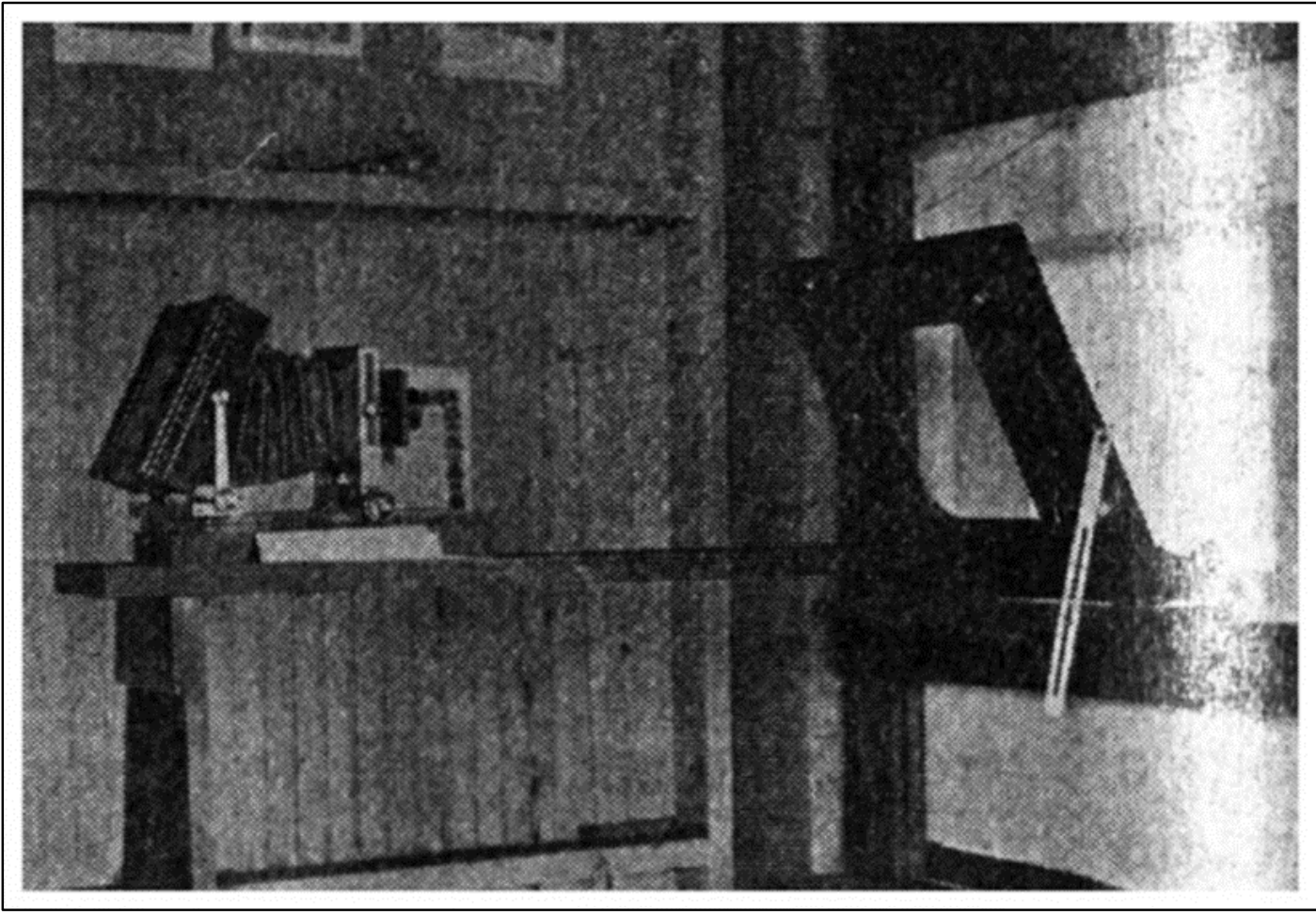

Figure 2.2: A View Camera and tilted plate holder for correcting perspective, as described by Hand. S. Ashton Hand, "Industrial Photography,"The Iron Trade Review 44 (1909): 198. 


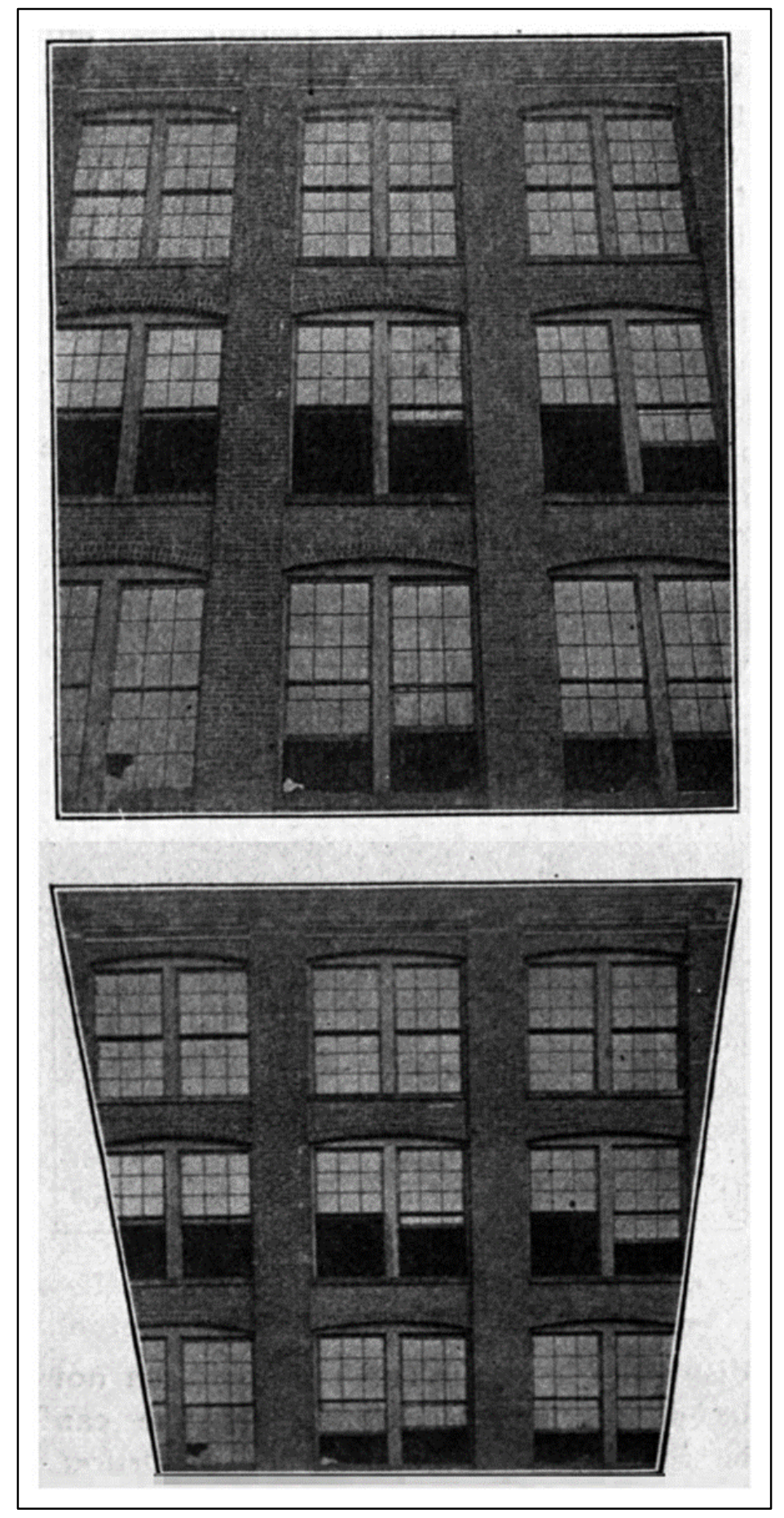

Figure 2.3: Building exterior photographed with the camera tilted upward (top). Perspective corrected view (bottom). S. Ashton Hand, "Industrial Photography,"The Iron Trade Review 44 (1909): 198. 


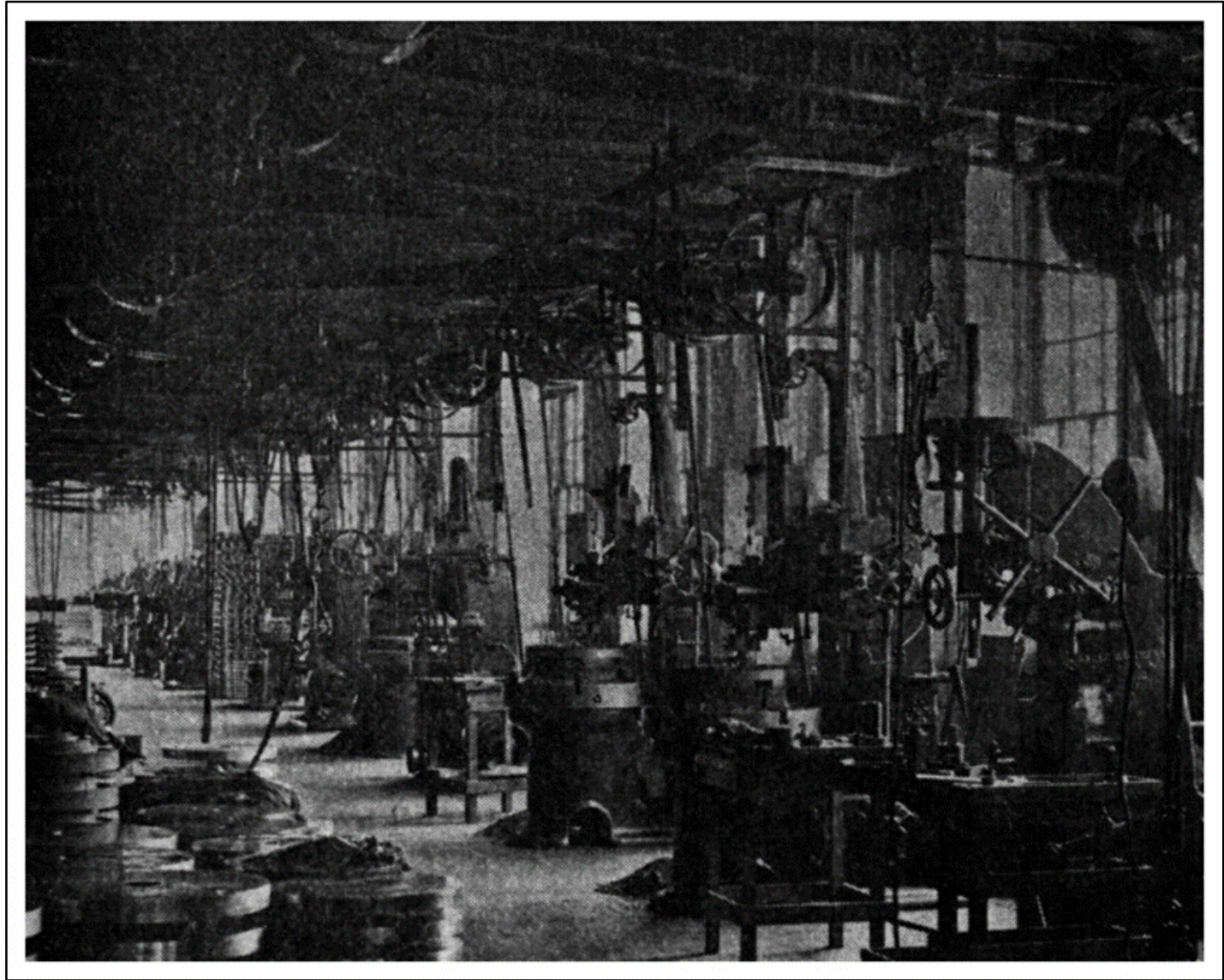

Figure 2.4: Shop Interior. S. Ashton Hand, "Industrial Photography,"The Iron Trade Review 44 (1909): 199. 


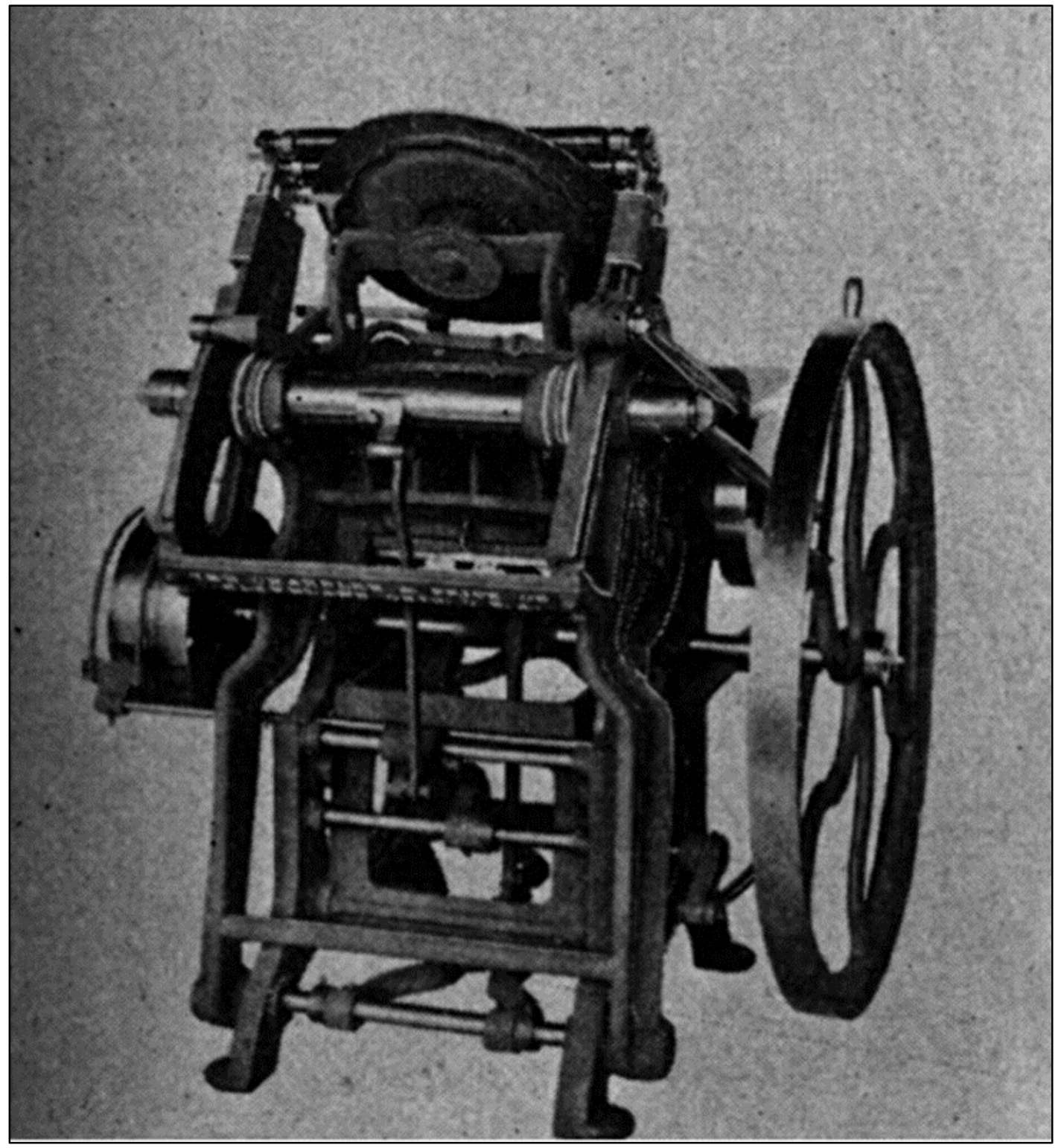

Figure 2.5: "Details brought out and shadows a voided by preparation of machine parts before photographing. S. Ashton Hand, "Industrial Photography,"The Iron Trade Review (1909): 199. 


\section{Don't Confuse the Photostat with any other apparatus}

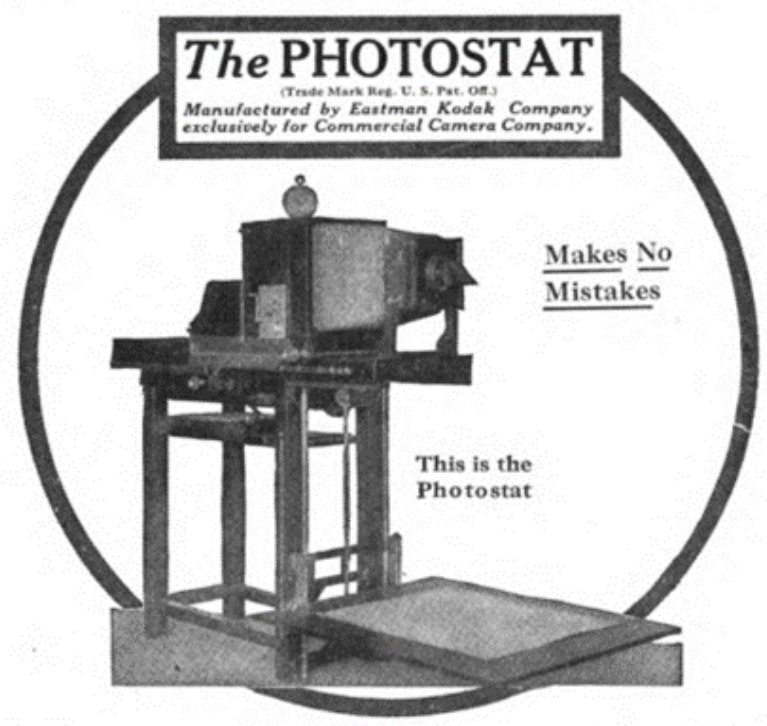

HE Photostat $s$ not an experiment - its almost unlimited scope and its
great value as a time and money saver and an efficiency promoter are now recognized facts.

\footnotetext{
The Photostat cannot make a mistake because it simply makes a photographic reproduction directly upon paper and further, because the focusing does not depend on the operator, it being an entirely mechanical operation. You can reduce a blueprint, for instance, any amount within the range of the machine and to scale.

This does away with the time you've always wasted in checking up the work of your men in tracing or of your typists in duplicating plans and specif cations.

Consider the space that two thousand bulky, unConsider the space that two thousand bulky, un theus $\mathrm{PHOTOSTAT}$ Topies would go into an dinary letter file.

You could slip a hundred Photostat prints in your pocket-but never blueprints.

Photostat prints are permanent - they can be kept
} flat-

they are clear and easily read-they are accurate, they cannot be otherwise.

You know what a nuisance it is to have to make a tracing of every pencil drawing. You no longer need do it - just Photostat it.

The same thing holds good with plans and specif eation records and documents. No matter how old they may be, how faded, the Photostat will give you just as good a copy as the original. Specifications need no longer be typed or printed just

One firm, in a pinch, made 160 duplicates in an hour and twenty minutes on their Photostat-another firm averages 166 prints of varying sizes per day. Still another firm saves \$250 per month with their Photostat by doing away with two draftsmen and a stenographer-another saves $\$ 200$ per month and another $\$ 1800$ per year. That is PHOTOSTAT SAVING

Send us work to photostat and get the bookJust write us on your firm letter head. Send us a blue-print; a
letter: a check: an old worn out leaflet: a a nencil drawing: and enclose ten cents to cover postage. etc. We will Photostat your sample
for you and send you the print together with THE PHOTOSTAT BoOK. No obligation. Send Now.

Commercial Camera Company 351 State Street Rochester, N. Y.

Figure 2.6: Advertisement for the Photostat. Engineering News 69, no. 25 (June 19, 1913): 6. 
Chapter Three:

\section{Changing Views: Halftone Photographs in Engineering and Mining Journal, 1886-1930}

Of all the uses for photography that industrial companies and various fields of engineering developed in the late nineteenth and early twentieth centuries, the arrival of halftone photographs in the engineering press had the most visible effects. New technologies, particularly dry plates and patent developers, allowed people from a wide range of social and economic backgrounds to take up the art of photography as a hobby, or additional facet of their employment, or both. More photographers meant industrial companies and the engineers working for them were able to use the camera for more applications and on a greater scale than was previously thought possible. Pre-sensitized plates and papers allowed them to easily create documents that ranged from records of construction processes and photocopies of documents, to surveys and microscopic views of ore samples. However, sharing images with other professionals relied not only on the relative ease of capturing images that was afforded by dry emulsions, but also on the innovation and widespread implementation of practical halftone printing methods.

Halftoning was an ideal means for quickly reproducing photographs and printing them in quantity. In the fifteen years leading up to the turn of the twentieth century, popular American periodicals such as Leslie's 
Illustrated Newspaper and Harper's New Monthly Magazine began replacing the line engravings that had been a constant in their pages for nearly half a century, with halftones taken from photographs and works of art. Professional literature such as Engineering and Mining Journal followed a similar course of action. Once applied to illustration in the engineering press, halftones offered professionals increased access to photographic prints. The rapidity with which $E \& M J$ latched on to this technology shows that illustration was as important to the engineering press as it was to news and literary publications.

$E \& M J$ had relied on line engravings as supplements to textual descriptions of equipment and machinery since the journal began in 1866 . However, in the 1880s and '90s the journal's appearance started changing with the arrival of halftone photographs. In the following decades the number of photos, and the overall number of illustrations in E\&MJ's pages increased as halftoning allowed printing plates to be made more quickly than did line engraving. With an increase in the number of illustrations came a broadening of subjects shown in them. Once reserved for measured drawings, graphs, charts, and schematics, as well as the occasional general exterior view and portrait, pictures in $E \& M J$ began including views of factory interiors, the underground workings of mines, photographic advertisements, and even human interest photos such as Roman tools found in a Rio Tinto mine. By the 1930s, the journal relied almost as heavily on images as it did on the written 
word. Though text remained integral to printed communication, illustrations could show things that were difficult or impossible to describe with words.

Between the 1880s and the early 1900s, a series of innovations in halftone printing technology opened the doors for change in the appearance of periodical literature. A series of refinements in the production of halftone printing plates, as well as in paper and printing practices took place in the late 1880s. Illustrations in periodicals thus increased in number as the new form of illustration gained acceptance. Overcoming technical obstacles was the first step in making the halftone photograph a viable form of illustration, but other factors played a role as well. Many believed that halftones were artistically inferior to more traditional line engravings, an idea self-servingly perpetuated by the engravers themselves. Initially printers showed reluctance to adopt the technology because it required them to rework printing systems that had been in place for a long time. Nevertheless, early successes demonstrated the new medium's potential and it was only a matter of time before it overtook traditional line engraving methods because it was faster and produced pictures that seemed to truthfully represent the original image.

The term halftone does not have a concise definition but rather refers to three steps, all of which can be accomplished using different means. In the first step a continuous tone image is translated into a series of tiny monochromatic dots that vary in size and distribution, and which correspond 
to the tones of the original. The large dots are in regions of the plate that are dark and the smaller dots are in areas that are gray. White areas have tiny dots or no dots at all. The step second uses a mechanical printing method to transfer the dots to a printing surface. This produces a system of discrete dots raised above the surface of the plate, similar to the letters in a block of raised typeface. The third and final step uses the plate in a printing press, where the raised dots are inked before being pressed against the paper. When viewed at a distance from the page, the dots, which are usually black on a white background, blend together to create an optical illusion that simulates continuous tones, making the process effective for reproducing photographs. ${ }^{1}$

Before halftone technology became commercially viable in the late 1880s, photographs for books were printed optically using sheets of light sensitive paper, or with photogravure ${ }^{2}$ methods that turned the continual tones of photos into intaglio reliefs on printing blocks. In the right hands these techniques produced quality images, but they were limited by the fact

\footnotetext{
${ }^{1}$ Stephen H. Horgan, Photoengraving in Black and In Color: Or Photoengraving Primer (Boston: American Photographic Publishing Company, 1938); Dusan C. Stulik and Art Kaplan, The Atlas of Analytical Signatures of Photographic Processes: Halftone (Los Angeles: The Getty Conservation Institute, 2013), 4-9.

${ }^{2}$ Photogravure is a technique in which a metal plate is first coated with photo-resist (a chemical that hardens when exposed to light). The plate is then exposed to a photograph causing the most heavily exposed areas to harden and become insoluble; the lightly exposed areas become semisoluble, and the unexposed areas remain soft. Acid, which etches the soft areas, is then applied to the plate.Finally, the unhardened photo-resist is washed away leaving the least exposed areas in relief and the most heavily exposed areas raised.
} 
that they had to be "tipped in," or separately inserted into the work between pages of text. Neither method was capable of putting photos on the same page as the printed word. Optical prints required their own special paper and thus meant extra pages and higher costs. In photogravure, the relief areas of the printing blocks deposited ink on the page, unlike blocks of raised typeface, where the high areas received and deposited ink. Photogravure was also limited by the fact that the plates were very delicate and could only be used a limited number of times before wearing out. These traits meant both methods were ill-suited for illustrating engineering journals that relied on rapid printing technologies to turn out thousands of copies on a monthly or weekly basis. The halftone provided a solution to these problems by allowing photographs to be reproduced by image blocks alongside blocks of raised type in a printing press. ${ }^{3}$

Until the late nineteenth century most illustrations in periodicals were made using line engraving technologies in which an artist would render an image by hand on a wood or metal block. Line engravings mimicked natural gradations of light using lines of differing widths which determined the amount of ink that was deposited on the paper in order to create the appearance of varying tones of light and dark. This method was widely used to turn photographs into printing blocks for use in the pages of a host of

\footnotetext{
3 Horgan, Photoengraving in Black and in Color, 4-9; "Pictures From Type Blocks versus Photo-Gravure," Anthony's Photographic Bulletin 22 no. 22 (1891): 673-675.
} 
publications. Skilled artists were capable of making engravings that closely resembled the images they were based on (often photographic prints) and since the blocks were simpler to print with than photogravure plates, line engravings remained the standard form of illustration well into the era of photography. Even as halftone technologies became practical, many publications refused to use them at first because they were despised by professional engravers, and would have alienated printing departments because they required the reworking of printing systems that did not favor touchy halftone plates. Nevertheless, halftones offered advantages over line engravings, including time-efficiency, which allowed printers to respond to readers' demands for more illustrations. ${ }^{4}$

A handful of innovators attempted to solve the problems posed by existing photogravure methods throughout the late nineteenth century, and eventually they met with success. As shown in the 1886 volume of $E \& M J$, a practical solution came to fruition with the printing of the journal's first few halftone photographs. The basic principle of halftoning was demonstrated by Stephen H. Horgan in 1880 when he published one of his first halftone photographs in the New York Daily Graphic. What separated Horgan's method of making photographic printing blocks from those of earlier

4 T.C. Hepworth, "Journalistic Photography, "Photographic Times 36, no. 8 (1904): 355-358. 
innovators like William Henry Fox Talbot, ${ }^{5}$ was Horgan's discovery that placing a perforated cardboard screen slightly above the image caused light to diffuse through the screen's apertures. Doing so produced dots that were slightly out of focus and had sizes directly proportional to the amount of light shining through the screen at that point (Figure 3.1). ${ }^{6}$

Once Horgan demonstrated that halftone photographs were viable as a form of illustration, a series of further innovations made the process more practicable by introducing commercially manufactured equipment, making it readily accessible to printers on a much wider scale. Frederick Eugene Ives patented the first commercial halftone system in 1881 that, unlike Horgan's, did not use a screen. Instead, Ives employed a method known as "stippling" in which the negative to be reproduced was first chemically treated to take the form of a relief, similar to a photogravure printing plate. In other words, the emulsion (light sensitive compound) on the glass negative was chemically treated so the most heavily exposed areas became thinner, while the thickness of the unexposed areas remained unchanged. According to Ives'

\footnotetext{
5 William Henry Fox Talbot was an early photographic innovator, who in the 1830s created the first negative to positive process, known as the Calotype or Talbototype, which made photographic images on sensitized paper. Talbot also experimented with printing processes that used screens to break images into fine grids of light and dark dots for printing purposes. ${ }^{6}$ Christopher R. Harris, "The Halftone and American Magazine Reproduction 1880-1900," History of Photography 17, no. 1 (1993): 77; John Hannavy, Fox Talbot (Haverfordwest, Pembrokeshire: CIT Printing Services, 1997), 35-40; "A Scene in Shantytown," New York Daily Graphic (March 4, 1880): 38.
} 
patent, "the variations of light and shade are represented by variations in thickness of the relief." ${ }^{7} \mathrm{He}$ then inked the plaster cast and used a roller surfaced with tiny rubber fingers called "stipples" that picked up varying amounts of ink that corresponded with how firmly they came into contact with the surface of the plaster. The final step was passing the roller over a sheet of paper to print the final image. The problem with Ives' method was that the dark areas of the image were the lowest spots on the negative. This necessitated the plaster cast in order to reverse the image into a positive, and subsequently made the process cumbersome despite the quality of the images it produced.

Even though making quality images with Ives' process was arguably less costly and more time-effective than doing so with traditional line engraving methods, many were reluctant to adopt the new technology because they had difficulty using it. This began to change as a competition between Ives and a German innovator named George Meisenbach fostered the development of a less labor-intensive halftoning process. In 1882 Meisenbach patented a screen made of glass with ruled lines that was able to render fine resolution images with greater ease than Ives' plaster casting system. However, Meisenbach's was a "single line" screen that had lines running only in one direction. The short spacing between the lines meant

${ }^{7}$ Frederick Eugene Ives, United States Patent: US 245,501 A-Method of Producing in Line or Stipple from Photographic Negatives, August 9, 1881. 
that putting two perpendicular sets of them on the same side of the glass screen would reduce its transparency. Ruling both sides of the glass was not an option either as even the short distance between the faces of the glass made it impossible to focus both sets of lines on the same etching surface. Therefore Mesienbach's screen suffered from the setback of having to be rotated ninety degrees halfway through the exposure, which was an extra step that added to the uncertainty of the outcome. In 1885 Ives one-upped Meisenbach by patenting a cross-line screen that made it possible to turn a negative into a halftone with a single exposure. The cross-line screen was made out of two single line screens cemented together at a ninety-degree angle with the ruled sides placed in contact with one another in order to solve the focusing problem. In 1893, a joint venture between Ives and Max Levy marked the beginning of commercial halftone screens that were marketed by their Philadelphia company, which bore Levy's name. This contributed to the rapid increase in the number of halftone photographs that appeared in American publications during the 1890s, despite the reluctance of many printers and continued resistance on part of engravers and artists. ${ }^{8}$

The art of line engraving had become a large industry by the $1890 \mathrm{~s}$ and those who made their livings as engravers showed disdain for the halftone photograph, which threatened to destroy their livelihood. Engravers

\footnotetext{
8 Carl Hentschel, "Process Engraving," Journal of the Society of Arts 48, no. 2,474 (1900): 461-474; "Halftone Photo-Block Printing," Anthony's Photographic Bulletin 23 (1892): 438-442.
} 
defended their art with claims that it was superior to photography in its artistic, as well as its monetary value. Writing for The Century Magazine 9in 1895, W. Lewis Fraser commented on the various methods of reproduction used by the magazine's art department, which included both line engraving and halftoning processes. Engraving was deemed more valuable by the author with his claim that, "In this day of numberless cheap illustrated periodicals, a word in regard to cost may not be out of place... First-class wood-engraving is ten times dearer than a good half-tone."10 Fraser was not referring solely to the price of the images as he also indicated the image quality of halftone reproductions was sometimes inferior to line work as, "The methods employed in The Century's art department in regard to reproduction [were] all devoted to one end- the getting as near as possible to the original, cost not being a consideration." 11 Similarly, in a letter to the editor of The Critic in 1894, line engravings were praised for their artistic superiority. In reference to an engraved portrait that appeared in The Century, an anonymous author claimed, "Here we have something that mechanical engraving can never give-the personality of the engraver, the touch of the artist. In looking at this picture one feels the dignity of the engraver's art."12 Clearly, surmounting technological hurdles was only one of several factors

10 W. Lewis Fraser, "A Word About the Century's Pictures," The Century Magazine 49 (1895): 479.

11 Ibid., 479.

12 "Letter to the Editor," The Critic 25 (1894): 98. 
that contributed to the rise of the halftone; social factors played an equally vital role.

While engraving artists sought to maintain their advantage by touting the superiority of their craft over that of halftone etchers, printers also struggled to overcome challenges in adapting their presses to accommodate halftone blocks. Being used to the relatively deep and large trenches cut by engravers' tools, they were at first confounded by halftone blocks' shallow and intricate grid-works of dots, the depths of which were measured in micrometers. Early on, halftone prints were often less than satisfactory as the smallest miscalculation in the amount of pressure applied to the plate resulted in an image that was either too faint or too dark to discern any detail. Additionally, rough paper that yielded good results when printing raised type and line engravings proved unusable when printing halftones, as did many kinds of ink, all of which had to be discarded in favor of materials that were better suited to the delicate nature of the halftone printing block. Cleanliness also became a priority in printing shops, previously regarded as, “a synonym for all that was dirty, foul, and generally objectionable," because even the smallest alien particle or a single drop of oil on the etched surface of a block would show up in the print as a bullseye blemish. ${ }^{13}$

Despite opposition on part of engravers whose jobs were at stake, and the reluctance of many printers who wanted to place the blame for failure on

13 T.C. Hepworth, “Journalistic Photography,” 358. 
the new image blocks rather than on the deficiencies of their old printing systems, halftones caught on. During the 1880s the demand for more illustrations in periodicals was demonstrated by competition between the daily newspapers of New York City. The circulation of The World increased after it began regularly featuring wood cut illustrations in 1884, and their competitors, including The Herald and The Sun, followed suit after initially criticizing The World as being un-journalistic, only to find their circulations dropping off. Initially most of the pictures used in these papers were line engravings, but as publishers tried to out-do one another with an ever increasing number and variety of illustrations, they began using halftoning because it was faster than line engraving. ${ }^{14}$

A survey of several leading popular publications from the 1880s and '90s shows the rapidity with which halftone photographs came to dominate the pages of periodicals. ${ }^{15}$ Leslie's Illustrated Newspaper, a weekly publication devoted to providing illustrated coverage of major events began in 1855 under the lead of the accomplished illustrator, Frank Leslie. Only thirty copies of the first edition sold, but by 1897 circulation had reached 65,000 copies a week, making it one of the most widely read papers in the United

14 "Photo-Engraving On The Newspapers," Anthony's Photographic Bulletin 26, no. 1 (1895): 206-207.

15 The photo counts for Frank Leslie's Illustrated News and Harper's New Monthly Magazine (Figures 3.2 and 3.3, respectively) were taken from, Christopher R. Harris, "The Halftone and American Magazine Reproduction 1880-1900," History of Photography 17, no. 1 (1993): 77-80. 
States. The papers were comprised of sixteen large pages, each page having one or two illustrations. Throughout the first three and a half decades of the paper's life, the pictures were printed from line engravings on wood-blocks and metal plates, some of them being copied by hand from photographs. However, during the 1890s, Leslie's began using halftone photographs and nearly ceased printing other forms of illustration by 1900 . Over the course of fifteen years the number of illustrations in Leslie's more than doubled, going from twenty in 1880 to forty-eight in 1900 (Figure 3.1).16

The illustrations in Harper's Monthly Magazine followed a similar course as those of Leslie's, though the transition was a bit different as Harper's relied heavily on publishing traditional art and thus used halftoning to reproduce drawings and paintings rather than photographs. Founded in 1850, Harper's specialized in publishing serialized versions of popular British novels, as well as essays on politics, international affairs, the environment, science, industry, culture, and other pertinent issues. The intent of the publishers was to provide the public with an educated perspective on literature in an affordable and accessible form, something that the American publishing industry lacked at the time. In the first issue, an introductory editorial stated that each ensuing issue, "will contain as great an amount and

16 “Frank Leslie's Weekly," Accessible Archives, 2015, April 17, 2015, http://accessible-archives.com/frank-leslies-weekly/; Christopher R. Harris, "The Halftone and American Magazine Reproduction," 79. 
variety of reading matter and at least as many pictorial illustrations, and will be published in the same general style, as the present." 17

Between 1850 and 1860 this structure proved effective in selling magazines as circulation increased from 7,500 copies to over 200,000 monthly. The magazine's success was partly due to the fact that it was the first in the United States to use wood-cut illustrations on a wide scale. The Harper brothers promised to spare no expense in producing, "a popular circulation unequaled by that of any similar periodical ever published in the world."18 Thus, they were somewhat reluctant in accepting halftone photographs.

The innovation of the halftone provided a means of creating dozens of new periodicals, the cheapest of which sometimes boasted of having more than one-hundred illustrations in their pages. Though popular, they were not favored by all. In the words of T. C. Hepworth, "ease of production has had the natural result of much rubbish being palmed off upon the public." 19 As was the case with The Century, Harper's art department saw photographs as having less merit than other forms of more traditional artwork. Though the number of halftones from photographs decreased between 1895 and 1900, the number of halftones from artwork increased (Figure 3.3). Staying true to the

\footnotetext{
17 "A Word at the Start," Harper's New Monthly Magazine 1, no. 1 (1850): 1 .

18 Ibid.

${ }_{19}$ T.C. Hepworth, “Journalistic Photography,” 357.
} 
promise of providing quality content in a consistent format, Harper's embraced halftone technology as a means of reproducing traditional artworks rather than photographs. In an age marked by the rise of hundreds of cheap pictorial periodicals, Harper's wanted to maintain the status of a publication aimed at a discriminating audience. The content of their illustrations was thus their primary concern, and photo-mechanical reproduction seemed to preserve the character of the original artwork better than engraving, even though technicians made subjective decisions during the halftoning process, which eliminated color and relegated three dimensional objects to two dimensions.

While popular periodicals used illustrations to increase their circulations, the engineering press began demonstrating the increasing importance of photography to engineers. Founded in 1866, Engineering and Mining Journal absorbed seven other trade journals by 1917 to become one of the nation's leading industrial trade publications. Issued weekly, the journal provided articles that discussed the latest innovations in mining machinery and equipment, as well as stock quotations and news regarding mining and other industries around the world. The journal effectively shrank the world by conveying information that was crucial to companies, engineers, and investors, who all needed to make decisions based on current conditions in an increasingly complex economy. The illustrations of $E \& M J$ show there were publications intended for professionals that recognized the potential of 
halftone photographs beyond using them as a means to attract readers. Though readers of $E \& M J$ likely welcomed photographs of subjects traditionally shown in the journal's line engravings, like general exterior views and machines, halftones were better able to reproduce technical subjects like photo-micrographs of ore samples and $\mathrm{x}$-rays of castings. Additionally, photographs offered a first-hand view of distant sights without subjecting them to the interpretation of artists beyond that of retouchers, who were sometimes employed to bring out details of photographs that would have been lost during the halftone process. ${ }^{20}$

Illustrations were a major component of $E \& M J$ from the beginning, and their numbers grew throughout the nineteenth and early twentieth centuries as other American periodicals took on an increasingly visual character (Figure 3.4). Early on, the majority of the journal's graphics accompanied articles about the design and operation of various machines. For its first full year of publication in 1867, the journal printed 121 line engravings; 119 of them were from drawings of machines including steam engines, pumps, furnaces, and drills, as well as host of graphs and charts concerning the same. ${ }^{21}$ Equipment and data vital to the work of engineers and comprised the largest category of pictures even after halftone photographs overtook line engravings in the early twentieth century. Thus,

20 Engineering and Mining Journal 29 (1930): 1.

${ }^{21}$ Engineering and Mining Journal 2-4 (1867). 
the illustrations that accompanied articles in $E \& M J$ served primarily as a means of educating engineers on technological developments in their respective fields. However, pictures that showed the details of the facilities at distant mines and factories or the faces of prominent figures within the business community brought distant sights to the reader and imparted a visual character that enhanced the text. This second category was present all along, but it grew in popularity in the 1890s when halftone photographs began competing with line engravings for space (Figure 3.4).

Illustrations were common in large advertising sections that punctuated the issues of some volumes. Most of them showed equipment and machinery, but they served a different purpose than the pictures accompanying the primary content. Overall, the advertising illustrations were smaller and less detailed, meaning they were primarily intended to make the advertisements stand out and to capture the reader's interest rather than to communicate technical details. Moreover, they were probably printed using plates provided by the advertisers themselves and therefore do not represent decisions made in-house at $E \& M J$. This explains why the ad sections showed less dramatic results in the years after 1886 when halftone photographs began appearing in the articles.

For example, the line-engraved, measured cross-section shown in Figure 3.5 is from an 1887 volume of Engineering and Mining Journal. It illustrates differences between the old and new blast furnaces used at the 
South Chicago Iron Works, a company that was the topic of several articles printed that year. The engraving is typical of the journal's early illustrations in that its primary purpose is schematic, as it clearly communicates details that would have otherwise required lengthy and confusing written descriptions. In contrast, an illustrated advertisement for the Gates Rock and Ore Breaker (Figure 3.6) appeared in the advertising sections throughout E\&MJ'S 1889 volumes. Though the line engraving offers a general impression of the machine, the fact that it only occupied approximately one-sixteenth of the page suggests it was intended to draw the reader's eye to the ad, more than to illustrate the details of the machine.

In volumes where the ad sections appeared, the number of illustrations was always larger than in volumes where the advertisements were not present. ${ }^{22}$ The 1875 volumes have a total of 213 line engravings, almost twice as many as 1867 , but the increase is due to the fact that most of them are advertisements. In 1880 with the ad sections gone once again the number of illustrations was less impressive. Standing at a total of forty-four for the entire year, twenty-five of the engravings show machinery and equipment, a category that continued to make up the majority of illustrations. Though the illustrations in the ad sections affect the engraving counts significantly, they have little bearing on the halftone counts. Advertisers lagged behind in 
accepting halftones since the great majority of illustrated advertisements used engravings into the 1930s.

Though the number of illustrations used in conjunction with the journal's primary content decreased between 1867 and 1880, it rose to 134 in 1886 despite the fact that the advertising sections again were not present. Eighty-one of the illustrations show equipment and machinery and the rest are an assortment of general exterior views of industrial sites, portraits, maps, and cross-sections of mines, a similar variety of subject matter as the pictures in earlier volumes.

This began to change, albeit slowly at first, with the arrival of the first halftone photographs in E\&MJ in 1886. Of the three photos printed in the volumes for that year, one was of an excavation for the Croton Aqueduct in Yonkers, New York, (Figure 3.7). The photo is a general view of the work site where a trench was being cut to construct an underground aqueduct. Upon viewing the image it is immediately clear that it is a photograph and that it was not produced using a line engraving. It exhibits the continual tones characteristic of photographs, and no marks made by engraving tools are visible. Despite the fact that the image is a halftone photograph, it does not stand out from other illustrations because general exterior views were a common sight in E\&MJ. The picture beneath the view of the aqueduct illustrated an article on Rand mining drills. It shows how retouching was able to bring out details while simultaneously giving the photo an artificial 
look, almost like a painting. Part of the reason the photo required retouching was because the photographer was unable to achieve proper contrast using a combination of electric light and magnesium flash light. The third halftone photograph that appeared that year was a portrait that accompanied the obituary of Nathan Waller, a prominent figure at the Rand Drill Company. Though portraits and general exterior views are entirely different subjects, these two images are similar in that they simultaneously represent change and continuity. The halftone process used to produce them was new, but the subjects shown in the halftones were much like those shown in the journal's line engravings. Additionally, they were displayed in the same manner, taking up about a third of the page with brief captions describing their content. Except for the continual tones characteristic of photographs, they do not stand out significantly from the line engravings.

As the journal began relying more heavily on halftone illustrations in ensuing volumes, the variety of the subjects shown in the illustrations began to broaden out. For 1887, a total of four photographs accompanied an article about the New South Chicago Iron Works; one showed a general view of the works and the other three were portraits of the company's president, superintendent, and chief engineer. In 1888, the volume's primary content was illustrated with a total of seventeen photographs that represented a 
departure in subject matter from those in earlier volumes, as in addition to the usual portraits they included photo-micrographs, and steel ingots.

In 1888 images of machinery and equipment still made up the majority of the illustrations in the primary content of $E \& M J$, but they were all line engravings. Though the advertising sections appeared that year, the previous year's shot of the South Chicago Iron Works was the only photograph reused in them. It was not until 1889 that photographs of machinery appeared, accounting for nine of the 29 photos. The fact that most of the journal's illustrations from the very beginning were of equipment and machinery shows that this was the most important category of subjects, and may partially account for initial reluctance to print such pictures using halftone plates.

At first, many of the halftones printed in $E \& M J$ were of relatively poor quality in comparison to the line engravings and it is likely that the journal, along with the companies who advertised in it, did not want to take the chance of important illustrations getting messed up. An article in volume 47 (pg. 411) about the Osgood Dredge Company of New York included a muddy, low contrast halftone photograph of a boom dredge (Figure 3.8). Though the halftone reappeared in an advertisement for Osgood later in the same volume, in volume 48 (pg. VII) ${ }^{23}$ from later that year, it was replaced with a crisp line-engraving taken from the same photograph (Figure 3.9). Evidently,

23 Pages of the advertising sections are numbered with Roman numerals. 
Osgood was dissatisfied with the quality of the halftone, which made it difficult to discern details of the dredge and may have reflected poorly on part of the company. ${ }^{24}$

General exterior views, like the one of the South Chicago Iron Works (Figure 3.10), were a common subject of the illustrations in E\&MJ. Printed in 1887, the photograph was one of the first halftones to appear in the journal. The image's haziness demonstrates that halftone photographs, especially early on, were not always superior to line engravings in regard to their clarity. However, the speed and relative ease of reproducing images with the new technology spurred it on. Additionally, the idea that photographs were more true to nature than engravings likely influenced printers catering to the scientific needs of engineers. It is also likely that halftones were a welcome sight to the journal's readers since the technology allowed the number of illustrations to increase drastically in the ensuing decades.

Though the results were not always excellent, $E \& M J$ continued using halftones in greater numbers, a decision that left its mark not only on the number of illustrations in its volumes, but on the variety of subjects shown in them. In the late ' 80 s and early ' 90 s, equipment, exterior views, and landscapes continued to dominate the illustrations, but things like a picture of Roman artifacts found at a Rio Tinto Mining site (Figure 3.11) marked a

24 Engineering and Mining Journal 47 (1889): 411, IX; Engineering and Mining Journal 48 (1889): VII. 
departure from the traditional focus on technical detail. Like other early halftones, this one exhibits low contrast and poor resolution, making it difficult to discern the tools from the rock that props them up. A quality line engraving would probably have done a better job of showing the tools.

However, the subjects of the image are unlike that of most other illustrations, and probably had little bearing on the work of engineers. Thus, the printers most likely would not have bothered to obtain a line engraving of the tools, but the speed and ease of halftoning encouraged them to sometimes depart from their primary subjects of illustration.

Photographic technology also made it practical to capture images that would have been difficult to record with drawings and line engravings. Uniting the camera with the microscope led to the rise of photo-micrographs of metal and mineral samples used in quality control (Figure 3.12). Additionally, rapid dry plates used in conjunction with flashes allowed photos to be taken in poorly lit places like factory interiors and mine shafts. Halftone printing made it possible to show such images without drawing, thus preserving their photographic appearance and making it easier for printers to include them in the volumes.

During the 1890s, the growing number of halftone photographs demonstrated they were becoming the preferred means of illustration in editorial sections of $E \& M J$. The printers began illustrating the editorial content of the journal with halftones earlier and more extensively than the 
advertising sections. In 1891, all of the images of various tools and farm implements that appeared in a thirteen-page catalog section were printed from line engravings, as were all of the illustrations in the 62 to 64 page advertising sections between the issues of the volumes, while the editorials included 97 photographs. This could have been due to a number of factors.

The illustrations of the editorials were only used one time each, whereas the illustrations in the advertising sections were used repeatedly, for months or even years. Making a single line engraving for multiple advertisements was likely more time and cost effective than making a line engraving for an editorial that was printed only one time. Thus, the use of halftones in editorial illustration was probably a way of speeding up the printing process and saving money. By comparison, the engraving plates used in the advertisements are usually much smaller than the plates used to illustrate articles, meaning they wouldn't have taken as long to make. The small spaces allotted for individual advertisements did not warrant halftones as a photograph measuring only an inch or two may have been less than impressive. This is especially true since the quality of engravings was more reliable and they often yielded better contrast.

During the next decade, the ratio of photographs to engravings continued to rise. The 1900 volumes had almost as many photographs as line engravings, 269 halftones versus 377 engravings. In 1900, pictures of equipment, industrial sites, portraits, and a handful of x-rays were shown 
mostly with photographs, the line engravings being primarily reserved for measured drawings and cross-sections of machines. Even though halftones were competing with engravings, there were still applications, such as schematics, in which traditional engraving methods proved equally effective because photographs of them did not appear much different. Moreover, photographs were fast and easy to produce but they lacked the artist's abilities to interpret, extrapolate, and show things that the camera cannot see, such as the inner workings of a machine. In this sense, photographs were more objective than drawings. They showed things in a similar manner to how the eye perceived them firsthand.

In the first quarter of the twentieth century the journal became more photographically-oriented and halftones replaced line engravings as the standard type of illustration. In 1915, the volumes had a total of 848 photographs from halftones that were accompanied by a handful of measured drawings of buildings and the inner workings of machines. In 1930, the journal had a total of 792 photographs, which was fewer than in 1915, but there were more photographs per page in 1930 . There was approximately 1 photograph for every two pages since both volumes for 1930 totaled 1,276 pages, compared to 2,214 pages or approximately one photographs for every 3 pages in 1915 .

Overall, changes in the appearance of American periodical literature during this time resulted in increasingly visual publications that relied on 
new technologies to put more pictures in their pages. That halftone photographs greatly outnumbered line engravings in $E \& M J$ by 1930 shows they had become the norm for illustration, except for certain applications in which augmented views of subjects were required. This was largely the result of technological innovations, but social factors played a significant role as well. A series of modifications in halftoning processes put relatively simpleto-use screens on the market. This encouraged the use of halftones because publishers eventually proved keen on accepting changes that let them print pictures more quickly. Unwilling to adapt the new technology at first, printers eventually refined their techniques to overcome obstacles that had previously discouraged them from using the touchy etchings. Though, considering that other periodicals and journals began using halftones extensively during this period, the printers of $E \& M J$ may have viewed photographic illustrations as a necessity in order to keep up with the times, and to satisfy readers' preferences. 


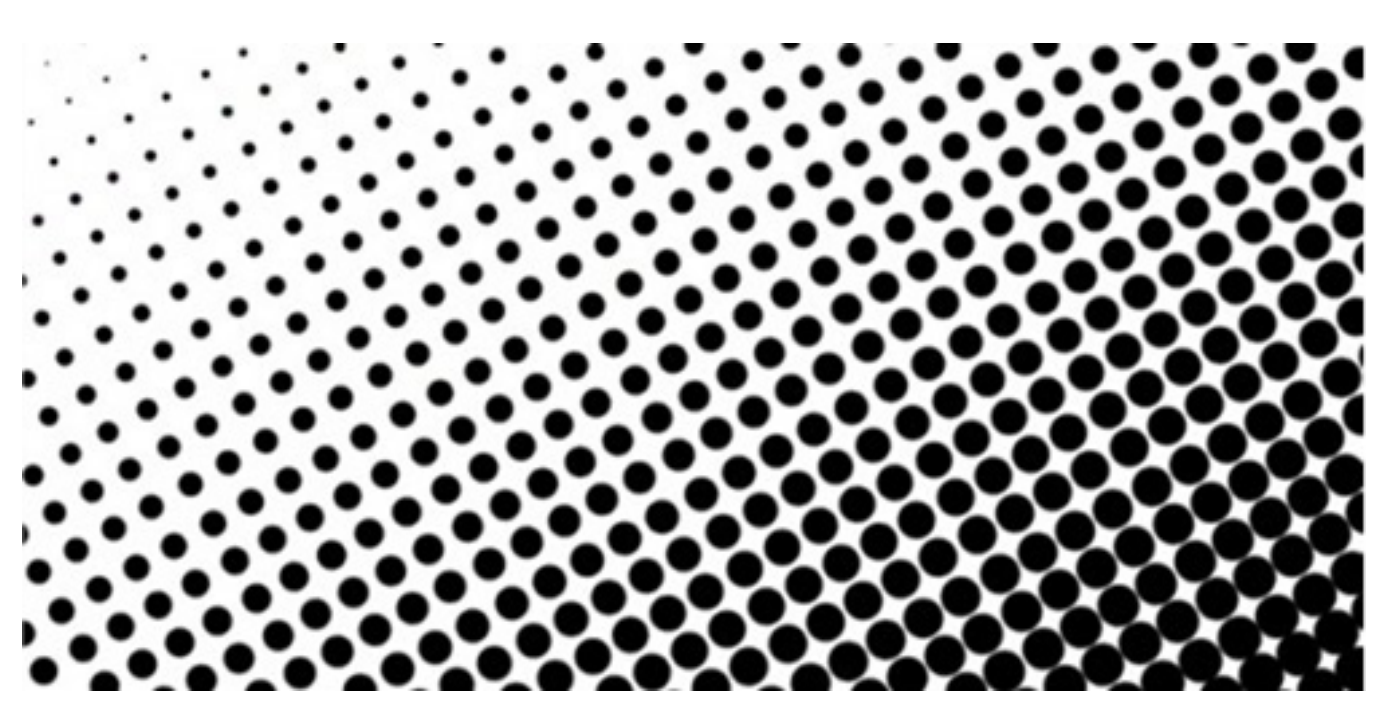

Figure 3.1: Close up illustrating how halftone dots of varying size represent continuous tones of photographs. By R.D. Anthony.

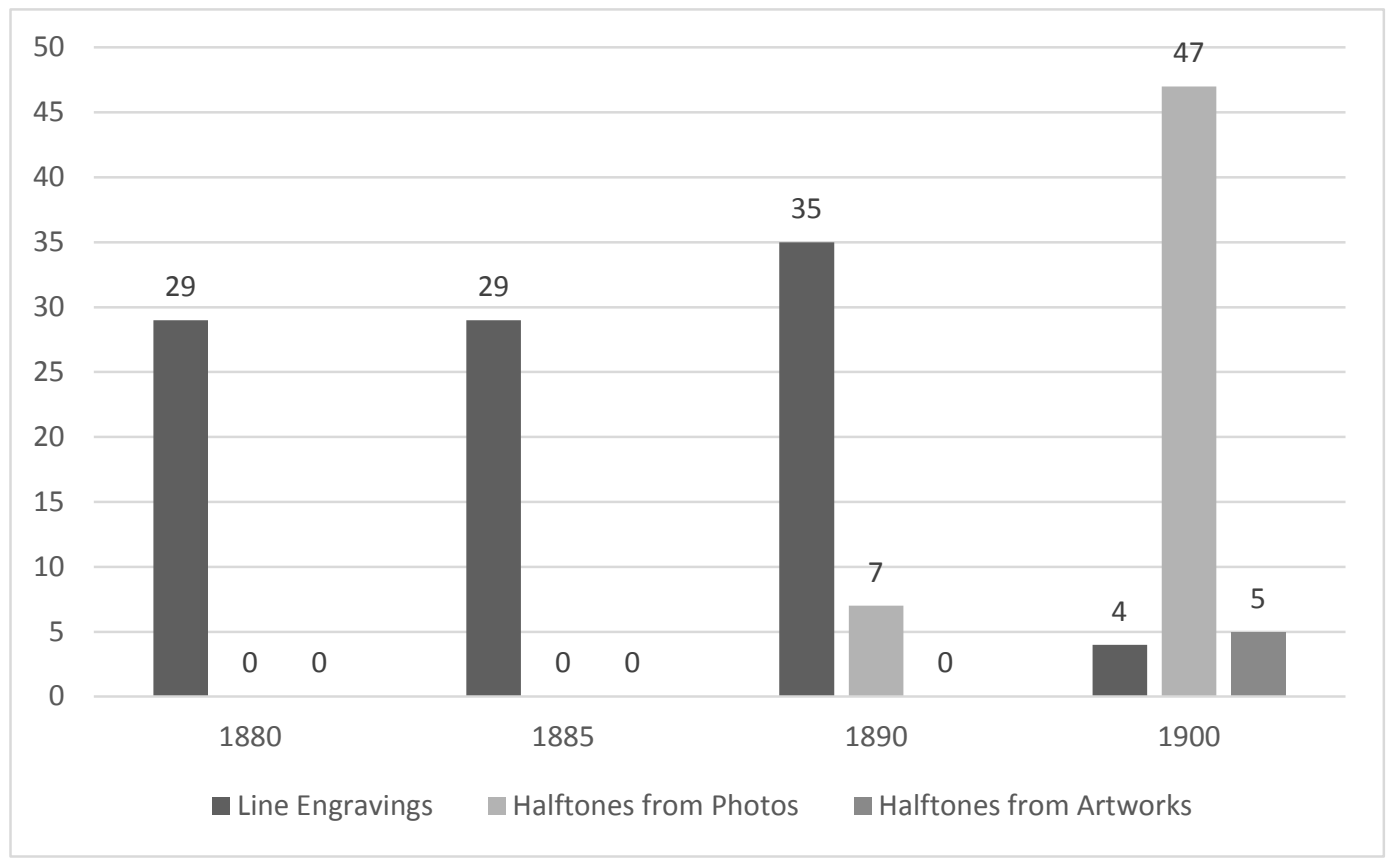

Figure 3.2: Line Engravings versus Halftones in Frank Leslie's Illustrated Newspaper, March 1880 through March 1900. 


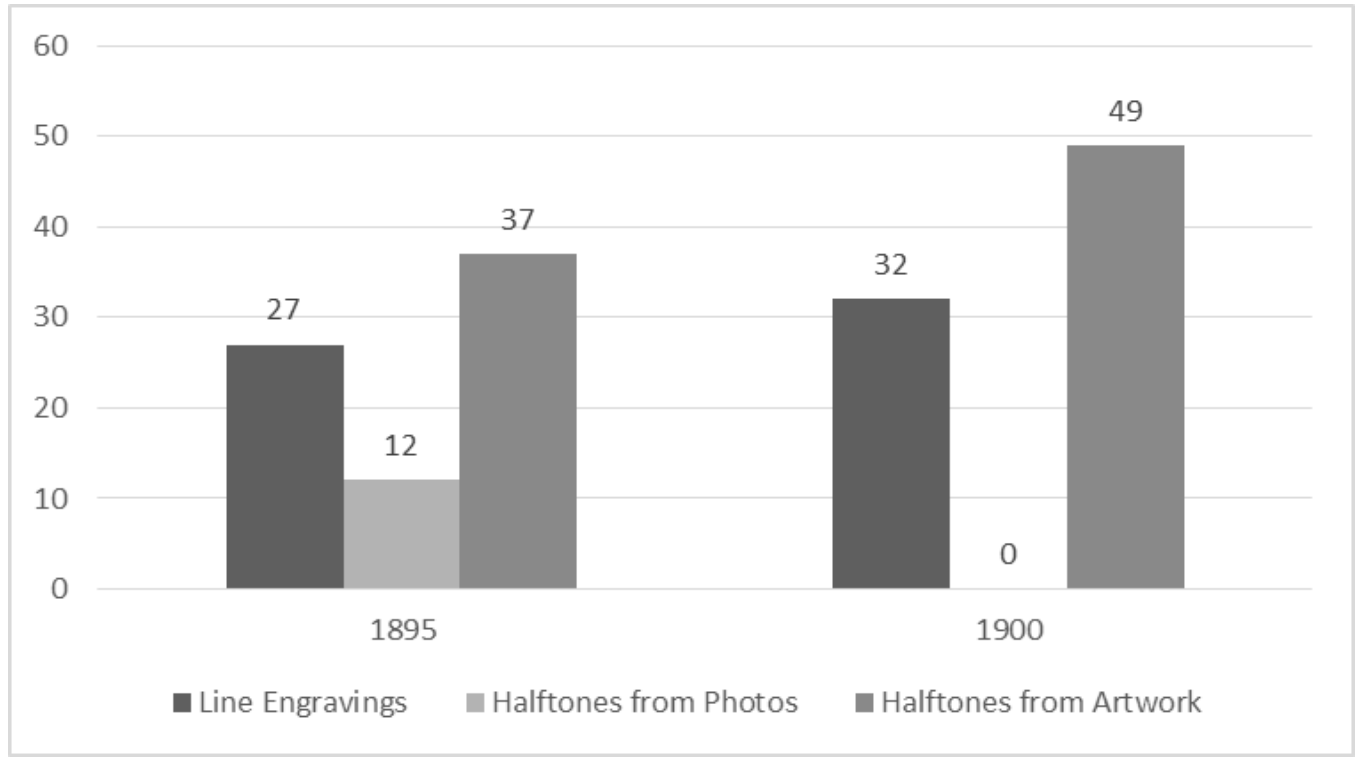

Figure 3.3: Line Engravings versus Halftones in Harper's

Monthly Magazine, March 1895 and March 1900.

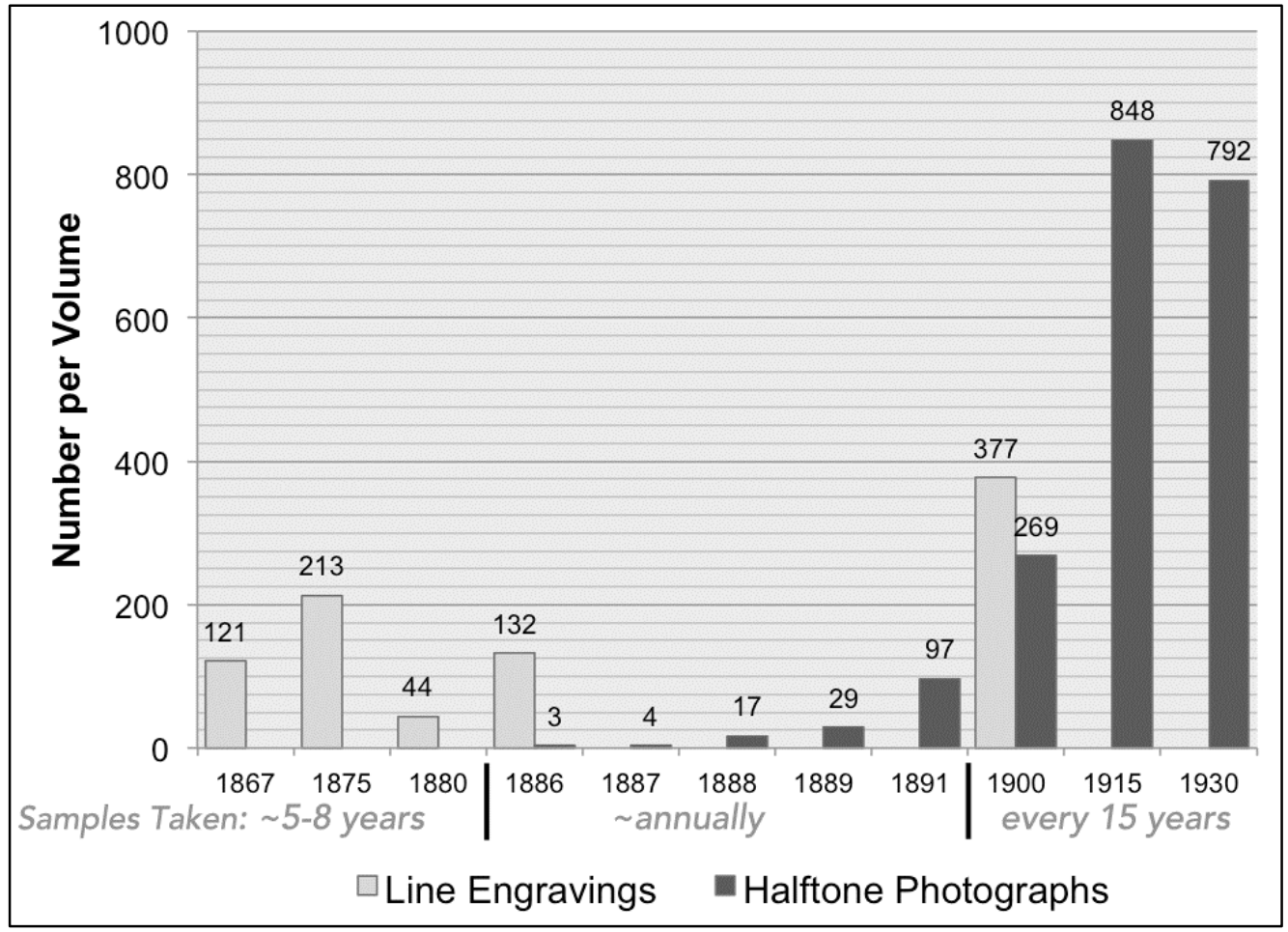

Figure 3.4: Line Engravings versus Halftones in Engineering and Mining Journal, 1867-1930.1 


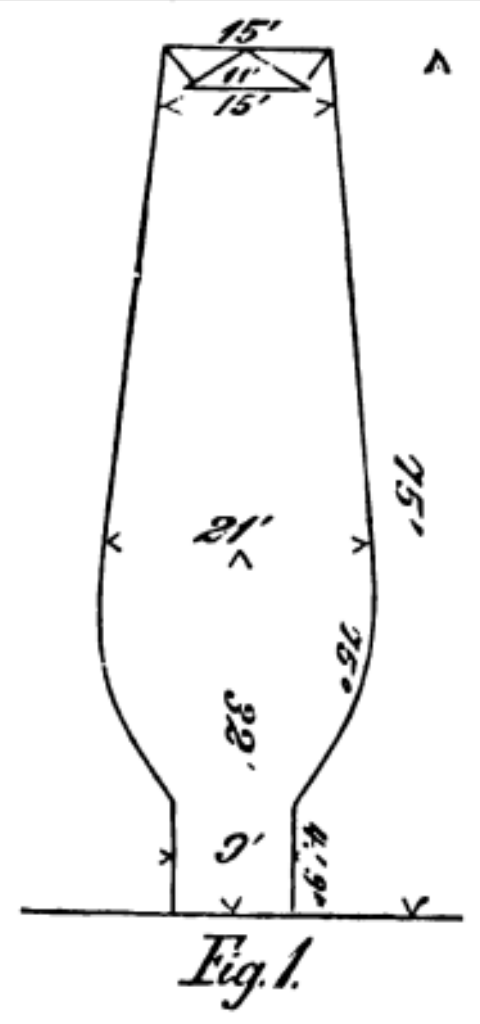

Lnew of Orional Fuaxaces.

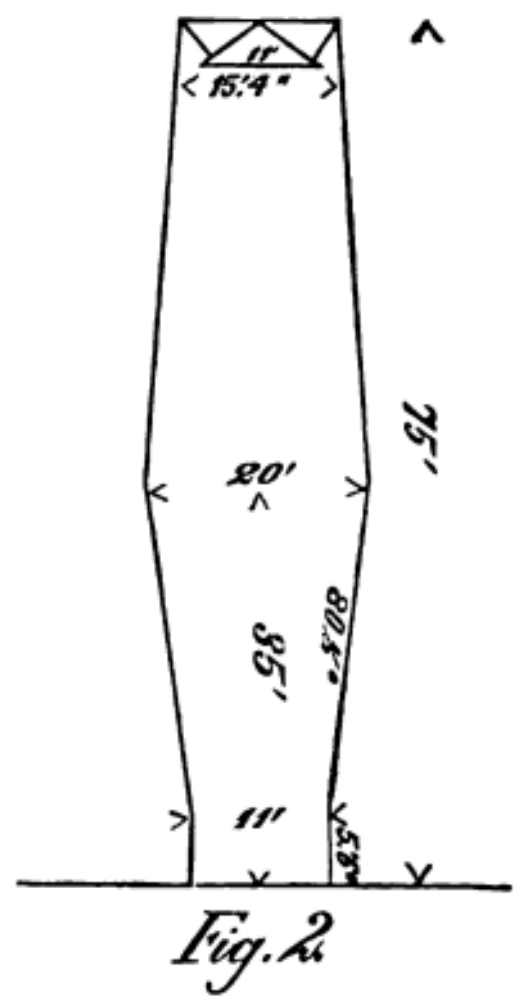

I.INES OY NEW-FURAACES.

Figure 3.5: Comparison of old and new furnaces at South Chicago Iron works. Engineering and Mining Journal 44 (1887): 41.

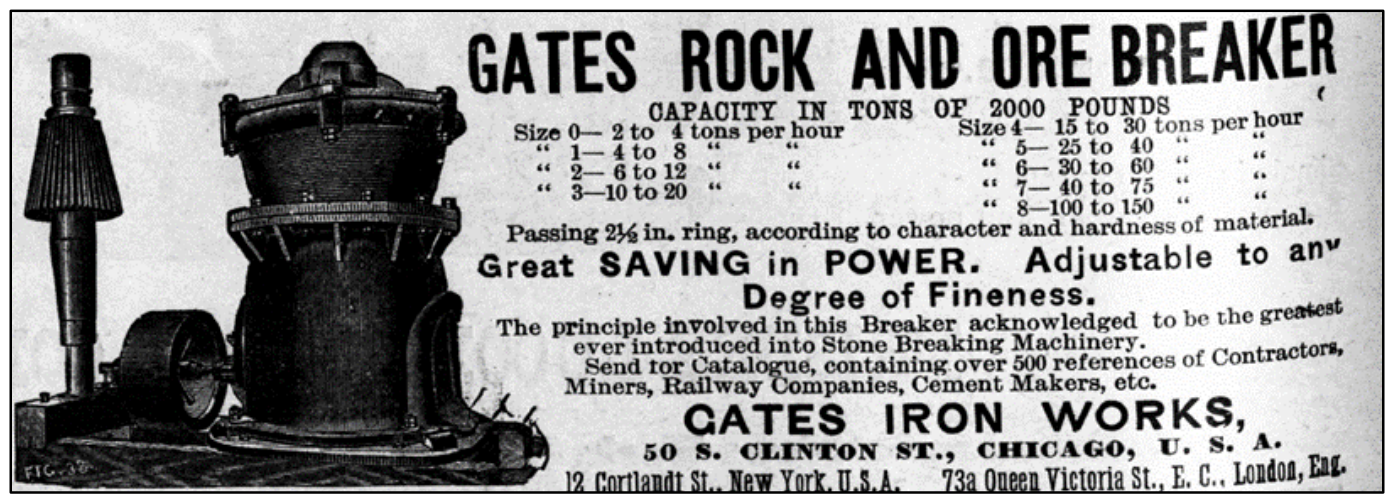

Figure 3.6: Advertisement for Gates Rock and Ore Breaker. Engineering and Mining Journal 48 (August 10, 1889): $x x$. 


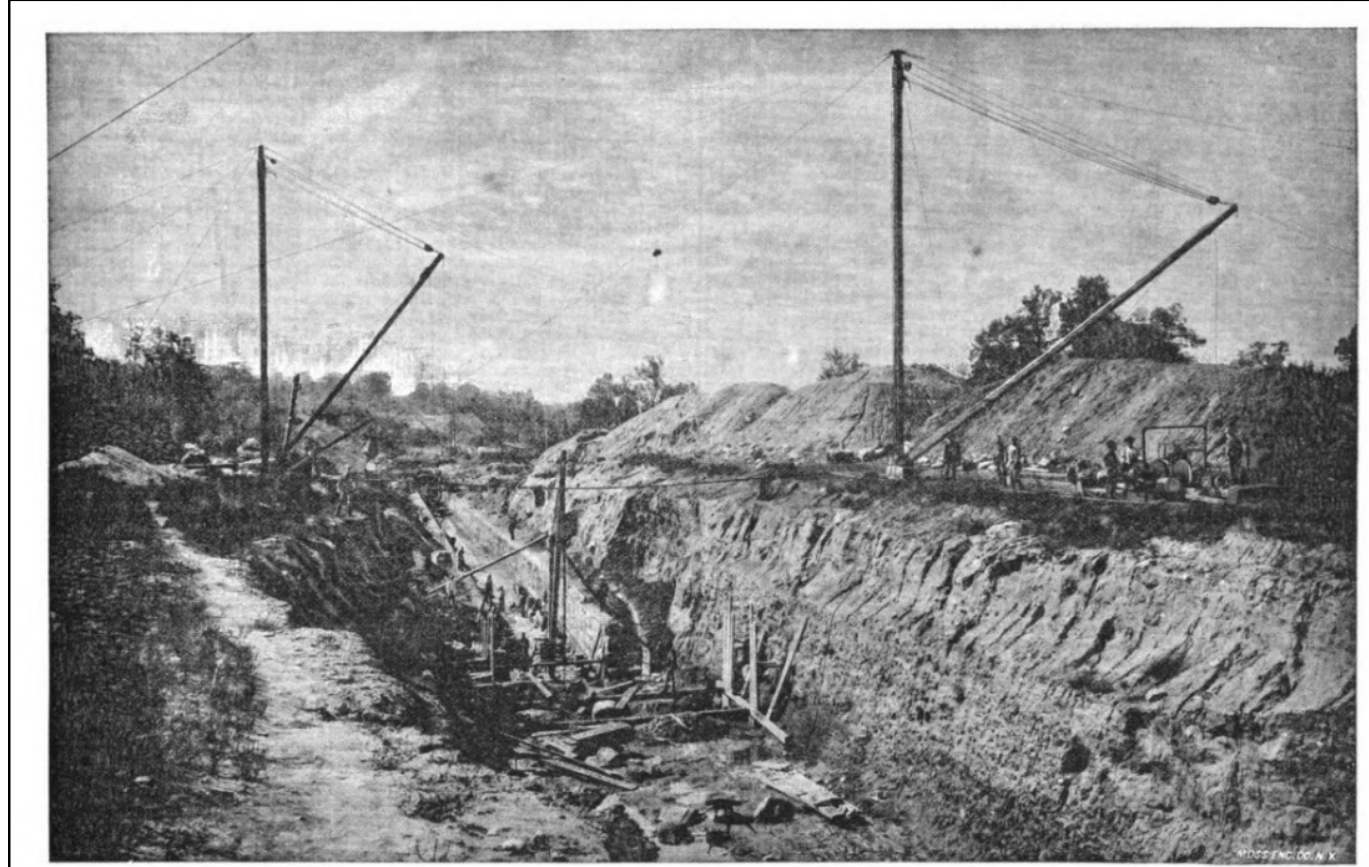

OPEN CUT AT SOUTH YONKERS, NEW YORK-NEW CROTON AQUEDUCT.

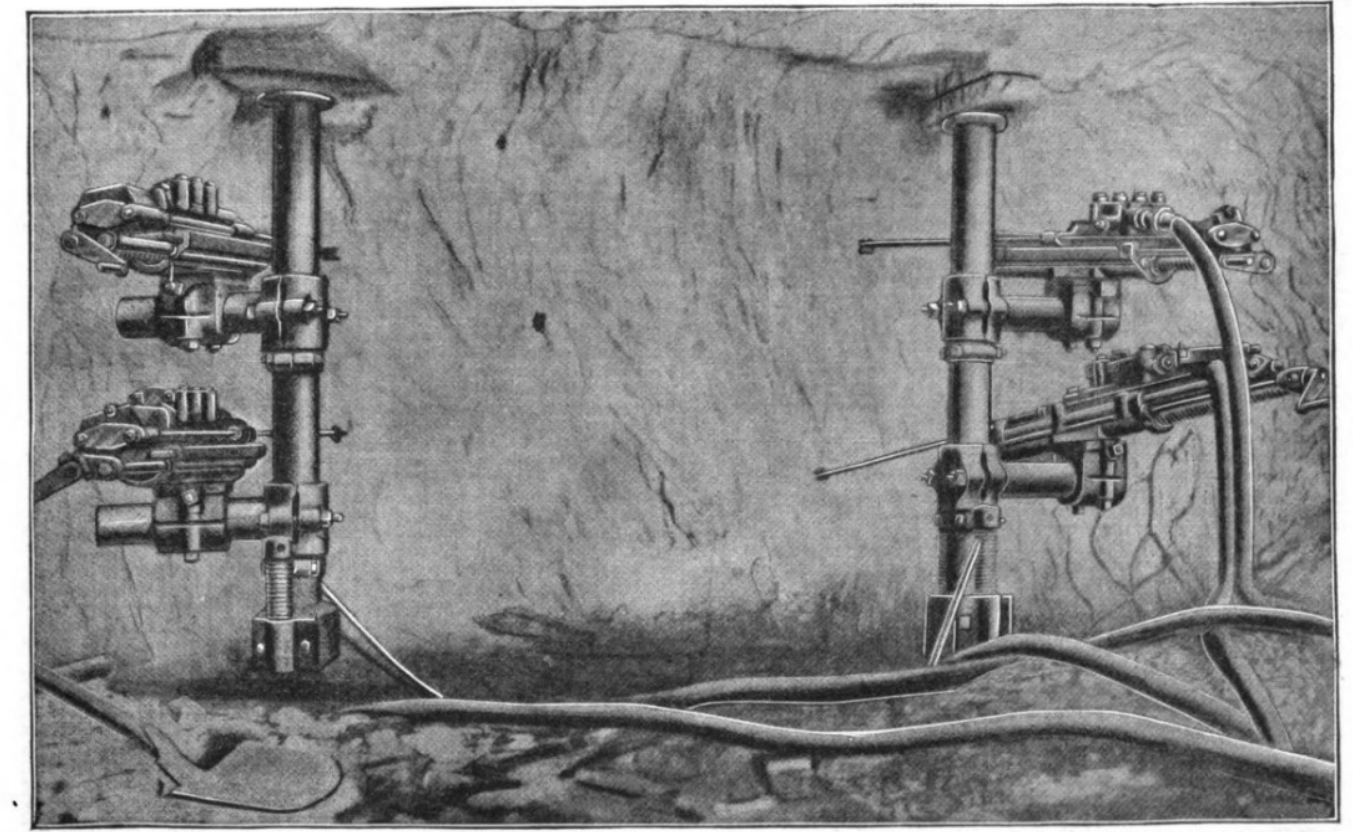

METHOD OF MOUNTING FOUR RAND DRILLS ON TWO COLUMNS.

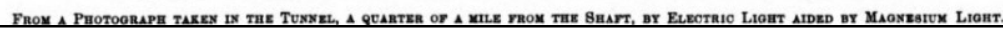

Figure 3.7: General exterior view of excavation for Croton Aqueduct in New York State (top). Halftone of Rand mining drills from retouched print (bottom). Engineering and Mining Journal 41 (1886): 319. 


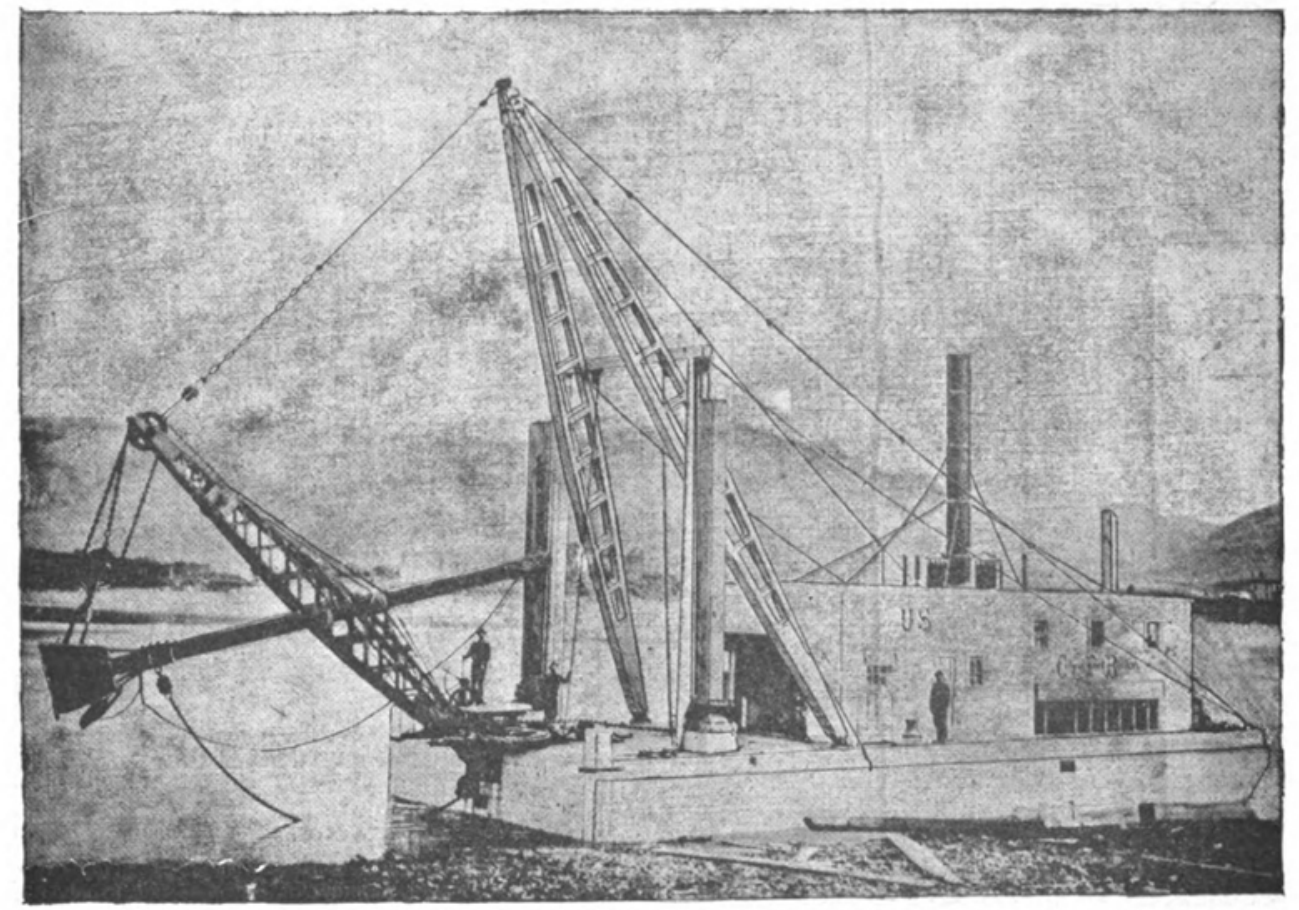

OsGOOD BOOM DREDGE.

Figure 3.8: Poor quality halftone of Osgood boom dredge.

Engineering and Mining Journal 47 (1889): 411.

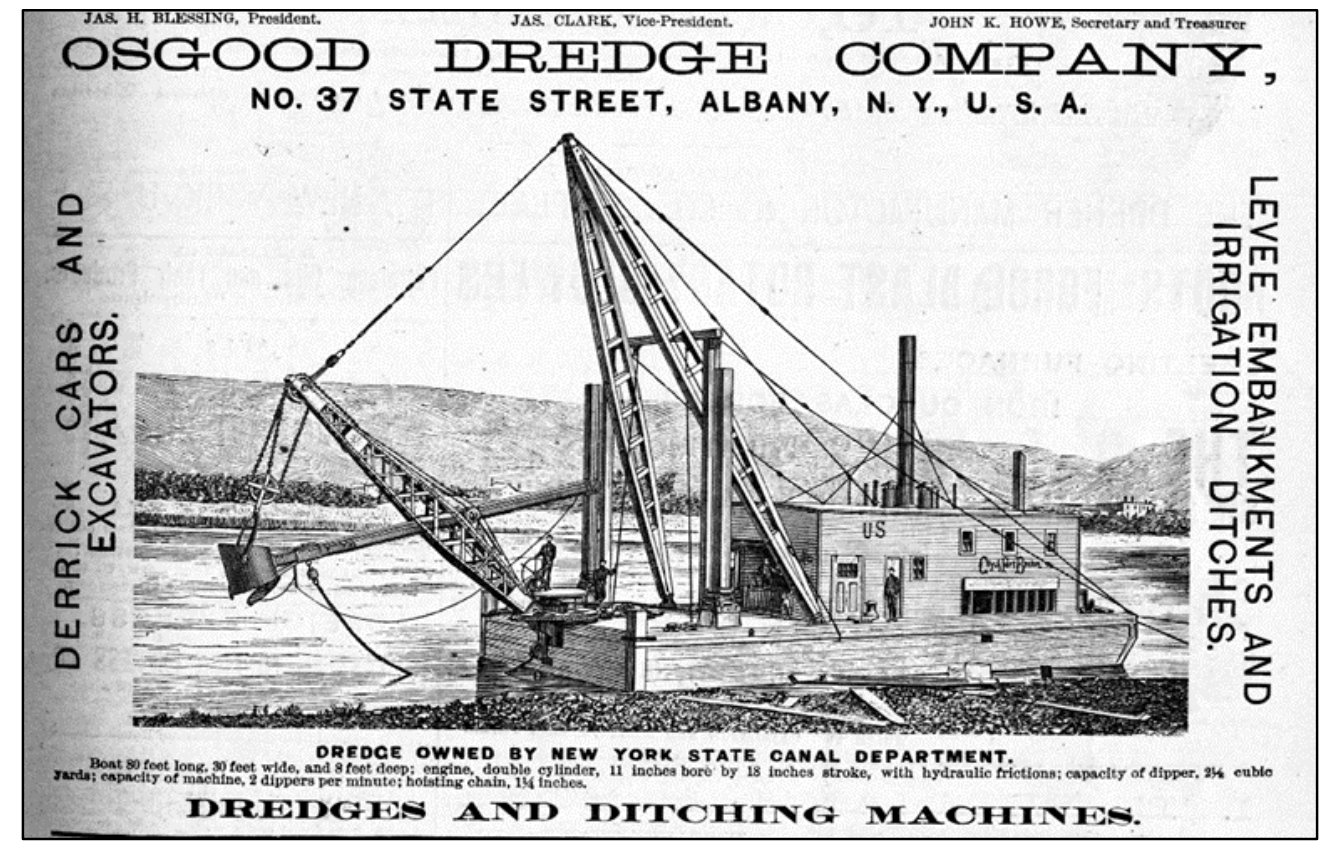

Figure 3.9: Line engraving of Osgood boom dredge. Engineering and Mining Journal 48 (1889): vii. 


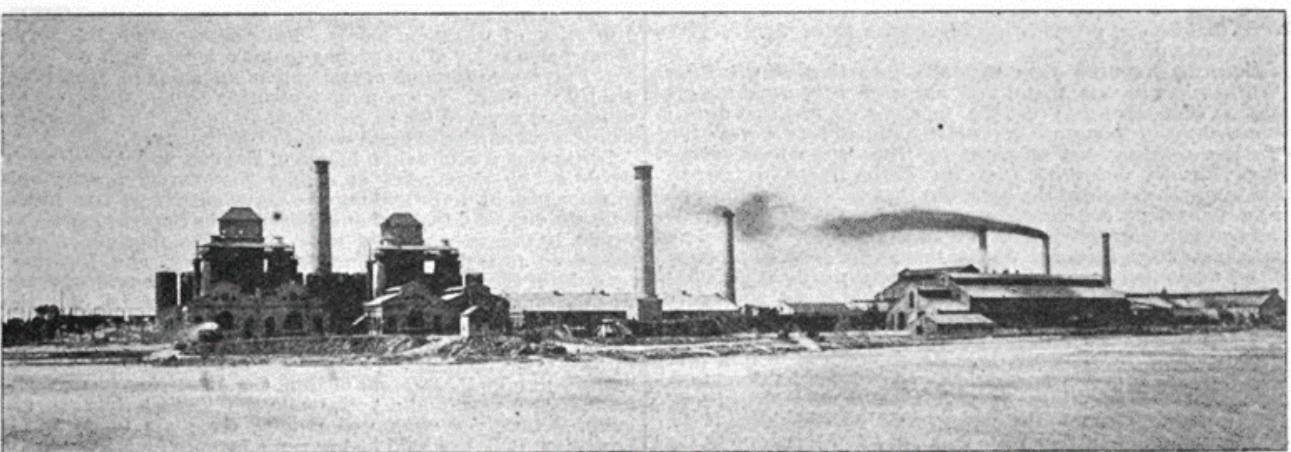

THE SOUTH CHICAGO WORKS (NOBTH CHICAGO ROLLING-MILL CO.).

Figure 3.10: General Exterior View of South Chicago Irons Works Rolling Mill. Engineering and Mining Journal 44 (1887): 43.

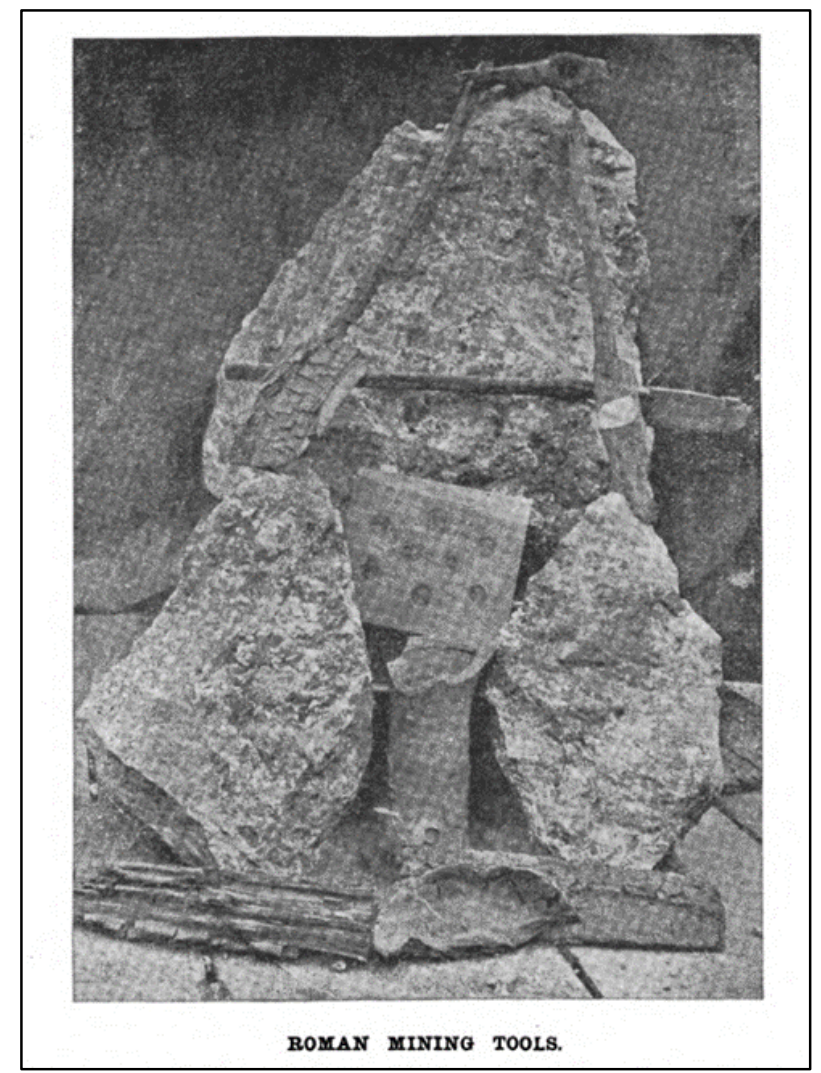

Figure 3.11: Roman mining tools.

Engineering and Mining Journal 45 (1888): 125. 


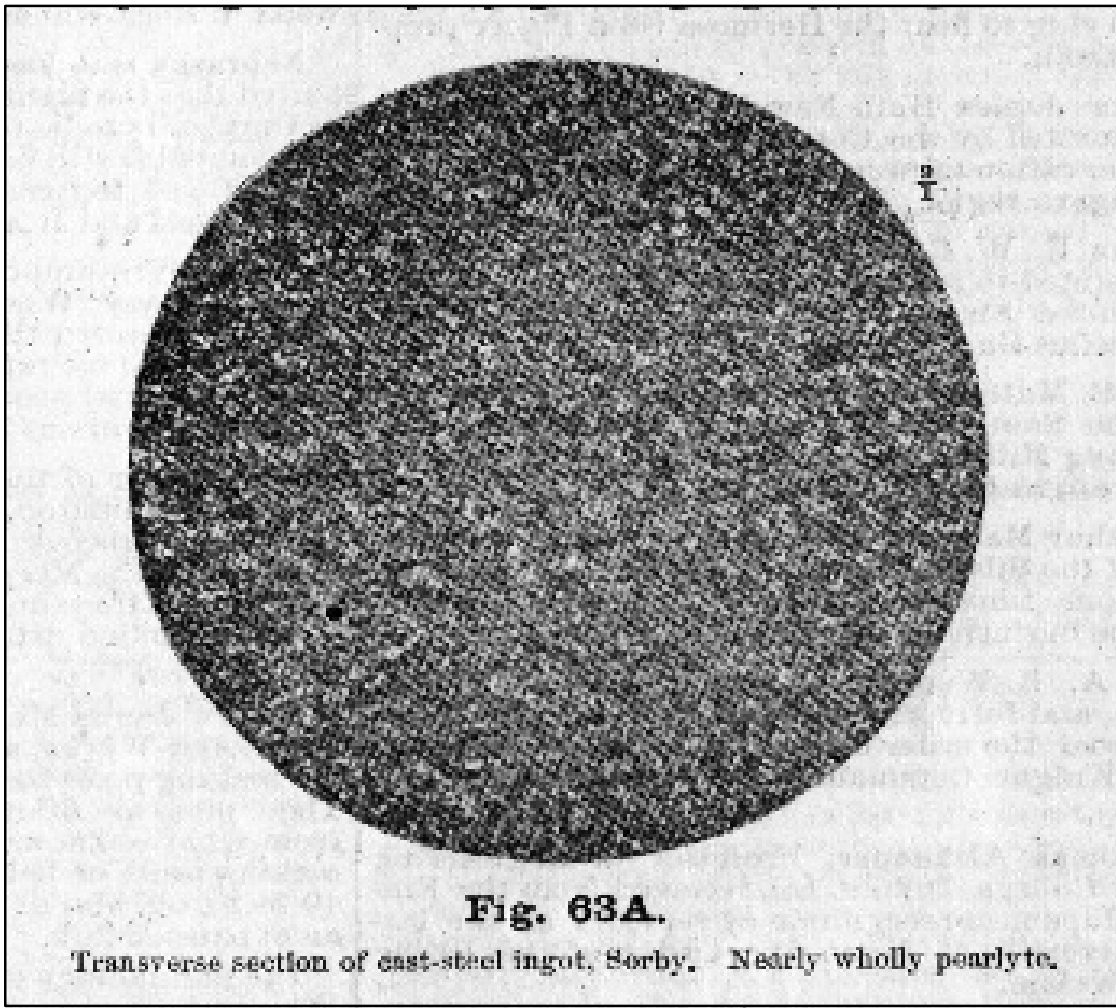

Figure 3.12: Transverse Section of Steel Ingot. One of the first photo-micrographs printed in E\&MJ. Engineering and Mining Journal 46 (1888): 375. 
Chapter Four:

Industrial Photography and the Lake Superior Mining District, 1880-1931

The photo collections of three Michigan mining companies Calumet \& Hecla, Quincy, and Cleveland-Cliffs Iron show that their needs differed somewhat from those of large companies that relied on marketing to the general public. The value of photographs as illustrations in advertising and in technical writing is shown by the halftones that appeared in the engineering and industrial press in the 1880 s, and the continual increase in their numbers over the ensuing fifty years. Additionally, a host of technical applications for photography including photo-microscopy and photo-surveying were developed and written about in an extensive body of literature. That photography was also on the rise with industrial companies is supported by the fact that two of Michigan's largest mining ventures, The C\&H mining company, and the Quincy mining company, began documenting their property in photographs during the mid-nineteenth century. However, contrary to what contemporaneous experts on industrial photography were saying about the importance of photography to a wide range of business and technical applications, not all companies began keeping photographic records until well into the twentieth century. The Cleveland Cliffs Iron (CCI) Company, another of Michigan's large mining ventures didn't begin 
documenting its operations in photographs until 1910, and even then the effort was piecemeal.

These three case studies highlight important points regarding the history of industrial and engineering photography in that they show marked similarities, as well as striking differences with leading opinions regarding industrial photography. All three companies used photographs to some extent during the 50-year period when industrial photography arrived and matured into a well-developed field with its own body of literature. Additionally, the companies' use of photography greatly increased during this time frame as photos from the late nineteenth and twentieth centuries are more numerous than those from the mid-nineteenth century. Additionally, all three collections show a strong focus on infrastructure, machinery, and equipment, which is similar to the categories of halftone photographs that were being printed in the engineering press. In contrast, the companies' collections do not encompass the entire breadth of subjects laid out by the articles discussed in chapter two.

Photography was not as universally applied to industrial pursuits as authors like John Graff made it appear, nor as methodically as David Nye suggested. Graff and other authors identified dozens of uses for photography, and S. Ashton Hand went as far as to give detailed instruction on taking pictures of industrial subjects for halftoning. However, the records of $\mathrm{C} \& \mathrm{H}$, Quincy, and CCI show that the approaches to photography presented in how- 
to articles may have been the exceptions rather than the rule. According to Graff, the photographic department he oversaw at the Berlin Mills Company in Berlin, New Hampshire was intended to serve all fifty of the company's other departments and thus it needed to be highly organized in order to make sense out of extensive assemblages of photos. In Graff's opinion,

It should be needless to mention that explorers, estimators, inspectors, commercial reporters and agents should always be equipped with the best of hand cameras and all of their reports and observations should be illustrated, the films or plates being developed, printed, classified, and filed in the company's own photographic department. ${ }^{1}$

Though this may have been an ideal approach to photography, neither $\mathrm{C} \& \mathrm{H}$, Quincy, nor CCI approached it in a manner that was as thorough or as well organized as this. The company collections of C\&H and Quincy both have hundreds of photographs taken between the 1880s and the 1930s, but they are not categorized or filed with other documents. Many of them lack information that identifies the photographer, the date the picture was taken, and how the archives obtained them. This at times makes it a challenge to determine whether a picture was taken by the company for its own use, was made by an independent photographer for commercial purposes, or was taken by an amateur and ended up in the collection. However, it does indicate that

\footnotetext{
1 John H. Graff, "Technical Photography and it use in Industrial and Commercial Organizations." The Journal of Industrial and Engineering Chemistry 9, no. 11 (1917): 1052-1054.
} 
the companies' photo departments were neither systematic nor wellorganized.

Thus, none of these companies maintained strictly organized photographic departments that answered to all company departments as did those of Westinghouse and the Berlin Mills Company. By comparison C\&H and Quincy both ran blueprinting offices that produced visual material such as underground maps and measured drawings that were copied using blueprinting technology. By the late nineteenth century, the underground workings of mines had become complex enough that engineers needed regularly updated maps to monitor progress and plan excavation. Also, laws required mines to submit recent maps to a government safety inspector on a regular basis. Blueprinting made these tasks faster and easier because existing maps could be updated and blueprinted, and the copies given to engineers and inspectors. This saved time and money. Instead of having a draftsman redraw entire maps multiple times, office boys could make blueprint copies in a matters of minutes. Blueprinting also improved accuracy. ${ }^{2}$

A blueprint, if printed correctly, was as truthful as the original drawing, but if it was incorrect, it was obviously wrong and could be done again. On a tracing, errors could seem like truthful data, Thus tracings needed to be executed (or double checked) by someone capable of understanding the intellectual content of the work, where blueprints

2 Eric C. Nystrom, Seeing Underground: Maps, Models, and Mining Engineering in America (Reno, Nevada: University of Nevada Press, 2014), 29-33. 
only needed to be proofed for proper exposure and readability. ${ }^{3}$

Blueprints were vital to the work of mining engineers and safety inspectors, providing them with visual representations of spaces that could not otherwise be seen in their entirety. Similar to the idea that halftones were more truthful copies of photographs than engravings, blueprints were more truthful copies of maps and measured drawings than were tracings. Accordingly, mining companies made significant investments in blueprinting equipment.

$\mathrm{C} \& \mathrm{H}$ and Quincy each had a darkroom in the attic of their main office building, indicating that they did produce their own visual materials. However, though both darkrooms were likely used for processing photographs, it appears as though their primary purpose was for photocopying large documents and making blueprints. Being the larger company of the two, C\&H's darkroom is much bigger than Quincy's, taking up multiple rooms in the attic, and it was also much better equipped, having two large copying cameras, a contact printer capable of making images several feet wide, and an arc light blueprinting machine that stands approximately seven feet tall. On the other hand, the Quincy darkroom occupied a small partitioned section of the attic that was equipped with a sun printing table. The emphasis on copying and printing shows that reproduction of graphic materials was crucial to both of these companies, but it infers that

\footnotetext{
${ }^{3}$ Ibid., 32-33.
} 
photographs of things other than plans and drawings were of secondary importance.

There are several reason why photography may not have been used by Michigan mining companies in the all-encompassing manner described in the work of Graff. Foremost, these authors focus their writing on the largest and most successful examples of company photographic departments because they were trying to provide others with models to build on. Companies like Westinghouse that manufactured electrical equipment for the consumer market were among the biggest and wealthiest in the nation. They would have had plentiful resources to invest in developing large photo departments that required highly skilled photographers and expensive equipment. Clearly, $\mathrm{C} \& \mathrm{H}$ and Quincy both found blueprints, photographs and photo-copies valuable enough that they were willing to invest in them. However, they did not equip all of their agents and engineers with hand cameras, nor did they sort, label, and file their photographs methodically. Doing so was apparently not as vital for them as it was for companies with large public interfaces.

In addition to industrial scale electrical equipment like generators, Westinghouse manufactured appliances for public sale, and sales benefited from having a photographic department as an adjunct to the publicity department. The advertising produced by these departments included photographic materials such as pictures for advertisements as well as pamphlets illustrated with halftones, and it required expert photographers 
armed with an assortment of cameras, lenses, plates, and flash powders. ${ }^{4}$ On the other hand, the main product of mining companies was ore or raw metal ingots that were sold to other industrial companies in large quantities because the metal had to be refined and reworked before it was of any use to individual consumers. In short, unlike images of light fixtures and toasters, images of copper ingots and sheet metal were of little practical value to anyone outside of the metal working industry. Thus, C\&H, Quincy, and CCI probably saw little need to keep diligent photographic records of their products because they did not rely as heavily on advertising as other companies did.

Some large companies also approached engineering photography from a much different perspective than the Lake Superior mines. One key difference between General Electric's photographic department and those of Michigan mining companies was that GE published their engineering photographs in a company-run trade journal, The Review. The purpose of The Review was to influence engineers through a publication that had the appearance of an objective engineering journal, but which used the transparency of photographs not only to illustrate, but also to validate its editorial content. Neither, C\&H, Quincy, nor CCI had such a journal. One reason they did not need as many photographs as GE is because C\&H and

4 The Use of the Camera in Industrial Plants." Iron Age 90, no. 8 (1912), 393-397. 
Quincy's engineers relied on outside trade publications. Additionally, the companies did not use photographs to reinforce company ideology as intensely as GE, and therefore did not need structured photographic departments over which they could exercise firm control. ${ }^{5}$

It is also very likely that the concept of industrial photography took time to catch on. This is especially true with mining companies that were established in the 1860s and had long-standing traditions, as opposed to companies like Westinghouse that did not arrive until the 1880s. Literature on industrial photography drew from prime examples that were groundbreaking in their approaches, but older companies had been taking pictures for years and already had their systems worked out. Thus, it makes sense that mining companies did not develop photographic departments that even approached the size or level of sophistication reached by those of Westinghouse and Berlin Mills.

Despite the fact that the C\&H and Quincy collections contain hundreds of photographs, the original intent of the pictures is open to speculation. In the absence of contextualizing information such as the photographer and the date, determining whether a photograph is part of a collection assembled by the company or by archivists after the fact is best achieved by looking at who donated the pictures to the archives. With $\mathrm{C} \& \mathrm{H}$ it is safe to say that many of

5David E. Nye, Image Worlds: Corporate Identities at General Electric, 1890-1930, (Cambridge, Massachusetts: M.I.T. Press, 1985), 60-68. 
the images residing in the Michigan Technological University Archives were part of company records since most them were donated along with the rest of C\&H's records by Universal Oil Products (UOP: the company that bought out C\&H in 1968). Similarly, most of the Quincy collection photos were donated to Michigan Tech by a single organization, the Historic American Engineering Record after the company closed in 1945 . This indicates that the photos were part of a company collection that HAER gathered after Quincy went out of business. However, both collections do have quite a few images that are completely without identifying information, other than that which can be derived from examining their content.

In contrast to $\mathrm{C} \& \mathrm{H}$ and Quincy, photographs of the Cleveland Cliffs Iron Company predating 1930 are few in number-perhaps several dozen at most—but the purpose for which they were intended is made perfectly clear by the fact that they were published in the company's annual reports. This leaves little room for speculation about whether or not the photos were taken to be used as company records. CCI did not identify any of the photographers who took the pictures, nor did they specify the exact date they were taken. However, the annual reports allow the photos to be dated within a year, much more accurately than most photos in the $\mathrm{C} \& \mathrm{H}$ or Quincy collections. Moreover, the intent of CCI's photos is explained by the reports they illustrated; they were intended to show company property to shareholders. 
Categorizing the pictures according to what they show sheds some light on the $\mathrm{C} \& \mathrm{H}$ and Quincy collections. The collections of both companies are extensive, and the photos in them show a wide variety of subjects. However, there are a few subjects that make up large percentages of both sets. Shots that show the exteriors of buildings on company land are the most numerous, and ones that show the interiors of the buildings are a close second. The exterior pictures can be divided into "general exterior views" that show multiple structures covering large portions of the company's land, and "individual views" of buildings that provide more details of the structures. Most of the interior photos show machinery inside of wood shops and machine shops, mills, hoist houses, shaft rock-houses, and other work spaces. Like the exterior views, the interiors can be divided into ones that show all of the equipment inside a room, or close-ups of individual machines that show detail. Thus, there is a continuum of subjects that are interrelated and cannot be distinctly separated from one another. There are also a lot of pictures that don't correspond with these categories, but make up a significant portion of the collections. Many of them, including ones of C\&H's bathhouse (Figure 4.4) and library (Figure 4.11) appear to be evidence of the companies' paternalistic relationship with employees that were used for publicity purposes.

Figure 4.1 is an example of a general exterior view. Dating from 1875, it is the earliest known photograph of the Quincy mine, showing shaft houses 
2 through 5. Though the picture makes the Quincy mine appear far less impressive than $\mathrm{C} \& \mathrm{H}$ shown in the next figure, it should be noted that figure 4.2 of $\mathrm{C} \& \mathrm{H}$ was taken decades after figure 4.1 of Quincy, and serves as a comparison of change in technology over time, as well as a comparison of the two companies. Figure 4.2 is a general exterior view of the Calumet \& Hecla Mining Company; though it is undated, it was certainly taken after 1890 as the landscape shows a high level of development that would have required several decades to accomplish after the startup of C\&H in the 1860s. In addition to dozens of buildings, the photo shows a line of shaft houses along the conglomerate copper lode that $\mathrm{C} \& \mathrm{H}$ worked for more than half a century. Though the details of the individual structures are not easily discernable, the image does impart a sense of the size of C\&H's property and how expansive the company's operations were. General exterior views were popular in trade journals because, as the name indicates, they offer a general impression of a company's physical size and the extent of its investment in buildings such as shaft houses, mills, and smelters. A photograph like this one would have impressed viewers with the size and scale of C\&H's operations and served as a record of what the landscape looked like at a certain time, which came in handy when writing histories of $\mathrm{C} \& \mathrm{H}$ and the Lake Superior mining district. Individual exterior views afford the viewer a better look at architecture than do most general exterior views. Figure 4.3 is an undated photograph of C\&H's library and bath house, it must have been sometime after 1898 when 
the building was constructed, and the line of very young trees in the yard indicates it was taken within several years of the building's construction. The photographer is unknown, but the fact that it was donated by UOP implies the photo originally belonged to C\&H's company records. Once again, it is probable that this picture, as well as the one of the library's interior shown in figure 4.9 were intended for publicity purposes. In order to attract workers to the isolated copper country, most of the successful mining companies constructed houses and facilities such as libraries and bathhouses (figure 4.4), that raised the standard of living and made the area more suitable for miners to raise their families. Married men were typically preferred because they were perceived as being more responsible and more likely to stay with the company. ${ }^{6}$

In the late 1910 s and early ' 20 s, $\mathrm{C} \& \mathrm{H}$ produced a collection of large format prints that documented the company's property, particularly heavy machinery, as well as various aspects of its operations, including underground mining. For example, figure 4.5 shows the inside of a $\mathrm{C} \& \mathrm{H}$ hoist house along with the large Nordberg Hoist that would was used to raise ore rocks, and men out of the mine. Figure 4.6 shows miners dumping a tram car into a rock skip that would have been connected to a hoisting system similar

\footnotetext{
${ }^{6}$ Larry Lankton, Hollowed Ground: Copper Mining and Community Building on Lake Superior, 1840s-1990s (Detroit: Wayne State University Press, 2010), 43.
} 
to the one in the previous figure. This provides an example of a case where the company produced an organized set of pictures, but once again the specific purpose for which they were made is uncertain. Oversize prints made from large format negatives allowed fine detail to be recorded, and would have been ideal for company engineers to illustrate machinery in their reports, articles, or presentations.

Photographs of workshops, mills, and the machinery inside of them may have served similar purposes. They would have allowed managers to keep an eye on things, as well as providing engineers with visual records of the equipment they were in charge of. It is also possible that such images were taken for insurance purposes. At the time, most industrial properties in the United States were documented in detailed fire insurance maps that informed insurance agencies of fire risks. They also served as records of what was housed in industrial structures so compensation could be calculated if a property burned. Figures 4.7 of the Quincy machine shop and 4.8 of a steam stamp in a Quincy mill are examples of pictures that could have been used for insurance purposes.

In addition to informing engineers, managers, prospective employees, and possibly insurance companies, Calumet \& Hecla was particularly adept at producing publicity materials that flaunted the companies' success. In 1916, C\&H published a book entitled Calumet \& Hecla Mining Company Semi-Centennial that boasted of the company's progress during their first 
fifty years of operation, as well as the fact that $\mathrm{C} \& \mathrm{H}$ was by far the most profitable of the Keweenaw copper mines. The introduction states, the scope of the Semi-Centennial was of such a broad nature that nothing commonplace would do, so we decided to issue this book, which, in a general way, treats of the great progress that has been made since the first copper was produced from the mines of the Calumet \& Hecla Mining Company to the present day, so far advanced from that of fifty years ago that one could well imagine that it took centuries to effect the transformation. ${ }^{7}$

The articles throughout the book tell stories such as "Alexander Agassiz's Trials and Hardships in the Pioneer Days," and "1865-1916, Fifty-One Years of Progress," that highlight far-reaching changes in mining methods and in the Copper Country landscape. The book is illustrated throughout with pages filled with halftone photographs that, like the text, show stark differences between the built environment of the Keweenaw in the 1860s when $\mathrm{C} \& \mathrm{H}$ started, and the 1910s when the book was published. Additionally, many photos show the up-to-date mining, milling, and smelting facilities of $\mathrm{C} \& \mathrm{H}$. Such pictures act as testaments to C\&H's massive investments in modern technology that had effected great changes in copper mining. Many also doubled as advertisements for companies like Nordberg. Figure 4.9 is an advertisement for a Nordberg hoist owned by $\mathrm{C} \& \mathrm{H}$ that was published in the Semi-Centennial book. The ad highlights that the success of $\mathrm{C} \& \mathrm{H}$ was

7 The Keweenaw Miner: Calumet \& Hecla Mining Company SemiCentennial, 1866-1916, (Calumet, Michigan: Keweenaw Printing Company, 1916), 1. 
partially due to their use of Nordberg equipment. It simultaneously contributes to the prestige of $\mathrm{C} \& \mathrm{H}$, who were able to afford some of the most up-to-date and expensive equipment available.

The halftones in this advertisement are typical of industrial machine photographs in two ways. First, they do concentrate on people. A man is visible in the lower-right corner of the top image, but he is only there to give the viewer an idea of the hoist's size. The bottom image appears to show the operator sitting atop the hoist, but he is hardly discernable from the machine, making the hoist the undisputed subject of the photo. Second, though the background of the bottom halftone was not fully removed, retouching was clearly employed to distinguish the hoist from the background. The ghostly appearance of the hoist houses interior makes the hoist itself stand out, attracting the viewer's attention to the machinery.

In October 1931, the Mining Congress Journal printed a volume about the American copper industry that dedicated almost all of its 129 pages to illustrated articles about the Calumet \& Hecla Mining Company. The volume starts with a brief synopsis of how the onset of the Great Depression had negatively affected the copper industry and continues with a series of articles about the history of the entire Lake Superior Copper District. Aside from the first twelve pages the volume is dedicated to articles that describe C\&H's current methods of mining, milling, smelting, and management style. All of the articles are illustrated with halftone photographs, which total 130 for the 
entire volume, or about one for every page. There are also 4 halftones from artworks along with 41 line engravings, (giving a ratio of halftones, to pages-approximately 1 per page - that is similar to the 1930 volume of Engineering and Mining Journal). Also like E\&MJ, most of the photographs in The Mining Congress Journal show a variety of machines and heavy equipment used by $\mathrm{C} \& \mathrm{H}$, as well as an assortment of general exterior views that include shaft rock-houses, smelters, mills, and other company buildings. There are also a handful of portraits of prominent men, including one of $\mathrm{C} \& \mathrm{H}$ president Alexander Agassiz, and a few visual records of company paternalism. Regarding their subject matter, the halftone photos in this volume of $M C J$ are very similar to those of other engineering publications of the time, which favored certain subjects, particularly general exterior views, heavy equipment, and workshops. This format was developed during the era of line engraved images, but the arrival of halftone technology allowed printers to include more of these illustrations. ${ }^{8}$

Many of the photos published in the October 1931 volume of $M C J$ were taken by $\mathrm{C} \& \mathrm{H}$ and are now archived in the company collection at Michigan Tech. They provide a cross reference that shows what company photographs were used for. Figures 4.10 of a statue of Alexander Agassiz in the park that bore his name, and 4.11 of the $\mathrm{C} \& \mathrm{H}$ library reading room, both appeared in

8 The Mining Congress Journal 17, no. 10 (October, 1931): 459-588. 
$M C J$. This shows that companies furnished images to the press rather than the press sending their own photographers into the field. Thus, publicity was a large component of industrial photography even if manufactured products were not what was being advertised.

The photo of the library (Figure 4.11) is undated, and therefore it is possible it was taken in 1931, specifically for $M C J$. However, the gas light pipe visible at the top of the frame and the pristine condition of the floor indicate the picture is much older. Therefore, the image was probably taken shortly after the building's construction in 1898 , and was thus not originally intended for $M C J$. The image of the statue of Agassiz is dated 1923 at the dedication of Agassiz Park, long before $M C J$ published it in 1931, meaning it was not taken specifically for that volume. However C\&H may have used both images in earlier promotional material. They may also have been intended as historical records of the event for future use.

Photographs of equipment often focused attention on the machine itself by showing it in isolation from its normal context. The photos from Hand's article show individual apparatuses devoid of any background or indication of where they was used. Similarly, most of the photographs seen in this chapter, do not include people. Pictures of equipment, company buildings, and workshop interiors were intended to communicate with engineers whose occupations did not directly concern blue-collar employees. Thus, workers generally don't appear in photos intended for engineers because engineering 
professionals were supposed to be concerned with technology, not humanity. Nye argues that this reinforced socio-economic class divisions, which was intentional, at least in the case of General Electric and their company journal The Review. ${ }^{9}$ With mining company photographs, machines shown in isolation may have been more of a form of compliance with the established practices of scientific and engineering literature than a direct attempt to encourage class divisions.

Intentions aside, the photographers who took pictures for $\mathrm{C} \& \mathrm{H}$ and Quincy must have bought into the idea that engineers wanted to see the sort of machines and facilities that they designed, built, and maintained rather than the people who operated them. In most exterior views and images of machines people are completely absent (Figures $4.3,4.8$ ). Though, some have one or two people standing in front of the subject in order to give an impression of its physical size (Figures 4.1, 4.5, 4.9). There are also usually no people in pictures of factory and machine shop interiors (Figure 4.7). This is because workers were not considered to be of consequence in understanding the equipment of the shop.

This was not necessarily the case with underground shots, where miners or trammers are almost always present. It is likely these photos used workers to demonstrate underground procedures. Figure 4.6 illustrates the act of dumping a tram car into a skip rather than just illustrating equipment.

9 Ibid., 28-29. 
Figure 4.3 illustrates the appearance and use of the man engine in the Quincy Mine, but unlike many other machines the betterment of the workers - to save them from exhausting and dangerous ladder climbs—was much of the reason the man engine existed. The workers' presence also gives a better idea of how the machine worked, which may not be evident without people riding on it.

In addition to publicity and historic records, photographs likely also served as a way to communicate visual data across long distances, because they could be taken and processed more quickly than detailed drawings, and also because they were perceived as being more truthful. Photographs are transparent in that they appear indisputably real, and were therefore ideal for companies to give their messages the "aura of fact." ${ }^{10}$ It would have been extremely difficult for photographers to show non-existent structures, machines, or progress in a photograph, despite the fact that photographs are subject to many variables determined by the photographer. The nature of the photographic medium gives it a sense of objectivity through the ability to record form, shades, and minute details accurately. However, the nature of the medium also limits its own objectivity by reducing the world to twodimensional rectangles that stop time and obliterate color. Thus, industrial photographers were able to choose what they did and did not want to show, portraying subjects in an idealized manner.

10 Nye, Image Worlds, 16. 
Though the mines were located in Michigan's Upper Peninsula, many company officials resided in large metropolitan areas away from the mining district. For example, Alexander Agassiz presided over C\&H from Boston for nearly forty years from the 1870s until his death in 1910, and he is accredited with playing a significant role in making $\mathrm{C} \& \mathrm{H}$ the largest and most profitable of the Keweenaw copper mines. Agassiz spent most of his time in Cambridge, Massachusetts, where he served as a Harvard professor, juggling the duties of both his jobs. Photographs likely provided him with first hand views of his distant mining company so that he could ensure that company property and its infrastructure, as well as progress in the mines and on large construction projects were all as reported. ${ }^{11}$ For example, figure 4.12 shows construction of a shaft house at Quincy, which could have been used to prove to Agassiz and other company officials in distant locations that things were going as reported. Similarly, photographs of things from buildings and machinery, to mining and milling operations may have been a way for managers and engineers to observe company properties and underground operations at a glance. Of particular note are underground photographs that might have allowed managers and engineers to see the mine's inner workings without actually having to travel in to the mines.

${ }^{11}$ Lankton, Hollowed Ground, 92. 
In December of 1893, Frederick Fraley Sharpless, a photographer, engineer, and professor of the Michigan Mining School journeyed to the lower levels of the Quincy Mine, which at that time was more than 3,500 feet below the surface. Sharpless described the journey in detail, claiming that though such trips were in no way dangerous, before he entered the mine he was required to don safety gear including hob-nailed boots, clean duck trousers, a jacket, cap, hat and lamp. Accompanied by a mine captain, he descended into the earth on a man engine, a machine that required him to jump on and off of moving platforms in a long series that stretched the entire length of the vertical shaft. Moreover, it was difficult for Sharpless to observe his surroundings because the light of the small, dim lamp did not allow him to see more than twenty, or thirty feet at the most. Anticipating this problem, he brought along a supply of magnesium powder, which when ignited produced an intense flash of light that illuminated the interior of the mine, allowing it to be seen in the way it was shown in flash photographs. Thus, photos may have been an ideal way for higher management to see inside the mines. Pictures would have saved them from a long journey and offered a better view than the miners themselves had. ${ }^{12}$

${ }^{12}$ Frederick Fraley Sharpless, "Down in a Copper Mine: to be used in conjunction with Lantern Slides," MS-239-001-008, Manuscript, Frederick Fraley Sharpless Collection, Michigan Tech Archives and Copper Country Historical Collections. 
Figure 4.13 of the man engine in the interior of the Quincy Mine was taken by Sharpless during one of his trips underground. Like many other photographs it is undated, however, it is not part of a company collection, but instead is part of the Frederick Fraley Sharpless collection. An identified photographer makes deciphering a photograph's intent considerably easier. Sharpless's tenure at the Michigan School of Mines lasted from 1887-1893, when he left the Copper Country for employment as the American representative for a London engineering firm. More importantly, the college handbook specifies that Sharpless taught classes on mining, milling, and assaying that he illustrated with photographic lantern slides. He probably took this and other pictures to be used in conjunction with lectures. Rather than using valuable class time to take students on long field trips that were part of many MMS classes, he brought the mines to students in pictures. ${ }^{13}$ Photographs thus served as a means of communicating visual information across time and space without the need for anyone to travel, except for the photographer.

Throughout the late 1800 s and early 1900 s, C\&H and Quincy also photographed a host of subjects and events aside from buildings, machines, and mines. Often, they showed ways the company took care of its employees. Images like those of the library and bath house, along with the one of the

${ }^{13}$ Annual Catalogues of the Officers and Students of the Michigan Mining School, Houghton, Michigan, 1888-1889 (Marquette, Michigan: Mining Journal Print, 1890): 7, 18, 27; Ibid., (1890): 9, 32, 33. 
$\mathrm{C} \& \mathrm{H}$ broom factory where miners blinded in the line of work earned a living (Figure 4.14), were likely used for publicity purposes to advertise that the company engaged in benevolent endeavors to aid injured workers and the families of deceased miners. However, such photos are fewer in number since they were probably of secondary importance to images of engineering related subjects. Some images though, like the one of the great strike of 1913-14 (Figure 4.15), which brought intense labor strife to the Copper Country, may have served other purposes. In the picture marching soldiers protect the Quincy Mine from strike-related vandalism. Such an image would possibly have painted a controversial image of the company and the mining district, and therefore might not have been used for publicity per say, but could have been employed to record the extent of the conflict in company records. ${ }^{14}$

Unlike C\&H and Quincy, no known photographs of CCI's Michigan operations predating the 1900s exist. Though the company and its iron mines were well established in the Lake Superior District by the 1860s, its Michigan records, housed in the Northern Michigan University archives, indicate that the company did not use photographs as records until well into the twentieth century. Alternately, it is possible that most of the photographic collection was discarded at some point, or that the pictures reside in an unknown location. However, this is unlikely since the NMU archives have most all of the company's other Michigan records dating from

${ }^{14}$ See Lankton, Hollowed Ground, 191-206. 
1882-1960. Like C\&H and Quincy, CCI's capital was controlled by investors who lived away from the mines. The photos that do survive in the company's annual reports show that pictures served as a way of showing equipment and machinery to shareholders.

CCI's mining division began illustrating its annual mining division reports in 1910, and most of the few dozen images between then and 1930 show the interiors of buildings and mines, along with the machinery contained therein, such as in the one of the Prescott pump in the Franklin Mine (Figure 4.16). The relatively late arrival of photographs in CCI's annual reports seems unusual because such reports could have been a very useful place for pictures of property intended for investors. However, by comparison C\&H and Quincy did not illustrate their annual reports, except for one or two rare occasions where a halftone of a general exterior view, was inserted between the pages. It is possible that sending separate photographs along with the reports would have been easier than tipping them in or printing halftones on the pages.

None of the three companies' photo collections have technical photographs such as the photo-micrographs, x-rays, or aerial surveying pictures discussed in chapter three. Most of these photographic technologies probably did not have a direct bearing on mining companies. Aerial surveying likely would not have benefited mining operations as it would have cartographers, and since the companies mostly produced metal stock like 
ingots, sheets, and tubes instead of castings they would have had little reason to invest in $\mathrm{x}^{-}$ray machines. The absence of photo-micrographs is curious, though, since assaying ore and mineral samples, as well as examining the quality of smelted copper would have been important. However, photomicrographs and other technical images were tools of engineering that would have been of little use for publicity or for showing the companies' infrastructure and equipment to officials, who probably had little knowledge of mineralogy. Thus, photo-micrographs may have been kept by the engineers rather than being filed in company records, or would have been made by the downstream consumers of these mines' products.

Thus, the case studies of C\&H, Quincy, and CCI provide a valuable comparison of leading opinions on industrial photography and three mining companies' use of photography. Though case studies of only three companies are not an exhaustive study of industrial photography, they highlight the fact that industrial photography did not always follow the course laid out in articles by authors like Alvord, Graff, and Hand. The needs of the mining industry differed from that of other industries. Mining companies had relatively small public interfaces since they did not manufacture or sell consumer goods. They were also usually much smaller than corporations like GE and Westinghouse. For these reasons, they did not need big photographic departments to annually produce and organized thousands of images for use in company-sponsored periodicals and trade journals. 


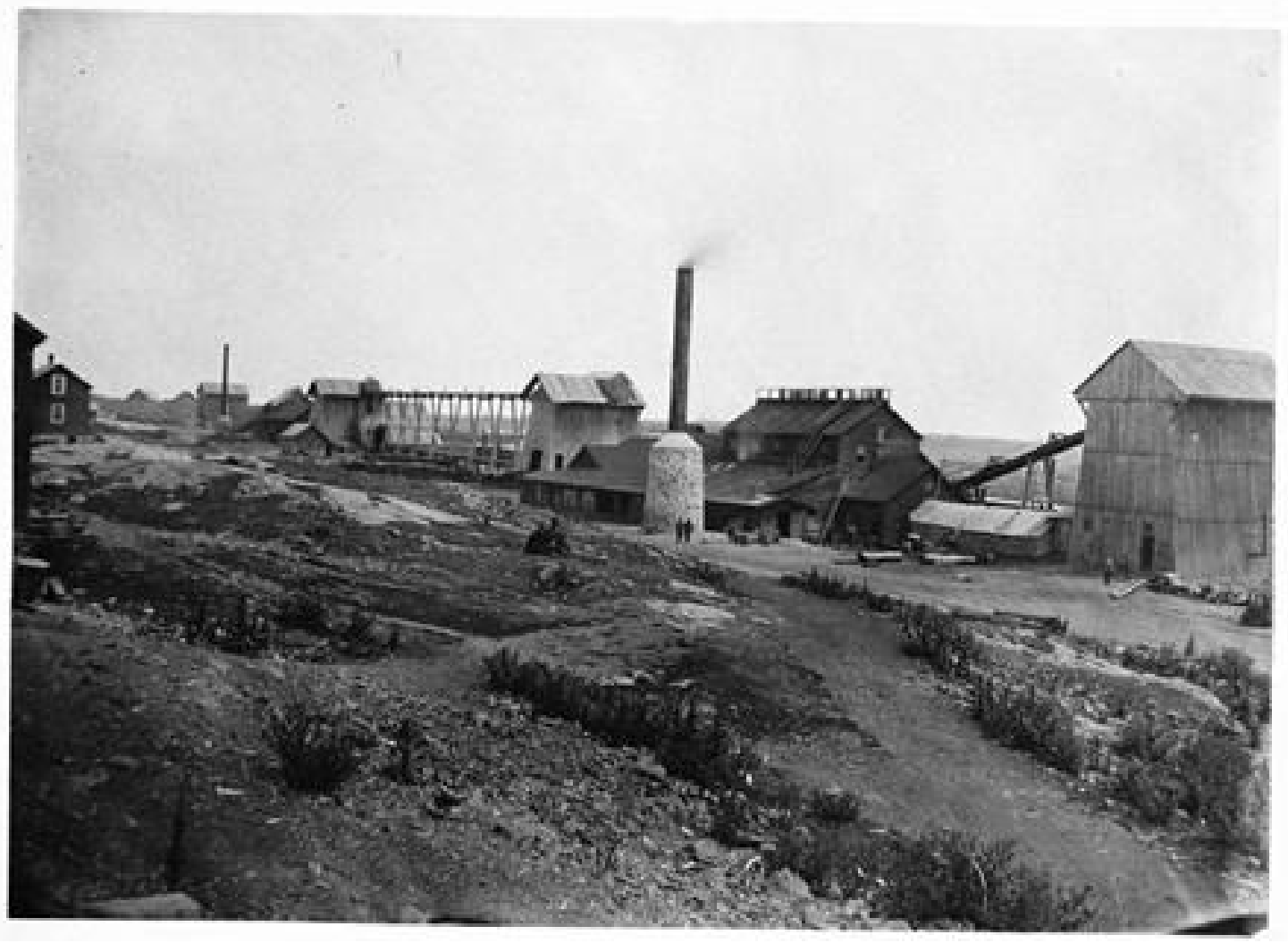

Figure 4.1: General exterior view of the Quincy Mine looking southeast, 1875. MS015-MI-2-8, Quincy Mining Company Survey, Michigan Technological University Archives Copper Country Historical Collections. 


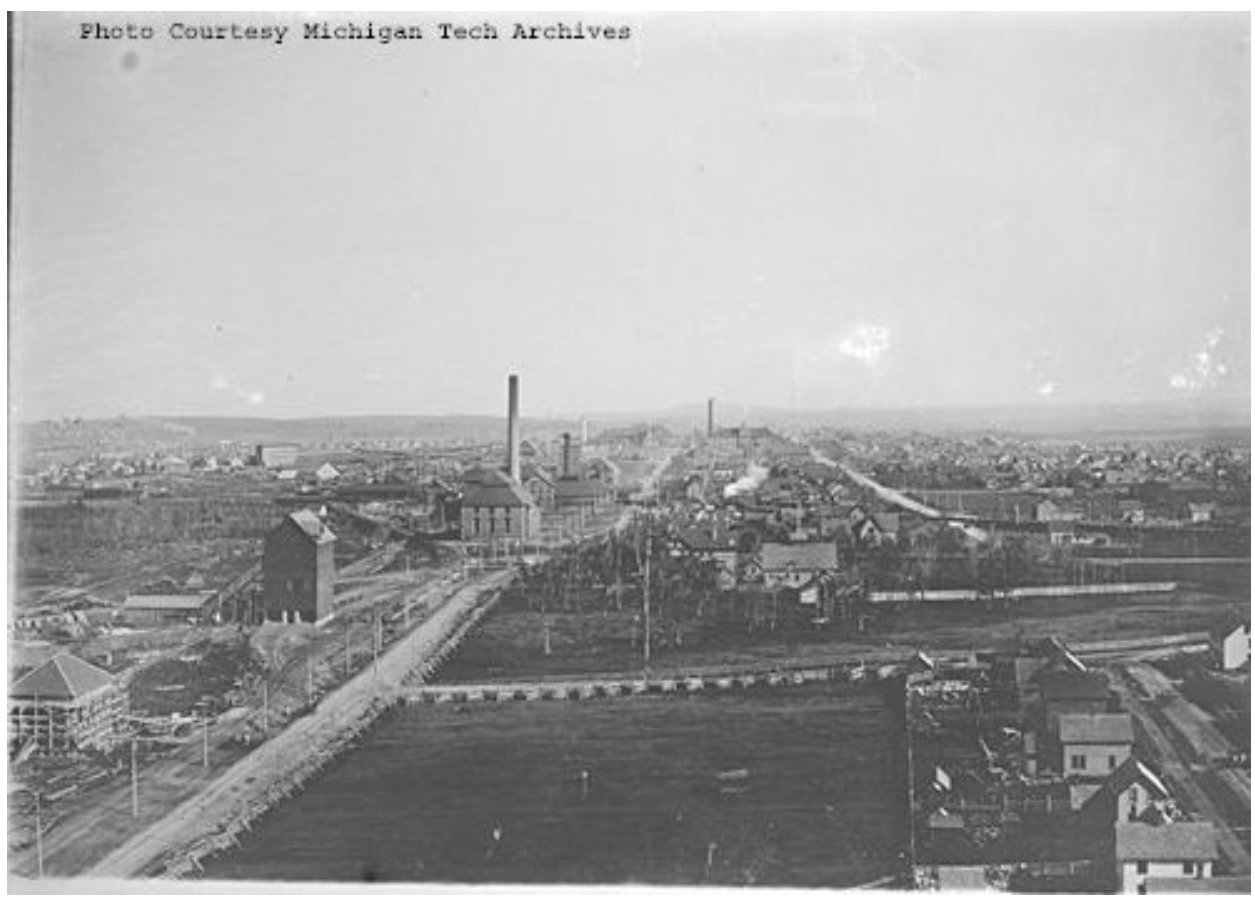

Figure 4.2: General exterior view of the Calumet \& Hecla Mine showing line of shaft houses on the company's large land holdings. Acc-03-095D-001-010, Quincy and Huron Photographic Collection, Michigan Technological University Archives and Copper Country Historical Collections.

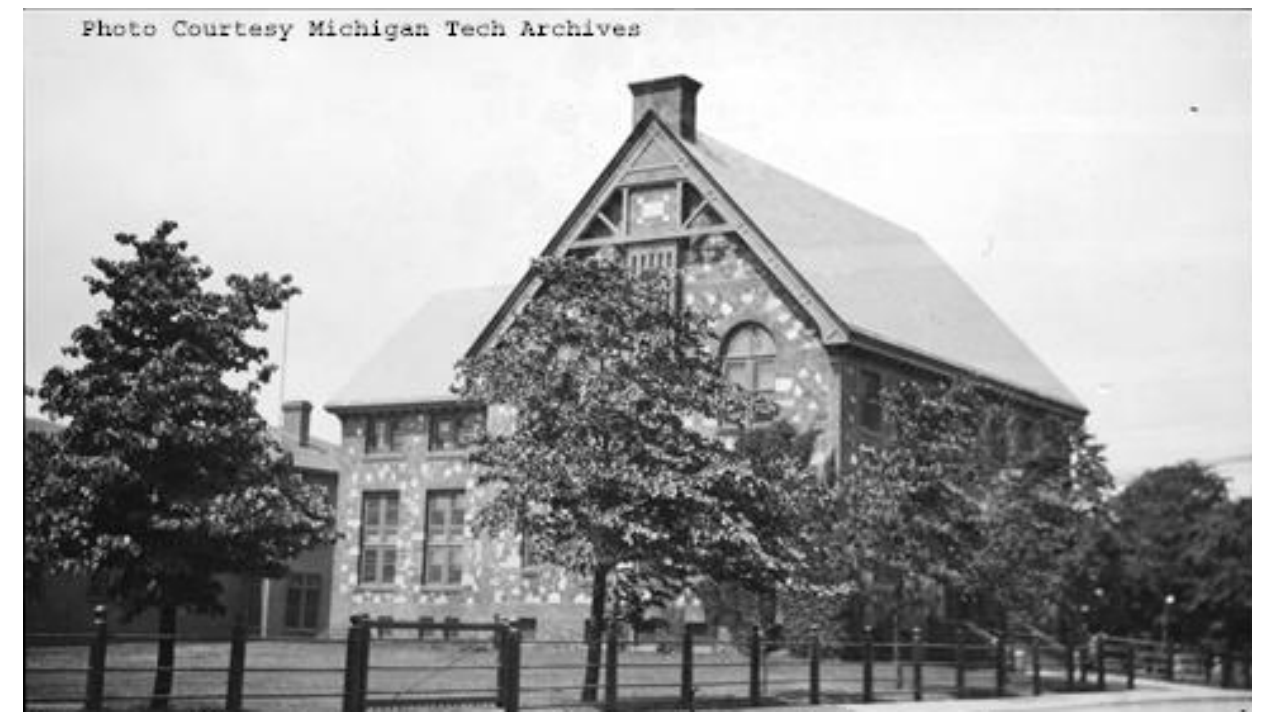

Figure 4.3: Exterior view of the Calumet \& Hecla library looking northwest. MS003-009-010-04, Calumet \& Hecla Photograph Collection, Michigan Technological University Archives and Copper Country Historical Collections. 


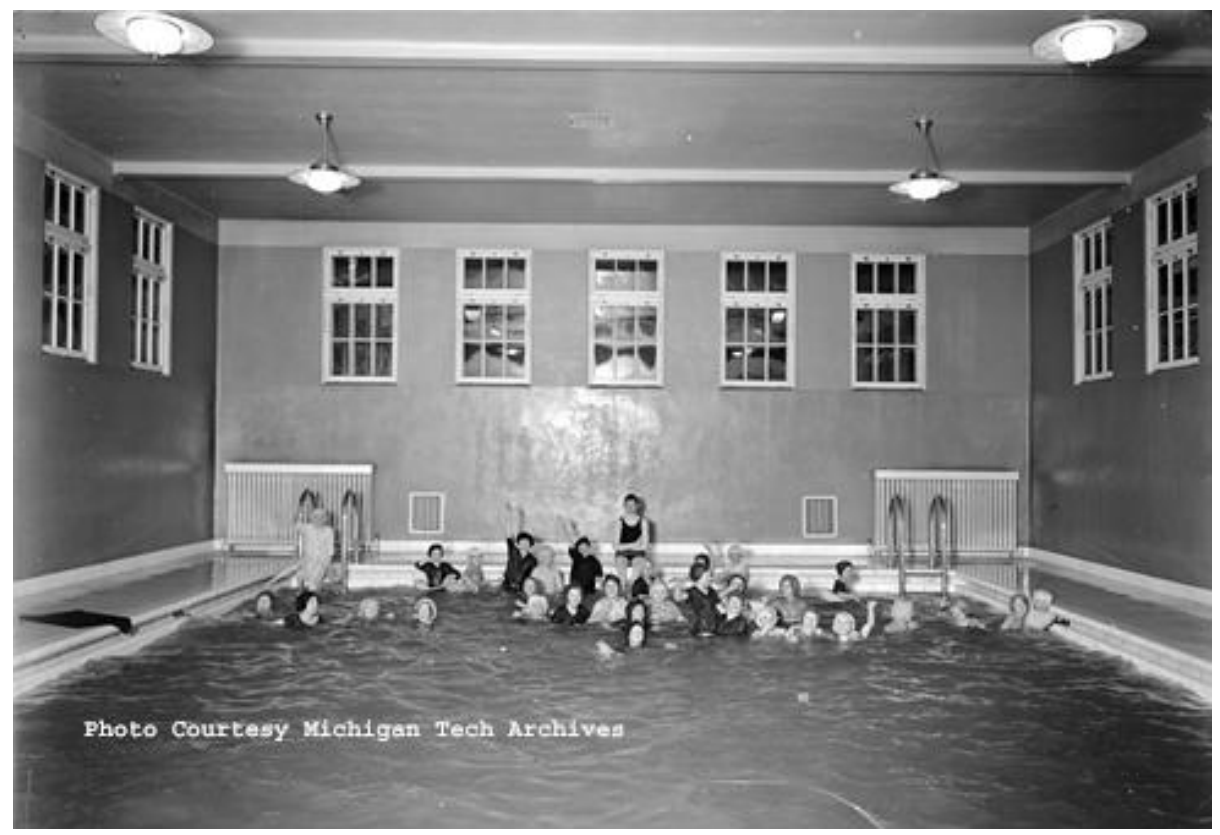

Figure 4.4: Calumet \& Hecla Bath House. MSO03-012-GN132.4, Calumet \& Hecla Photograph Collection, Michigan Technological University Archives and Copper Country Historical Collections.

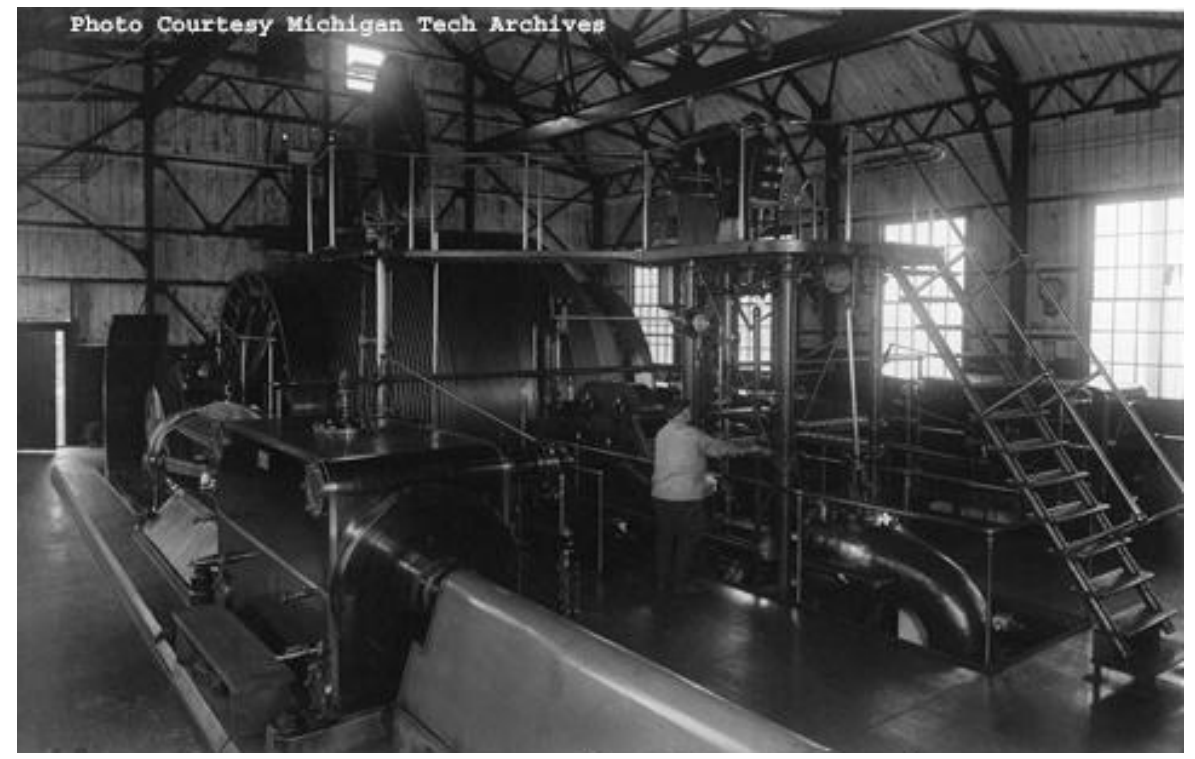

Figure 4.5: Interior of Calumet \& Hecla hoist house with Nordberg hoist that was connected to the rock skips and man cars in a neighboring building via the cable on the drum. MS003-25A-40, Calumet \& Hecla Photograph Collection, Michigan Technological University Archives and Copper Country Historical Collections. 


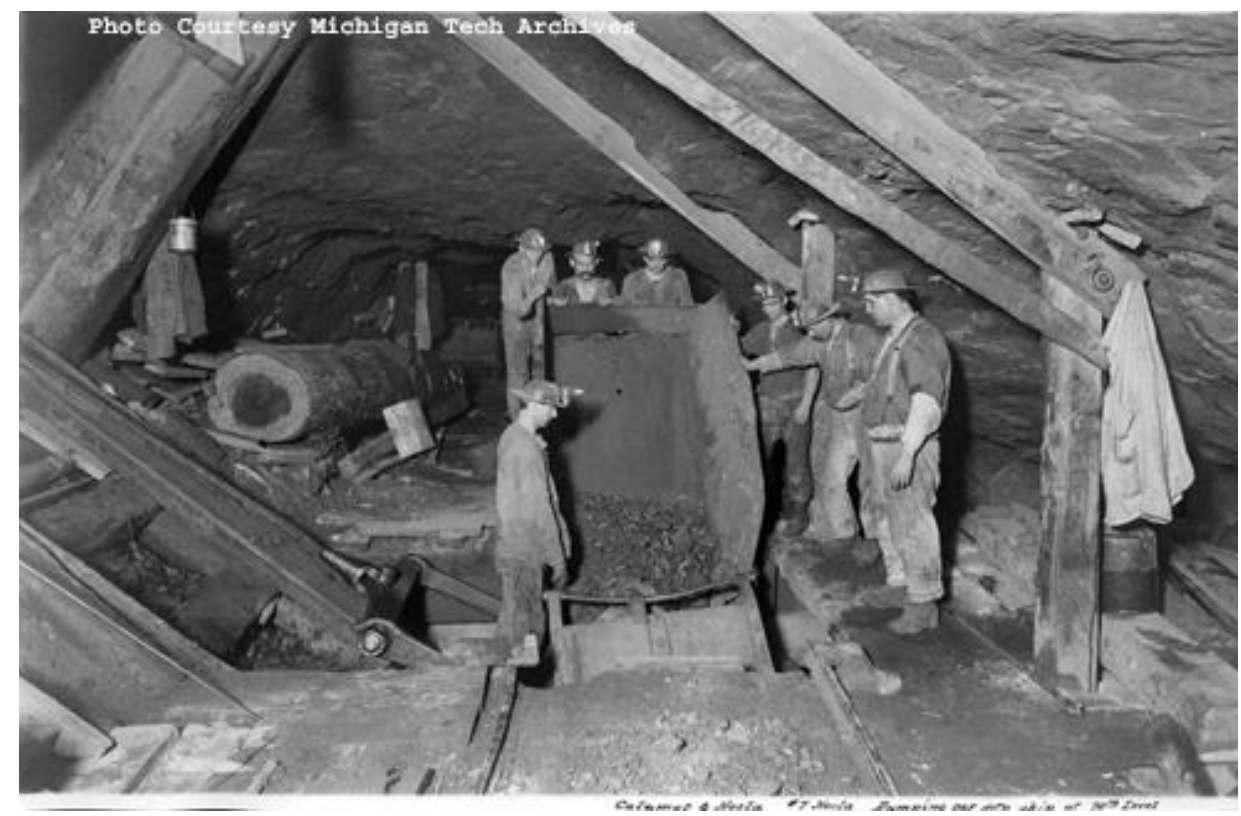

Figure 4.6: Dumping a car into a skip at the $70^{\text {th }}$ level in the Calumet \& Hecla Mine, 1915-1916. MS003-25A-002, Calumet \& Hecla Photograph Collection, Michigan Technological University Archives and Copper Country Historical Collections.

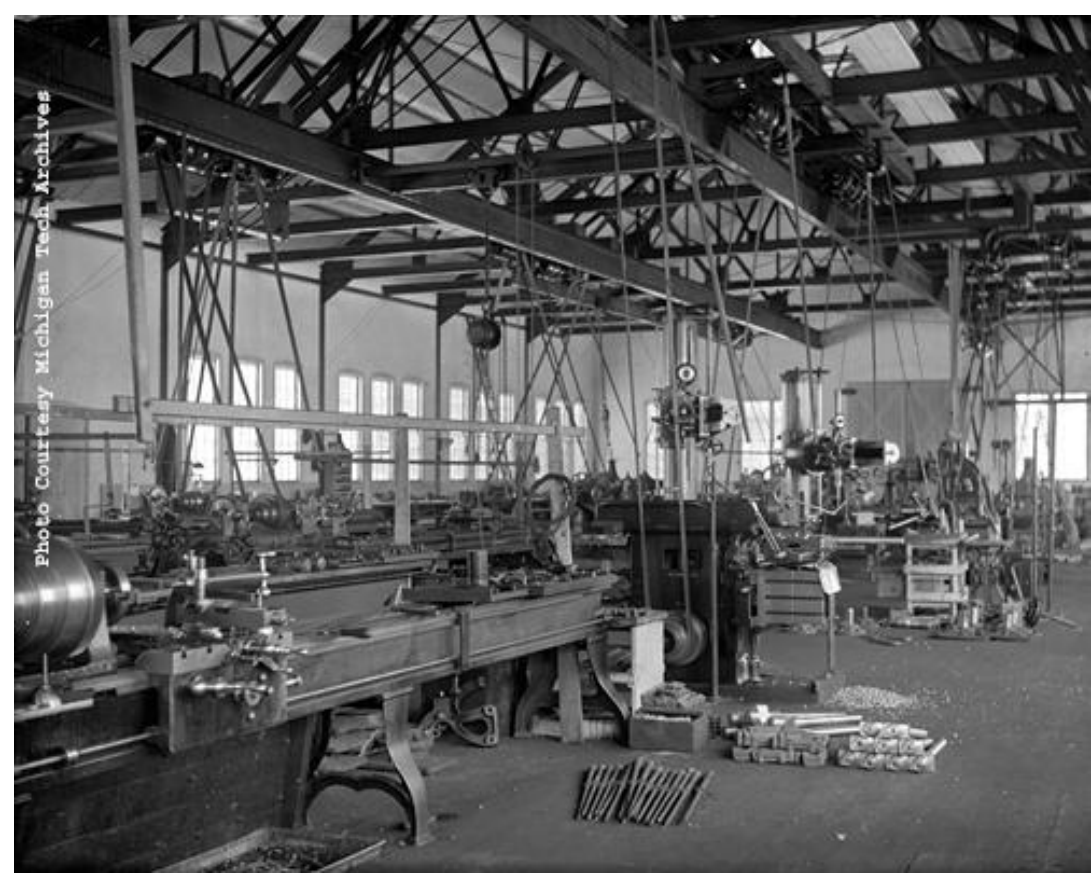

Figure 4.7: Interior View of the Quincy machine shop. Acc-03095D-001-023, Quincy and Huron Photographic Collection, Michigan Technological University Archives and Copper Country Historical Collections. 


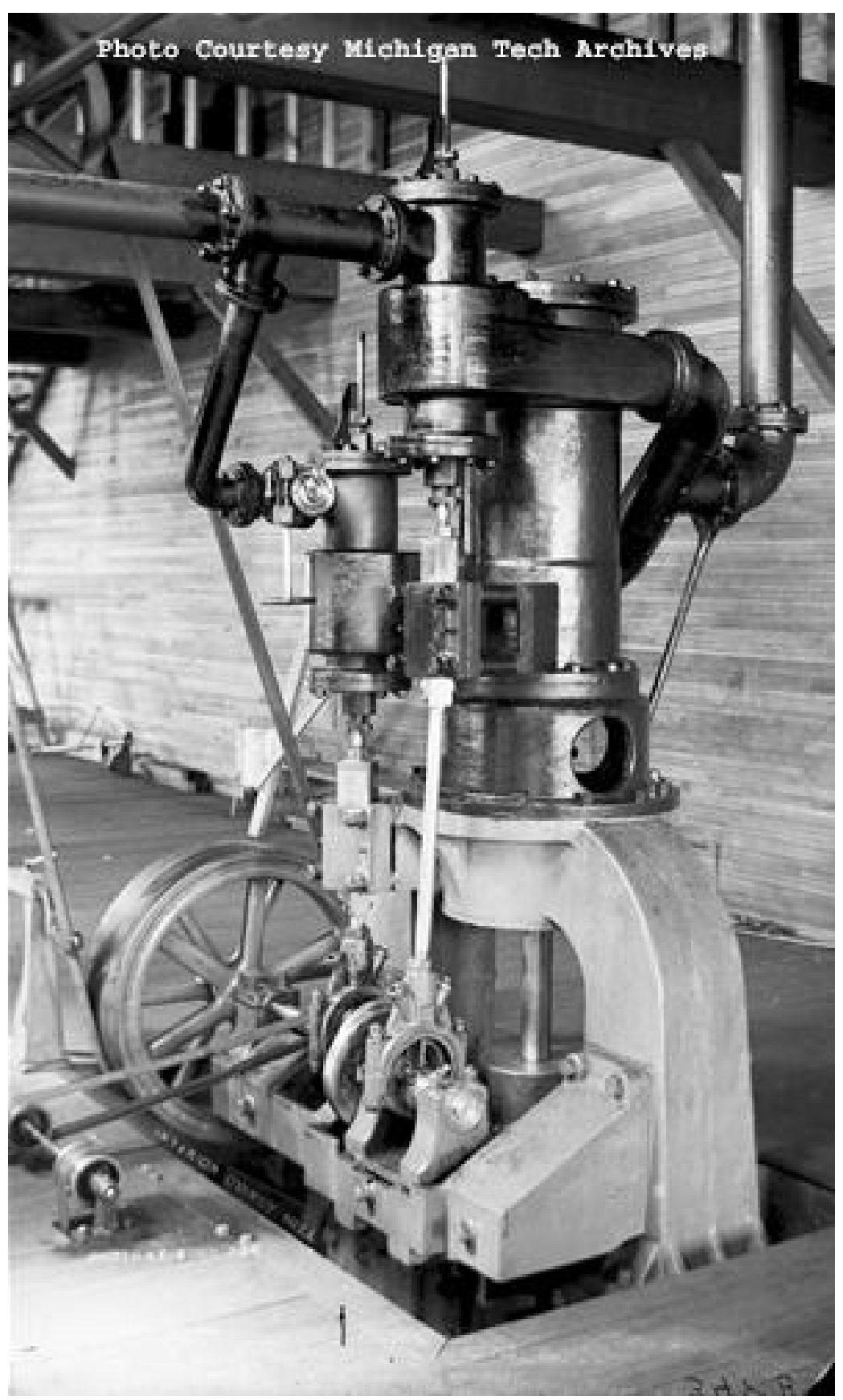

Figure 4.8: Steam stamp in a Quincy Mill. Acc-

03-095D-001-013, Quincy and Huron

Photographic Collection Michigan Technological

University Archives and Copper Country Historical Collections. 


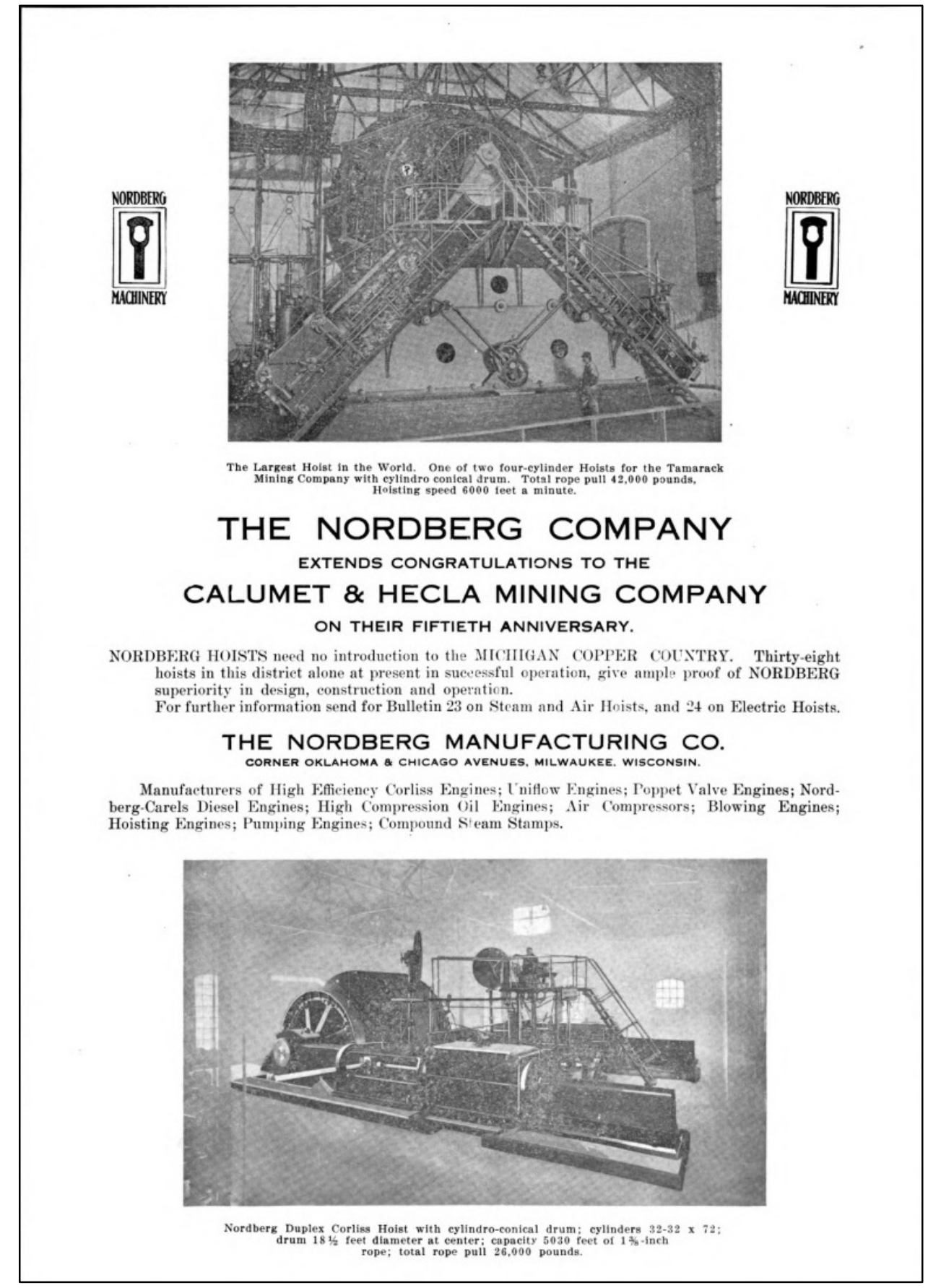

Figure 4.9: Advertisement from the Keweenaw Miner, featuring a Nordberg hoist owned by Calumet \& Hecla, 1916. From: The Keweenaw Miner: Calumet \& Hecla Mining Company SemiCentennial, 1866-1916 (Calumet, Michigan: Keweenaw Printing Company, 1916): 52. 


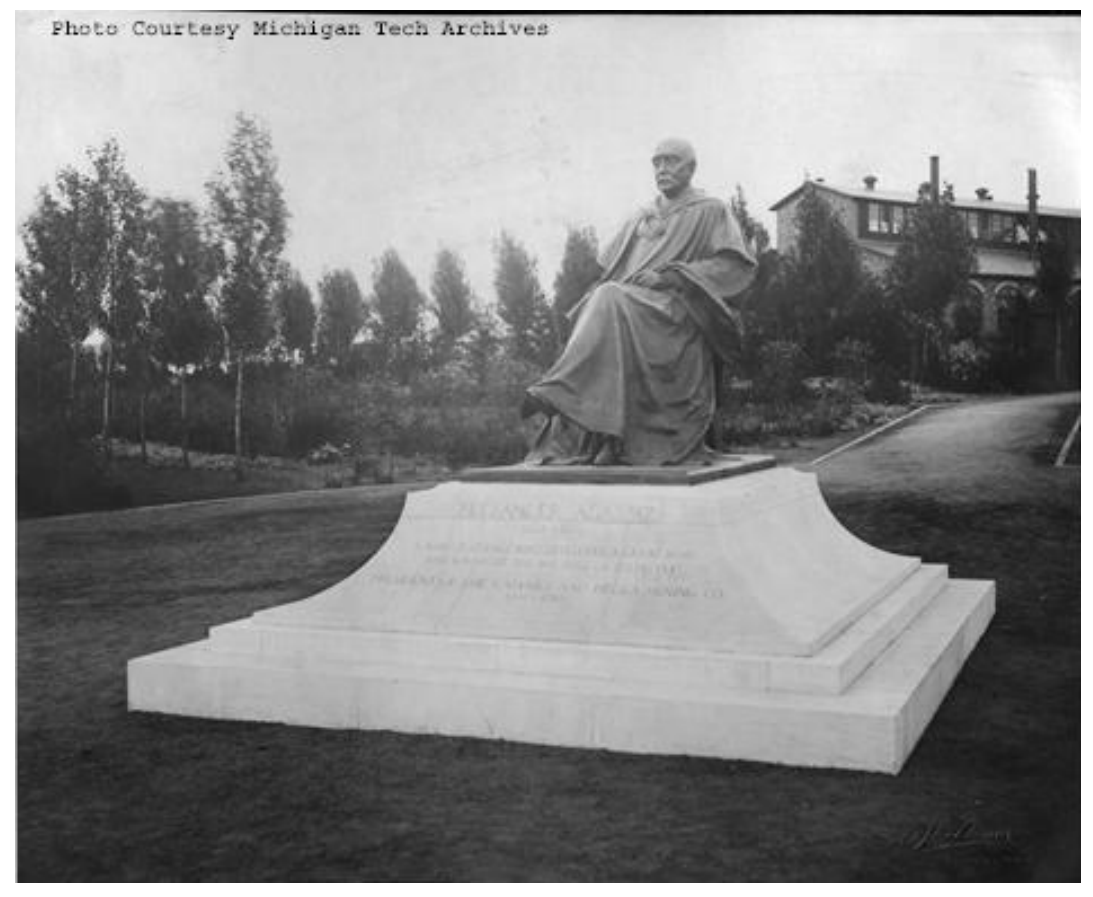

Figure 4.10: Statue of Alexander Agassiz in Agassiz Park, Calumet, Michigan, 1923. MS003-007-004-01, Calumet and Hecla Photograph Collection, Michigan Technological University Archives and Copper Country Historical Collections

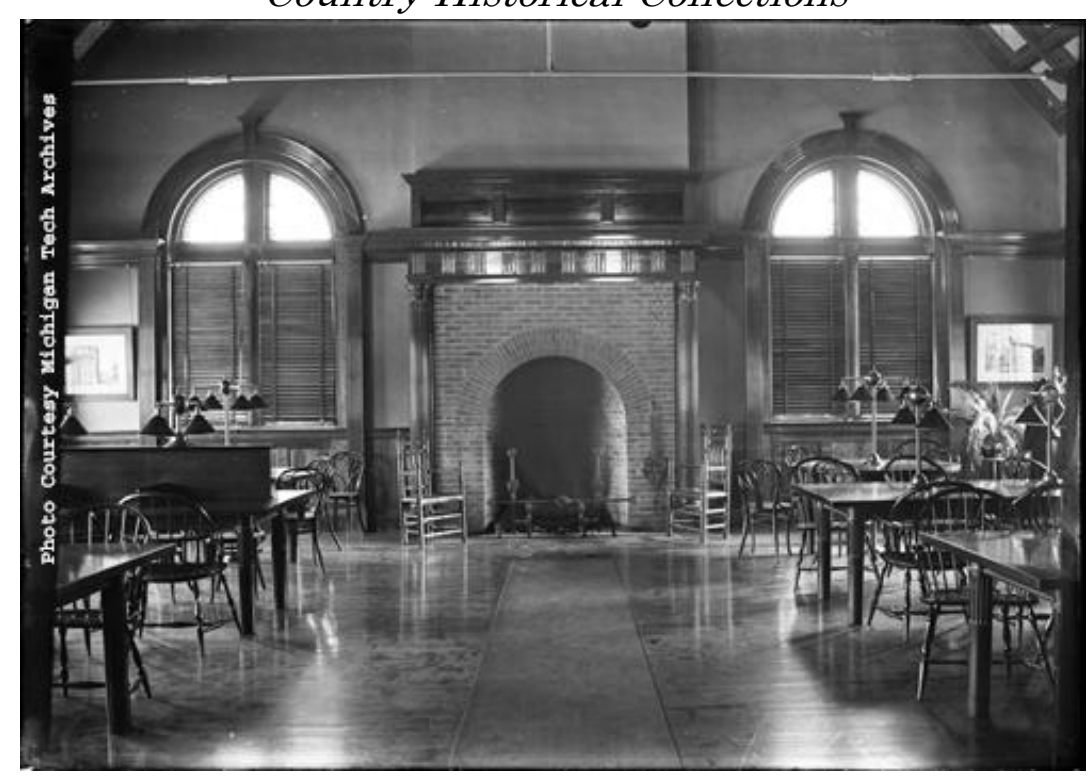

Figure 4.11: Calumet \& Hecla library reading room. MSO03014-GN-154-3, Calumet \& Hecla Photograph Collection, Michigan Technological University Archives and Copper Country Historical Collections. 


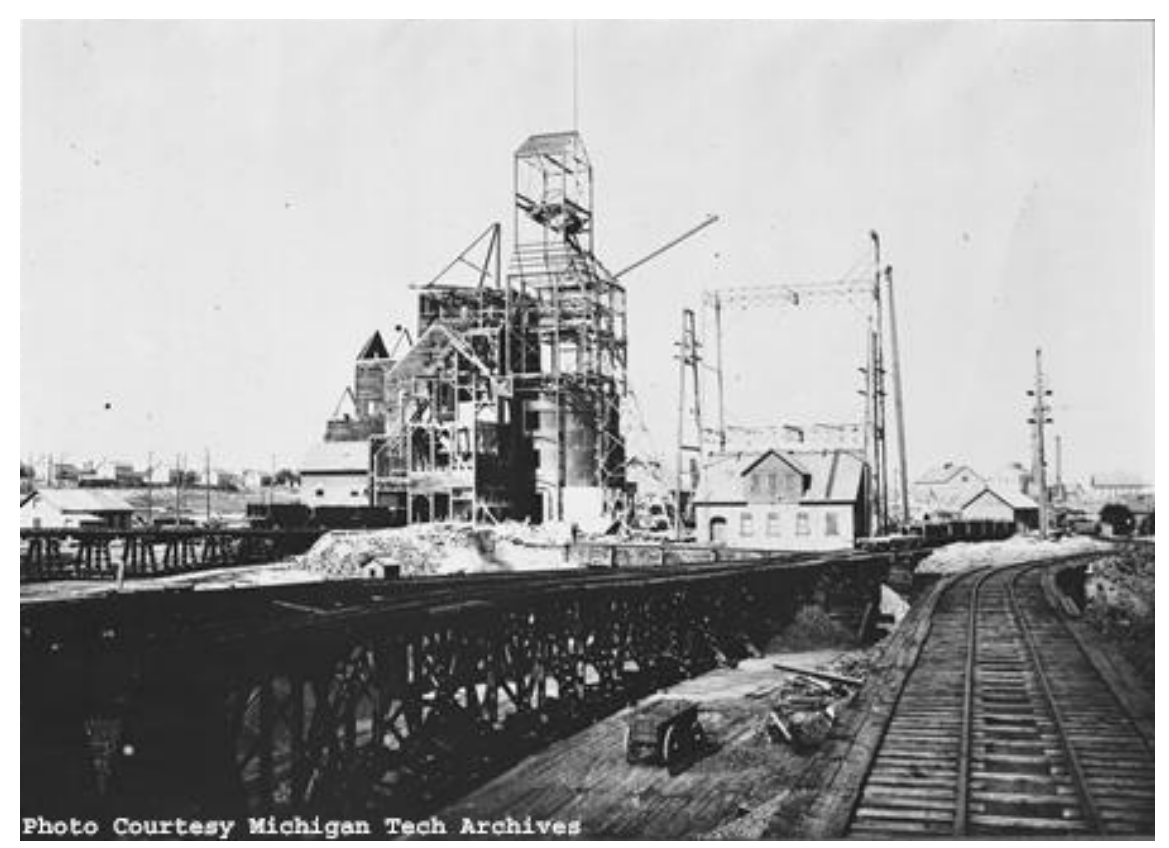

Figure 4.12: Quincy number 2 shaft-rockhouse during construction. Acc-541-01-01-1991-001-001, Quincy Mining

Company Glass Plate Negative Collection, Acc. \#54, Michigan Technological University Archives and Copper Country Historical Collections.

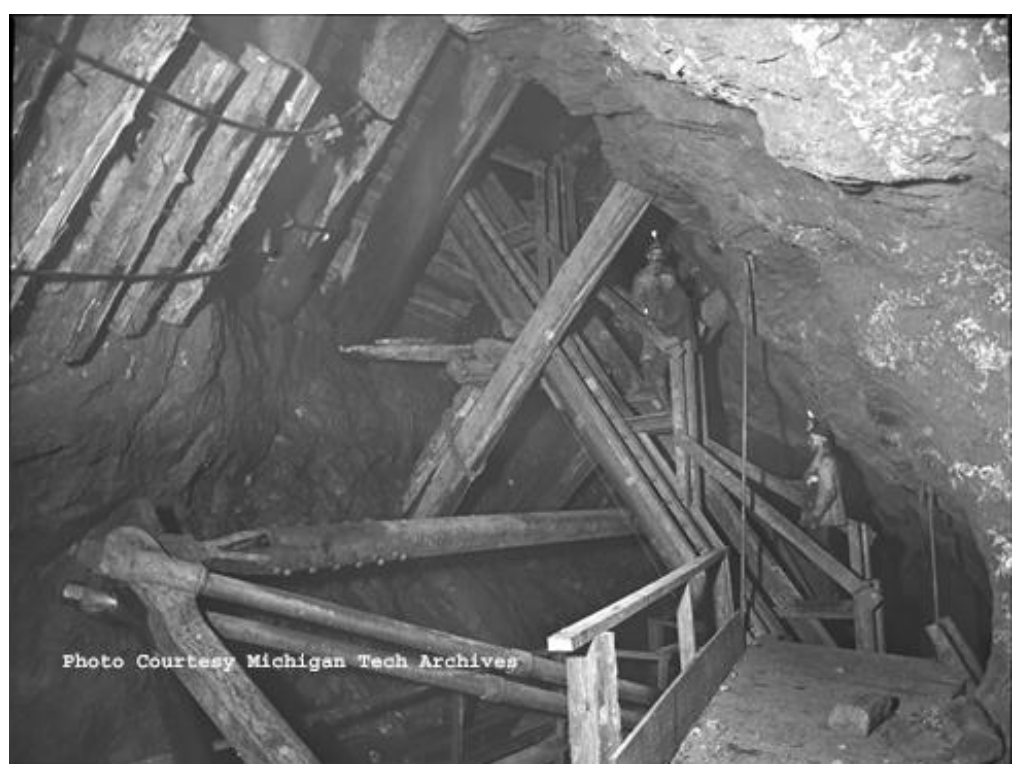

Figure 4.13: Man Engine inside the Quincy Mine, by Frederick Fraley Sharpless. ACC 239-5-6-1985-02-90, Frederick Fraley Sharpless Photograph Collection, Michigan Technological University Archives and Copper Country Historical Collections. 


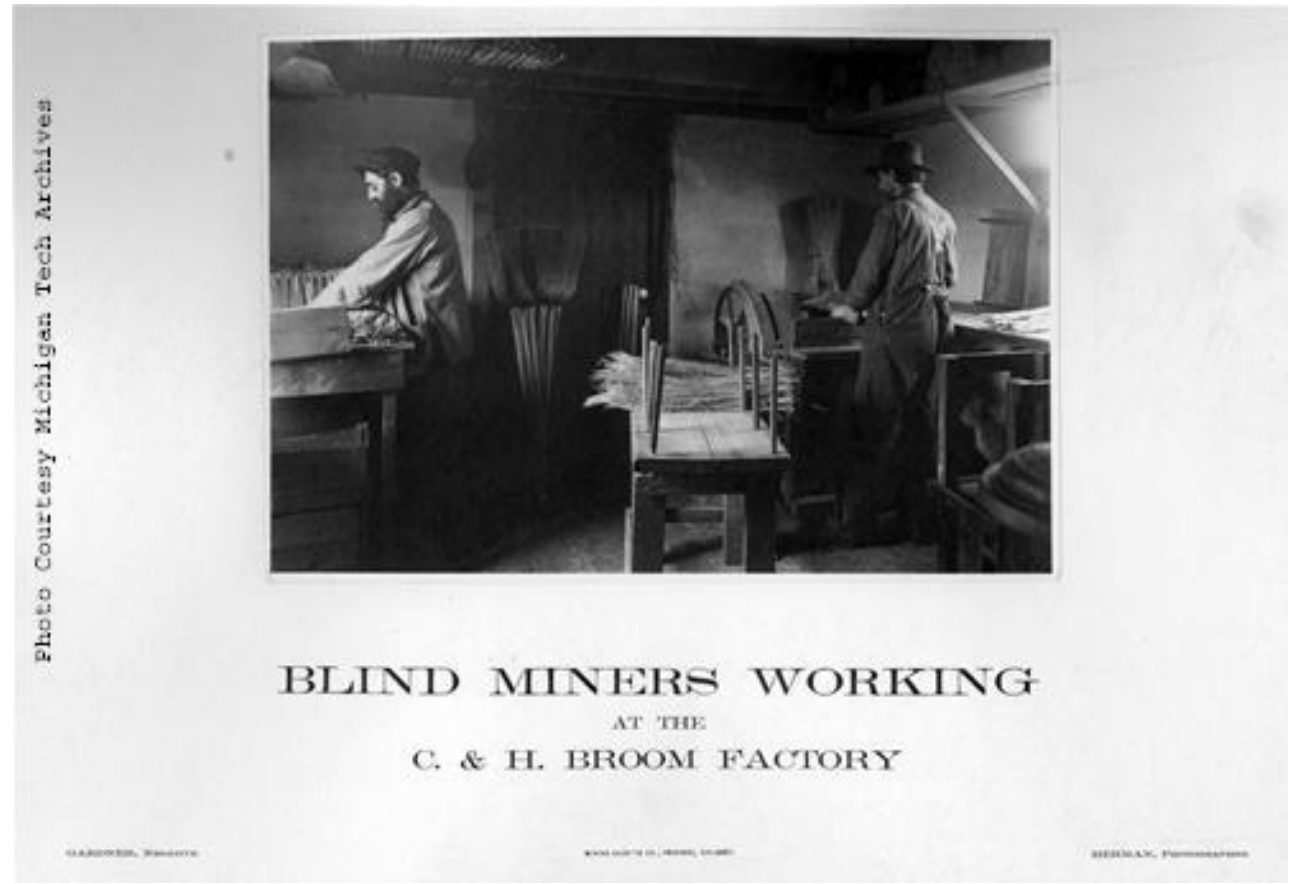

Figure 4.14: Photograph of blind miners working at the $C \& H$ broom factory. MS003-004-017-01, Calumet and Hecla Photograph Collection, Michigan Technological University Archives and Copper Country Historical Collections.

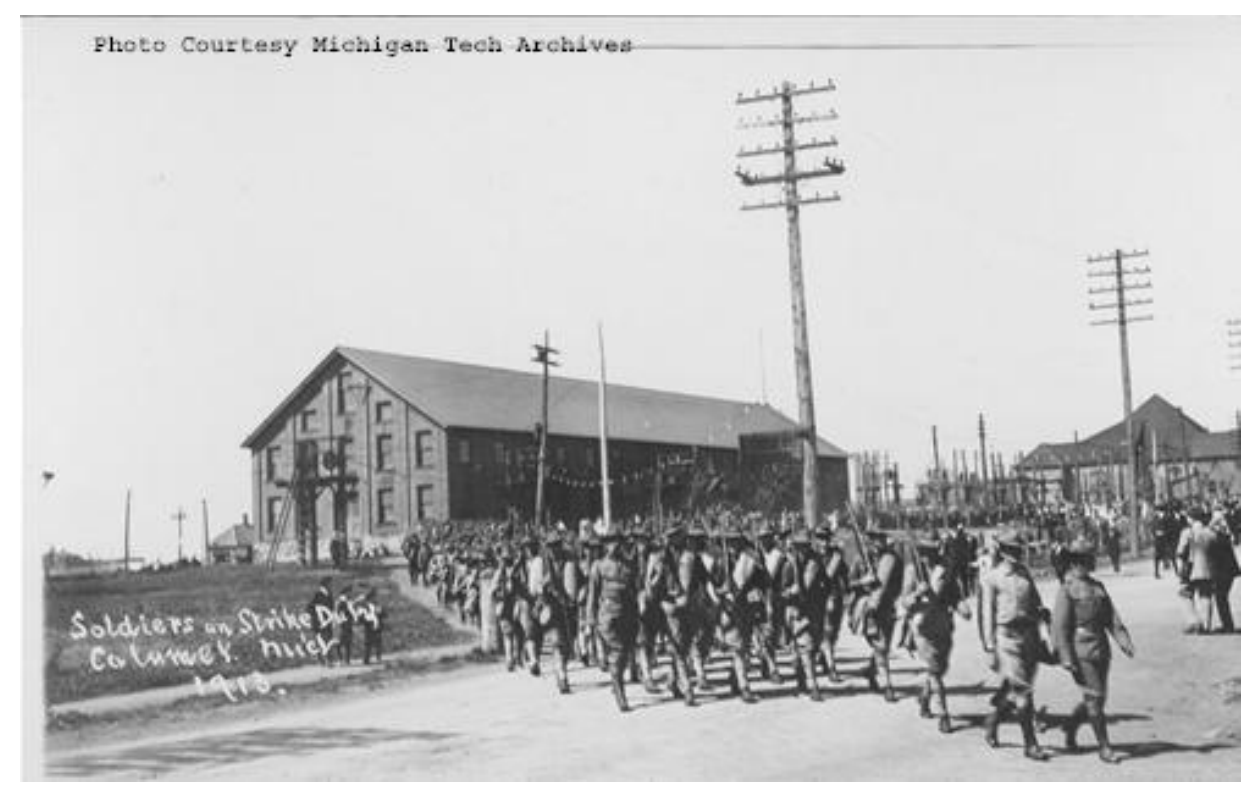

Figure 4.15: Soldiers protecting Quincy Mine property during the Great Strike of 1913-14. Acc-400-12-13-1988-01-08-34, Quincy Mining Company, Michigan Technological University Archives and Copper Country Historical Collections,. 


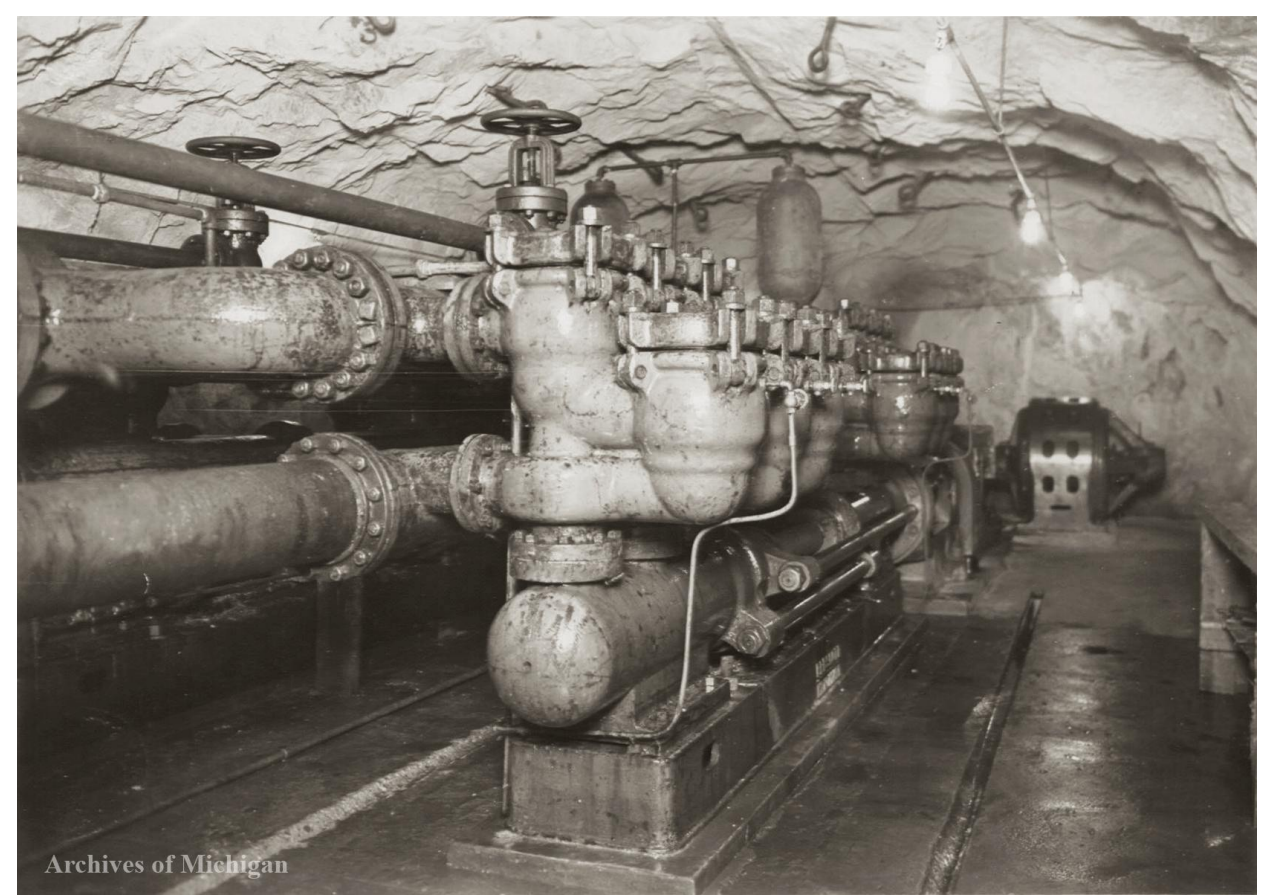

Figure 4.16: A large Prescott water pump in the 1060' level of CCI's Franklin Mine, 1918. MS86-100, Plate no. 167: Courtesy of the Central Upper Peninsula and Northern Michigan University Archives. 
Chapter Five: Conclusion

Beginning in the 1870s, new photographic technologies that were developed and marketed by a host of manufacturers opened up photography to a wide range of people with varying incomes and educations. Throughout most of the century, photography required substantial investment in apparatus, chemicals, and darkroom equipment. It also required thorough knowledge of chemistry and optics as photographers had to sensitize their own plates and mix their own chemicals. Thus, there was little in the way of standardization, and the success of a photographer depended on his or her own persistence in conducting trial and error experiments to perfect their techniques. Additionally, wet plate technology wedded the camera to a travelling darkroom, which limited where one could go to take pictures and probably placed an additional financial burden on the photographer. The introduction of commercially manufactured dry plates, papers and developers in the late 1870s, as well as the appearance of an assortment of hand cameras including the Kodak Brownie allowed those with little or no background in chemistry and optics to learn how to take pictures with relative ease.

Between 1880 and 1900, the number of professional photographers in the United States multiplied nearly threefold and photography entered 
industry as a tool of business. ${ }^{1}$ Moreover, one of the authors that introduced the concept of industrial photography, John Graff, claimed that by 1917 the number of amateur and avocational photographers had grown to the point where almost every industrial company could find photographers in the ranks of their engineers and other employees.

By the close of the nineteenth century, independent photographers had been taking pictures of industrial subjects for more than fifty years, though for present purpose these are not "company photographs" because they were not taken by photographers working for industrial firms. Scientists and surveyors did recognize the potential of photography as a professional tool during mid-century, however, and books on photo-microscopy for biologists and photo-surveying for military surveyors were published from the 1860s onward. It was not until the final decade of the century that photographers began to articulate the concept of industrial photography. There were three factors that gave rise to this at the turn of the twentieth century. First, industrialists and engineers who recognized the potential that new photographic technologies held for applying the medium to professional uses began to voice their thoughts in trade journal articles. They actively encouraged the idea that pre-sensitized plates and hand cameras made photography more accessible, more versatile, and pointed out dozens of new

1 David E. Nye, Image Worlds, Corporate Identities at General Electric, 1890-1930 (Cambridge Massachusetts, MIT Press, 1985), 33. 
applications for photographs ranging from advertising to photo-copying. Second, many new corporations like General Electric and Westinghouse developed large complex organizational structures. Thus, they used photographs as a way of communicating with large internal and external audiences that included employees, engineers, and consumers. Third, company photography did not threaten the livelihoods of independent photographers in the way that halftone technology threatened to eliminate the jobs of engravers, so industry was free to use this more mature technology for their purposes.

Halftone printing technology allowed industrial photographs to be disseminated among large audiences that included readers of magazines and trade journals. Halftones appeared in American periodicals and trade journals shortly after halftone technology became viable in the early 1880s. In the case of Engineering \& Mining Journal, photographs appeared in 1886 and their number increased steadily during the ensuing decades. By the 1930s they had surpassed line engravings as the journal's primary means of illustrating machines, people, and landscapes. Halftone printing blocks were faster to make than hand-engraved blocks. This meant that more illustrations could be printed, and that the content of illustrations in professional literature was no longer limited to subjects that were necessary to convey important information that textual descriptions of a reasonable 
length could not. Thus, human interest photos began appearing in $E \& M J$, which was geared primarily toward the professional needs of engineers.

Despite becoming ubiquitous in periodicals and trade journals during the first quarter of the twentieth century, the adoption of halftone technology was initially challenged by engravers and printers alike. Photographic technicians who did halftoning did not require training in traditional forms of art, and those who made their livings in the long-established art of engraving felt threatened by the new technology. They argued that halftoning was inferior to line engraving because photo-mechanical reproduction did not impart the artistic interpretations of the engraver, which they saw as a positive. Accordingly, conservative publications like The Century, that were illustrated with artwork showed reluctance in adopting halftone technology since they did not want to alienate their artists or disappoint their readers, who were used to seeing line engravings. Engineering journals, on the other hand, saw the lack of explicit artistic interpretation in halftoning as a positive, because their main purpose was to communicate technological knowledge in an objective manner.

Therefore, halftone photographs quickly came to dominate the pages of $E \& M J$. Though making a halftone did in fact require subjective decisions on behalf of the technician, such as exposure and cropping, engineers believed halftones to be more objective representations of the original image than engravings. Initially, printers also preferred line engravings to halftones- 
not for reasons of livelihood or artistic merit, but because they experienced difficulty in adapting their printing systems to accommodate the comparatively shallow etchings. They eventually refined their printing processes with new types of ink and smoother paper and began keeping their shops clean so that dirt particles and other contaminants would not foul the delicate halftone blocks. Lastly, even popular magazines like Harper's eventually came to favor halftones for reproducing artworks because photomechanical reproduction preserved the authenticity of the original, despite the fact that halftone prints often reduced the size of paintings and drawings, showed three-dimensional sculptures in two dimensions, and did not reproduce color.

Comparing the development of company photography to the adoption of halftones in periodicals illustrates two opposite, yet interlocked responses to new technologies. Innovations in plate and camera technology that allowed more people to take up photography opened the doors for photography to be applied to new business-related applications. Recognizing this, a handful of farseeing individuals published articles that introduced the concepts of company and engineering photography, and they also encouraged others to invest in the technologies that held potential to make the production of visual materials faster and easier, and arguably produce results that were more objective. Thus, no one resisted company and engineering photography, technologies that contributed to the success of company, the same way 
engravers and artists resisted halftones. Photo-mechanical reproduction likely decreased the number of jobs available for draftsmen, though it did not threaten to eliminate their profession in the way that halftones threatened engravers. Draftsmen were still needed to make original plans and drawings, whereas the primary work of engravers—copying pictures onto printing blocks - was mechanized and expedited by halftoning. Additionally, in the case of the engineering press the artistic merit of illustrations was of secondary importance to the communication of technological data. This further mitigated engravers' claims that their work was superior to halftones.

In Image Worlds, David Nye examines the rise of corporate photography between 1890 and 1930 through a case study of General Electric. As a large corporation that vied for monopolistic control over the American electrical industry, GE created a highly organized photographic department that produced tens of thousands of images annually. GE had a large public interface that marketed domestic appliances to the general public. Much of their photographers' work therefore consisted of providing images that celebrated the companies' products by portraying them as stylish labor-saving devices that had the ability to make day-to-day life easier and more enjoyable. ${ }^{2}$ Most of the photographs communicated this idea by showing people using GE appliances in a domestic setting. By comparison, the main product of relatively small mining companies like $\mathrm{C} \& \mathrm{H}$, Quincy, and CCI,

\footnotetext{
2 Nye, Image Worlds, 112-134.
} 
was raw metal that they sold in bulk to other industrial companies such as mills and foundries. Therefore, their photographic needs were different since they did not require large photo departments and because their main audience was engineers. Though mining companies occasionally sponsored public relations materials, most of their photos were printed in trade journals rather than magazines and brochures. Their photographs accordingly showed the companies' heavy machinery, workshops, and underground operations. Pictures of people were rare because engineers dealt with technology, not labor management or public relations. Lenses of Industry differs from Image Worlds by examining corporate photography with case studies of three mining companies whose use of photography contrasts that of the electrical industry.

Much of this thesis tracks conventional histories of photography through chronological narrative that identifies important technological innovations. Similarly, it discusses how new technologies such as dry plates and hand cameras contributed to photography becoming a common activity, which in turn opened the door for periodicals to turn away from traditional line engravings in favor of halftone photographs. However, unlike survey histories that treat the development of photography as a linear sequence of inventions and popular aesthetic movements, Lenses of Industry examines photography in the context of the functions it served in the growth of industrial companies during the late nineteenth and early twentieth 
centuries. Histories that examine photographs according to their function, for example, popular photography, family albums, and police photography, have been written, but for the most part are overshadowed by canonical works that give the public a "linear, abridged and palatable summary." 3 Thus, this thesis borrows from conventional technological histories of photography, but it is also a cultural study that focuses primarily on photography in relation to the development of American industrial corporations.

This thesis also sheds light on an underdeveloped area of industrial heritage studies and industrial archaeology. IA: The Journal of the Society for Industrial Archeology is punctuated with a handful of articles that examine the roles that visual arts played in industrialization. One of them considers photographs taken and sold by independent photographers, but paintings, drawings, and lithographs are the primary foci of this work. ${ }^{4}$ Another by William L. Taylor discusses publicity photographs taken by the Brown Company photographer of Berlin, New Hampshire. The essay ${ }^{5}$ succinctly discusses the Brown Company's use of photos, but Taylor does not contextualize the collection within the larger concept of industrial

\footnotetext{
3 Anne McCauley, "Writing Photography's History before Newhall," History of Photography 21, no. 2 (1997): 1.

${ }^{4}$ Helena E Wright, "The Image Makers: The Role of Graphic Arts in Industrialization," IA: The Journal of the Society for Industrial Archeology 12 , no. 2 (1986): 5-18.

5 William L. Taylor, "Documenting the History of an Industrial City: The Brown Company Photograph Collection of Berlin, New Hampshire," IA:

The Journal of the Society for Industrial Archeology 19, no. 1 (1993): 60-72.
} 
photography that emerged between the 1890s and the 1930s. Additionally, there are no studies that closely examine halftone photographs in trade journals, nor are there any that consider photography in relation to the mining industry.

Lenses of Industry demonstrates that the concept of industrial photography emerged at the close of the nineteenth century and developed rapidly during the first three decades of the twentieth as companies came to rely on photographs for advertising, publicity, and organizational purposes. It also demonstrates that the use of photography varied according to the needs of different companies and industries. Requiring little in the way of public advertising, the mining industry relied on trade journals to disseminate technological knowledge among engineers. Accordingly, halftones became ubiquitous in the pages of the engineering press during that time because they provided a means to quickly reproduce photographic images for publication, and because engineers considered photo-mechanical reproductions to be accurate representations of original pictures and documents. Thus, industrial photography emerged in the 1880 s and matured rapidly during the first thirty years of the twentieth century as industrial companies and their engineers came to rely on photographs to communicate large amounts of visual data in a truthful and expedient manner. 


\section{Bibliography}

“A Word at the Start." Harper's New Monthly Magazine 1, no. 1 (1850): 1 -2.

"Advertisement for Photostat." Engineering News 69, no. 25 (June 19, 1013): 6 .

Alvord, John W. "Photography for Engineers." The Annual Report of the Illinois Society of Engineers and Surveyors 10 (1895): 115-119.

Annual Catalogues of the Officers and Students of the Michigan Mining School, Houghton, Michigan, 1888-1889. (Marquette, Michigan: Mining Journal Print, 1889).

Annual Catalogues of the Officers and Students of the Michigan Mining School, Houghton, Michigan, 1888-1890. (Marquette, Michigan: Mining Journal Print, 1890).

Brown, Elspeth H. The Corporate Eye: Photography and The

Rationalization of American Commercial Culture, 1884-1929

(Baltimore: The Johns Hopkins University Press, 2005).

Derr, Louis. Photography: For Students of Physics and Chemistry (London: The Macmillan Company, 1906).

Eastlake, Elizabeth. "Photography." The Quarterly Review 101 (April 1857): 644.

Edwards, Elizabeth. "Unblushing Realism and the Threat of the Pictorial: Photographic Survey and the Production of Evidence, 18851918." History of Photography 33, no. 1 (2009): 3-17.

Engineering and Mining Journal 2-4, (1867); 19-20, (1875); 29-30, (1880); 41-42, (1886); 43-44, (1887); 45-46, (1888), 47-48, (1889); 51-52, (1891); 69-70, (1900); 99-100, (1915); 129-130, (1930).

"Frank Leslie's Weekly," Accessible Archives, 2015, April 17, 2015, http://accessible-archives.com/frank-leslies-weekly/.

Fraser, Lewis W. "A Word About the Century's Pictures," The Century Magazine 49 (1895): 479.

Graff, John H. "Technical Photography and it use in Industrial and Commercial Organizations." The Journal of Industrial and Engineering Chemistry 9, no. 11 (1917): 1052-1054.

Gustavson, Todd. Camera: A History of Photography from Daguerreotype to Digital. (New York: Fall River Press, 2009).

"Halftone Photo-Block Printing." Anthony's Photographic Bulletin 23 (1892): 438-442.

Hand, Ashton S. "Industrial Photography." The Iron Trade Review 44 (1909): 195-199.

Hannavy, John. Fox Talbot. (Haverfordwest: CIT Printing Services, 1997). 
Hansen, David A. "The Beginnings of Photographic Reproduction in the USA." History of Photography 12, no. 4 (1988): 357-376.

Harris, Christopher R. "The Halftone and American Magazine Reproduction, 1880-1900." History of Photography 17, no. 1 (1993): 77-80.

Harrison, W. Jerome. A History of Photography: Written As A Practical Guide And An Introduction To Its Latest Developments (New York: Scovill Manufacturing Company, 1887).

Hentschel, Carl. "Process Engraving." Journal of the Society of Arts 48, no. 2,474 (1900): 461-474.

Hepworth, T.C. "Journalistic Photography." Photographic Times 36, no. 8 (1904): 355-358.

"Historical Summary." Engineering and Mining Journal 129, no. 1 (1930): 1 .

Horgan, Stephen H. Photoengraving in Black and in Color: Or Photoengraving Primer. (Boston: American Photographic Publishing Company, 1938).

Ives, Frederick E. "United States Patent: US245501 A - Method of Producing Impressions in Line or Stipple from Photographic Negatives." August 9, 1881.

Jenkins, Reese V. "Technology and the Market; George Eastman and the Origins of Mass Amateur Photography." Technology and Culture 16, no. 1 (1975): 1-19.

Lankton, Larry. Hollowed Ground: Copper Mining and Community Building on Lake Superior, 1840s-1990s (Detroit: Wayne State University Press, 2010).

Laussedat, Col. Aime. Ouverture du Cours de Géométrie Appliquée aux Arts au Conservatoire (Paris: E. Lacroix, 1864).

Layton, Edwin, "Mirror Image Twins: The Communities of Science and

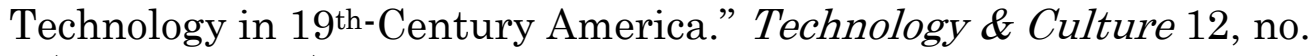
4 (October 1971): 562-580.

"Letter to the Editor." The Critic 25 (1894): 98.

Lloyd, Janet and Jean-Claude Lemagny and Andre Rouille, trans. $A$ History of Photography: Social and Cultural Perspectives (Cambridge: Cambridge University Press, 1987): 45-47.

McCauley, Anne. "Writing Photography's History before Newhall." History of Photography 21, no. 2 (1997): 1.

Mining Congress Journal 17, no. 10 (October, 1931).

Newhall, Beaumont. The History of Photography from 1839 to the Present Day (New York: The Museum of Modern Art, 1946).

Nye, David E. Image Worlds: Corporate Identities at General Electric, 18901930 (Cambridge Massachusetts: MIT Press, 1985). 
Nystrom, Eric C. Seeing Underground: Maps, Models, and Mining Engineering in America (Reno, Nevada: University of Nevada Press, 2014).

"Photo-Engraving On The Newspapers," Anthony's Photographic Bulletin 26, no. 1 (1895): 206-207.

'Pictures from Type Blocks versus Photo-Gravure," Anthony's Photographic Bulletin 22, no. 22 (1891): 673-675.

Reed, Lieutenant Henry A. Photography Applied to Surveying (New York: John Wiley \& Sons, 1888).

Sharpless, Frederick Fraley. "Down in a Copper Mine: to be used in conjunction with Lantern Slides.” MS-239-001-008. Manuscript. Frederick Fraley Sharpless Collection. Michigan Tech Archives and Copper Country Historical Collections.

Stenger, Erich. The History of Photography: It's Relation To Civilization and Practice, trans. Edward Epstean (Easton, Pennsylvania: Mack Printing Company, 1939).

Sternberg, George M. Photo-Micrographs and How to Make Them. (Boston: James R. Osgood and Company, 1884).

Stulik, Dusan C. and Art Kaplan, The Atlas of Analytical Signatures of Photographic Processes: Halftone. Los Angles: The Getty Conservation Institute, 2013.

Taylor, William L. "Documenting the History of an Industrial City: The Brown Company Photograph Collection of Berlin, New Hampshire," IA: The Journal of the Society for Industrial Archeology 19, no. 1 (1993): 60-72.

The Keweenaw Miner: Calumet \& Hecla Mining Company Semi-Centennial, 1866-1916. (Calumet, Michigan: Keweenaw Printing Company, 1916).

"The Use of the Camera in Industrial Plants." Iron Age 90, no. 8 (1912): 393-397.

"Value of Photography to Engineering." The Engineering Journal 16, no. 11 (1933): 474-480.

Vogel, Dr. H.W. "Letter From Germany: The Chicago World's FairPhotography in Different Countries." Anthony's Photographic Bulletin 24, (1893): 665-669.

W. Lewis Fraser. "A Word About the Century's Pictures." The Century Magazine 49 (1895): 479.

Worthington, J.C. \& J.C. Millen. The Photographic Primer: A Complete Manual of Practice (Riverton, New Jersey: The Riverton Press, 1896).

Wright, Helena E. "The Image Makers: The Role of Graphic Arts in Industrialization." IA: The Journal of the Society for Industrial Archeology 12, no. 2 (1986). 
Appendix of Permissions

According to "Copyrights"1, all material published before 1923 is in public domain, and therefore not copyrighted. Therefore, the following images are freely reproducible.

Figures 1.1, 1.2, and 3.8 were extracted from Engineering \& Mining Journal 47 (1889).

Figure 1.3 was extracted from Engineering and Mining Journal 52 (1891).

Figure 2.1 was extracted from Iron Age 90 (1912).

Figures 2.2, 2.3, 2.4, 2.5 were extracted from The Iron Trade Review 44 (1909).

Figure 2.6 was extracted from Engineering News 69 (1913).

Figures 3.5 and 3.10 were extracted from Engineering \& Mining Journal 44 (1887)

Figures 3.6 and 3.9 were extracted from Engineering \& Mining Journal 48 (1889).

Figure 3.7 was extracted from Engineering \& Mining Journal 41 (1886).

Figure 3.11 was extracted from Engineering \& Mining Journal 45 (1888).

Figure 3.12 was extracted from volume Engineering \& Mining Journal 46 (1888).

Figure 4.9 was extracted from The Keweenaw Miner: Calumet \& Hecla Mining Company Semi-Centennial, 1866-1916 (1916).

${ }^{1}$ Information from Legal Information Institute, "U.S. Code; Title 17 Copyrights," www.law.cornell.edu/uscode/text/17, Accessed 3 Dec. 2015. 
Figures 4.1, 4.2, 4.3, 4.4, 4.5, 4.6, 4.7, 4.8, 4.10, 4.11, 4.12, 4.13, 4.14, 4.15 are all courtesy of the Keweenaw Digital Archives and therefore permissions are not required to reproduce them.

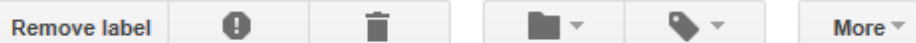

Re: Contact Us Form $\square \quad$ Thesis Backup $x$

Sawyer Newman <senewman@mtu.edu>

다 12

to me, copper -

Hi Rob,

You will not need to receive any permissions for using low resolution images directly from the Keweenaw Digital Archives. All we ask is that you leave the "Photo Courtesy Michigan Tech Archives" watermark visible on the image.

You do not need to fill out a Photographic Agreement Form, but on this form (attached) you can see an example of a citation for archival materials.

Let me know if you have any other questions!

Best,

Sawyer

On Sat, Oct 10, 2015 at 7:10 PM, Rob Anthony <rdanthon@mtu.edu> wrote:

Below is the result of your feedback form. It was submitted by

Rob Anthony (rdanthon@mtu.edu) on Saturday, October 10, 2015 at 19:10:23

realname: Rob Anthony

email: rdanthon@mtu.edu

Question: Hello,

I am a student in the industrial archaeology program here at Tech, and I am currently working on my

master's thesis, which I will complete this semester. One of my thesis chapters uses about one-dozen

photographs that I obtained through the MTU digital archives. They are from the C\&H and Quincy

collections. I am writing to you because I would like to know what sort of permission I will need to publish

them in my thesis. Any assistance you can offer will be greatly appreciated.

Best,

Rob Anthony

M.S. Candidate

Industrial Archaeology

Michigan Technological University

Form URL: http://www.mtu.edu/library/archives/contact/

$\cdots$ 
Figure 4.16 is courtesy of the Central Upper Peninsula and Northern Michigan University Archives. Therefore, it falls under the "fair use" domain of copyright law and permission is not required to reproduce it.

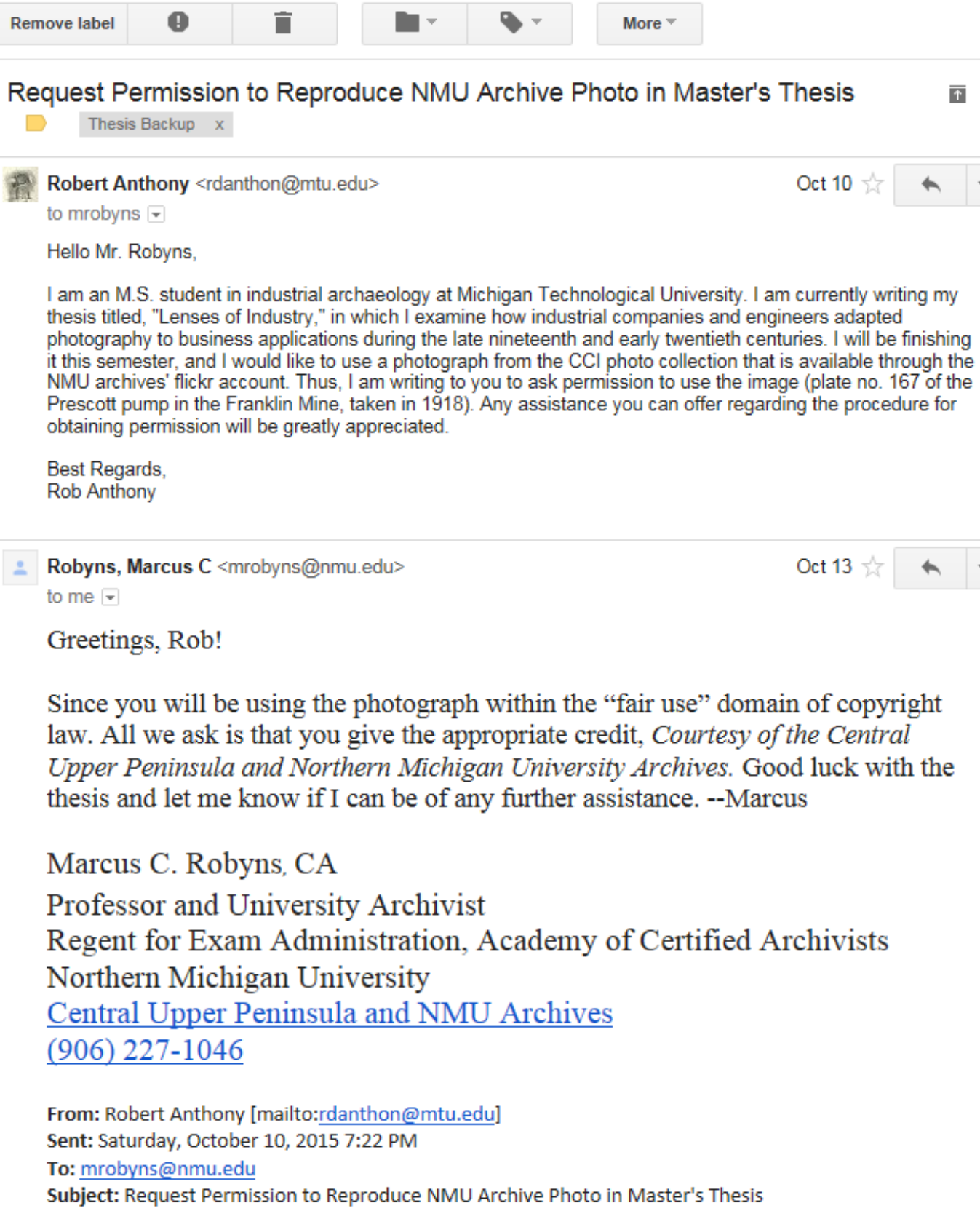

Marcus C. Robyns, CA

Professor and University Archivist

Regent for Exam Administration, Academy of Certified Archivists

Northern Michigan University

Central Upper Peninsula and NMU Archives

(906) 227-1046

From: Robert Anthony [mailto:rdanthon@mtu.edu]

Sent: Saturday, October 10, 2015 7:22 PM

To: mrobyns@nmu.edu

Subject: Request Permission to Reproduce NMU Archive Photo in Master's Thesis 